\title{
WestVirginiaUniversity
}

THE RESEARCH REPOSITORY @ WVU

Graduate Theses, Dissertations, and Problem Reports

2014

\section{Extent of Hydraulic Fractures in a Multilayered Geologic Media}

Carter L. Hulcher

Follow this and additional works at: https://researchrepository.wvu.edu/etd

\section{Recommended Citation}

Hulcher, Carter L., "Extent of Hydraulic Fractures in a Multilayered Geologic Media" (2014). Graduate Theses, Dissertations, and Problem Reports. 7314.

https://researchrepository.wvu.edu/etd/7314

This Thesis is protected by copyright and/or related rights. It has been brought to you by the The Research Repository @ WVU with permission from the rights-holder(s). You are free to use this Thesis in any way that is permitted by the copyright and related rights legislation that applies to your use. For other uses you must obtain permission from the rights-holder(s) directly, unless additional rights are indicated by a Creative Commons license in the record and/ or on the work itself. This Thesis has been accepted for inclusion in WVU Graduate Theses, Dissertations, and Problem Reports collection by an authorized administrator of The Research Repository @ WVU. For more information, please contact researchrepository@mail.wvu.edu. 
Extent of Hydraulic Fractures in a Multilayered Geologic Media

Carter L. Hulcher

Thesis submitted

to the Benjamin M. Statler College of Engineering and Mineral Resources at West Virginia University

in partial fulfillment of the requirements for the degree of

Master of Science in

Civil Engineering

Hema J. Siriwardane, Ph. D., P.E., Chair

Raj Gondle, Ph. D.

John D. Quaranta, Ph.D., P.E.

Department of Civil and Environmental Engineering

Morgantown, West Virginia

2014

Keywords: Hydraulic Fracturing, Fracture Propagation, Marcellus Shale 
UMI Number: 1555313

All rights reserved

INFORMATION TO ALL USERS

The quality of this reproduction is dependent upon the quality of the copy submitted.

In the unlikely event that the author did not send a complete manuscript and there are missing pages, these will be noted. Also, if material had to be removed, a note will indicate the deletion.

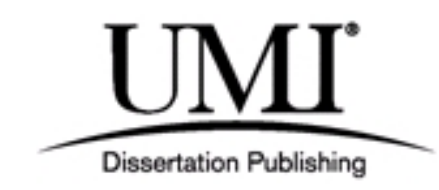

UMI 1555313

Published by ProQuest LLC (2014). Copyright in the Dissertation held by the Author.

Microform Edition () ProQuest LLC.

All rights reserved. This work is protected against unauthorized copying under Title 17, United States Code

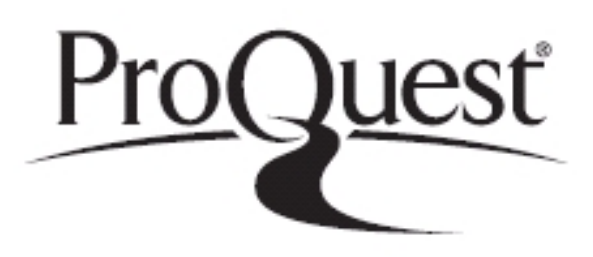

ProQuest LLC.

789 East Eisenhower Parkway

P.O. Box 1346

Ann Arbor, MI 48106 - 1346 


\title{
ABSTRACT \\ Extent of Hydraulic Fractures in a Multilayered Geologic Media
}

\author{
Carter L. Hulcher
}

In this report, the vertical extent of hydraulic fractures in a layered geological formation was investigated. In reality, the geology of the earth is heterogeneous, and therefore fracture growth will be significantly different. Fracture growth was simulated by using numerical models with relevant geomechanical, fluid flow and proppant transport properties. Results show the horizontal stress gradient plays an important role in fracture propagation. Lower horizontal stress contrasts between layers allow for greater fracture propagation in the vertical direction. Higher fluid viscosities tend to increase the fracture height and width, while decreasing the fracture length. Several other geomechanical properties such as the elastic modulus, fracture toughness, and leakoff coefficient have some influence on the vertical fracture growth. To account for the variability of properties, 300 realizations were considered by using a statistical sampling method. Most of the simulated fractures (about 50\%) extended into the immediate overburden layers. Results from these cases show that the clearance depth was in the range from about 4300 feet to 7500 feet. 


\section{ACKNOWLEDGEMENT}

I would like to take this opportunity to thank those who helped me in completing my thesis over the past two years. I would first like to thank the extraordinary chair of my committee, Dr. Hema Siriwardane. His supervision and exceptional support throughout my research work has been invaluable, and without it none of this work would have been possible. I would also like to thank Dr. Raj Gondle and Dr. John Quaranta for serving on my examination committee, reading and reviewing my thesis, and helping me in achieving my goal of completing my M.S. degree.

I would also like to thank and acknowledge the financial support provided by the United States Department of Energy through a Graduate Research Assistantship awarded by West Virginia University. I also want to thank those who worked with me on geomechanics research. These individuals are Raj Gondle, Sai Varre, Andrew Dietz, Hari Nambu, Zainab Jawad, and Amir Houshmandhyar.

Last, and certainly not least, I want to thank my parents, Janet and George, my fiancée Abbé Machi, and my entire extended family for their undying support of me throughout my many years in college. Without their continuous love and financial support, none of this work would have been possible. 


\section{Table of Contents}

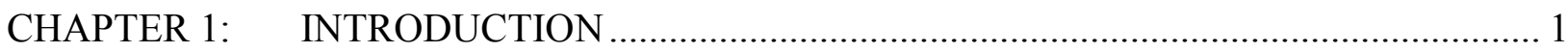

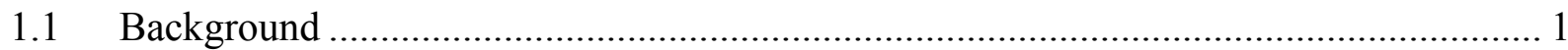

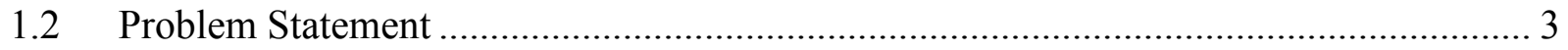

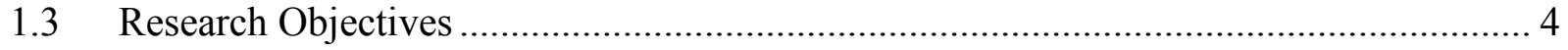

1.4 Scope of Work

CHAPTER 2: OVERVIEW OF HYDRAULIC FRACTURING ........................................... 6

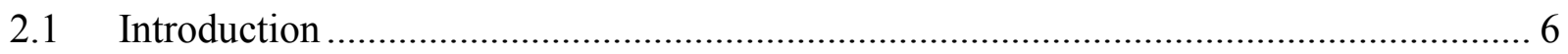

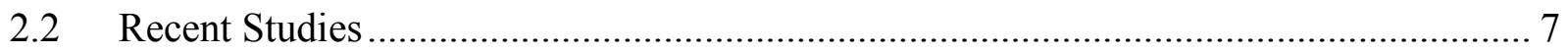

2.3 Fluid Flow through Porous Media ………………................................................... 12

2.4 Hydraulic Fracture Design and Execution .............................................................. 15

2.5 Data Acquisition and Evaluation Methods for Hydraulic Fracturing ............................ 19

2.6 Overview of Fracturing Models ………………….................................................... 20

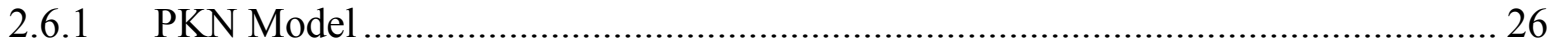

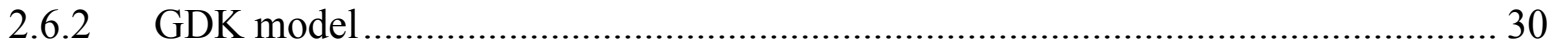

2.6.3 3D Ellipsoidal Fracture Model........................................................................ 33

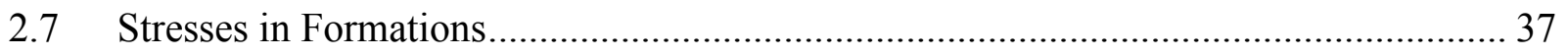

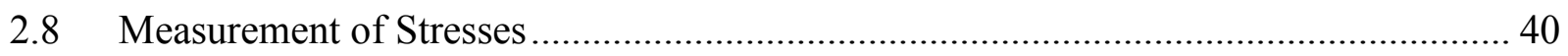

CHAPTER 3: INFLUENCE OF TREATMENT PARAMETERS ON HYDRAULIC

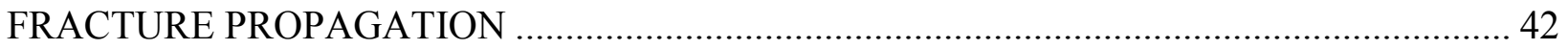

3.1 Influence of Injection Rate (Constant versus Variable) and Proppant Type................... 42

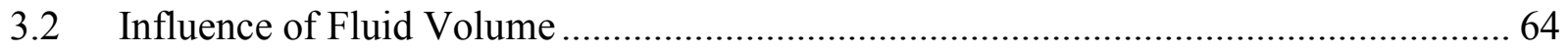

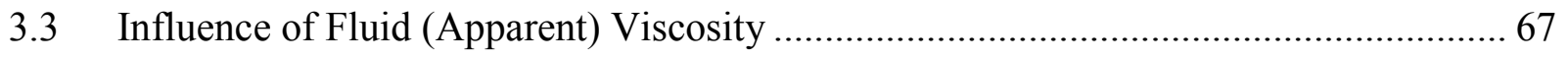

CHAPTER 4: INFLUENCE OF GEOMECHANICAL AND FLUID LOSS PROPERTIES

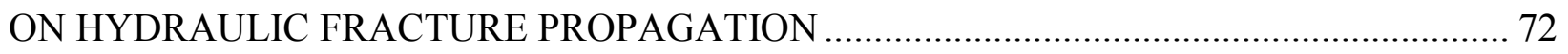




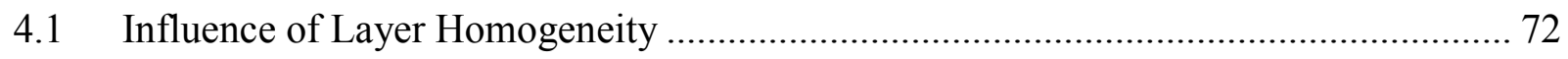

4.2 Influence of Poisson's Ratio and Horizontal Stress (Gradient) ……………………...... 77

4.3 Influence of Young's Modulus and Fracture Toughness................................................ 88

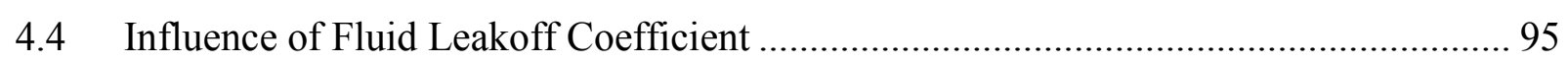

CHAPTER 5: FRACTURE PROPAGATION IN THE MARCELLUS SHALE USING

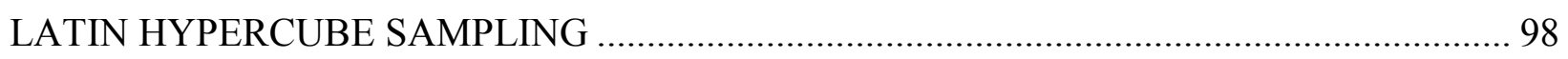

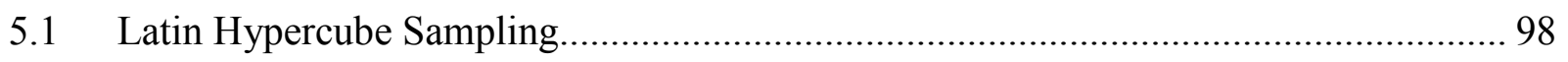

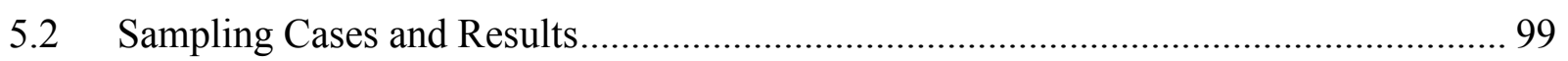

CHAPTER 6: SUMMARY AND CONCLUSIONS ........................................................... 111

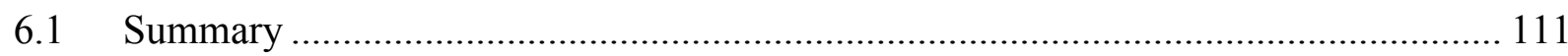

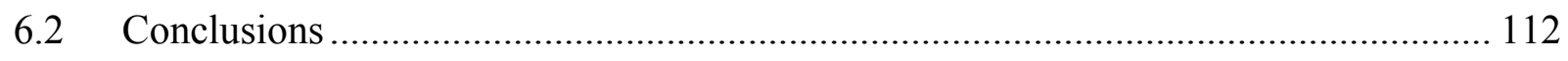

6.3 Recommendations for Future Work .................................................................. 114

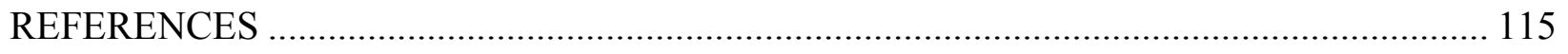




\section{LIST OF FIGURES}

Figure 1.1: Map showing the extent and approximate depth of the Marcellus shale (Marcellus

Center for Outreach and Research, www.marcellus.psu.edu, 2010) ............................................ 1

Figure 1.2: Horizontal (a) and Vertical (b) Well Configurations ............................................... 2

Figure 2.1: Drilling Rig Components (OSHA, 2013) ............................................................. 16

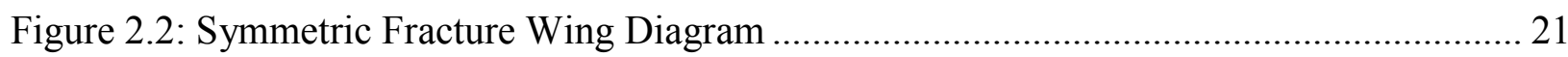

Figure 2.3: Fracture Model Width Profiles (Meyer, 1986)......................................................... 27

Figure 2.4: Length Profile for PKN, GDK, and 3D Fracture Models (Meyer, 1986) ................... 27

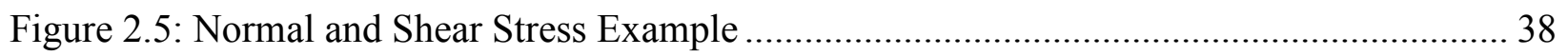

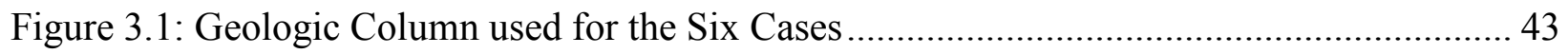

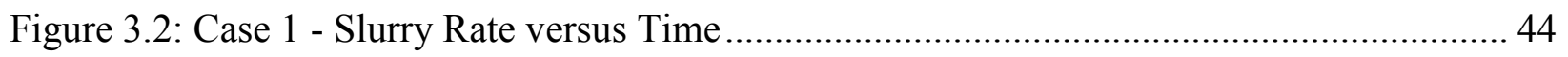

Figure 3.3: Case 1 - Cumulative Slurry Volume versus Time........................................................ 45

Figure 3.4: Case 1 - Proppant Rate versus Time ...................................................................... 45

Figure 3.5: Case 1 - Cumulative Proppant Mass versus Time....................................................... 46

Figure 3.6: Stress, Width Profiles, and Width Contours for Case 1 ............................................ 47

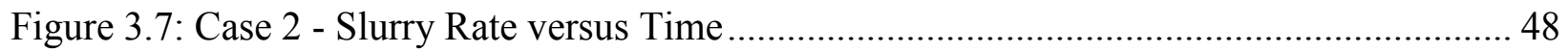

Figure 3.8: Case 2 - Cumulative Slurry Volume versus Time..................................................... 48

Figure 3.9: Case 2 - Proppant Rate versus Time ........................................................................ 49

Figure 3.10: Case 2 - Cumulative Proppant Mass versus Time.................................................... 49

Figure 3.11: Stress, Width Profiles, and Width Contours for Case 2 ………………................. 50

Figure 3.12: Case 3 - Slurry Rate versus Time ……………………………………………..... 51

Figure 3.13: Case 3 - Cumulative Slurry Volume versus Time.................................................. 51

Figure 3.14: Case 3 - Proppant Rate versus Time ………………........................................ 52

Figure 3.15: Case 3 - Cumulative Proppant Mass versus Time ...................................................... 52

Figure 3.16: Stress, Width Profiles, and Width Contours for Case 3 ……................................. 53

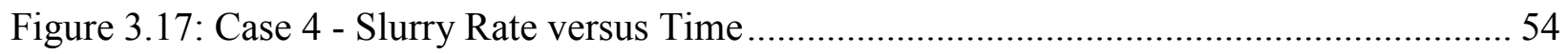

Figure 3.18: Case 4 - Cumulative Slurry Volume versus Time................................................... 54

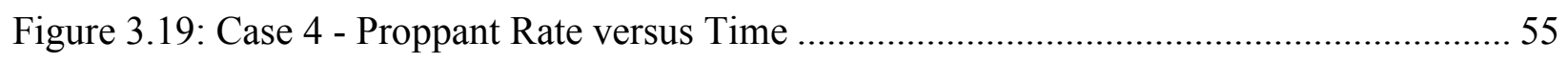

Figure 3.20: Case 4 - Cumulative Proppant Mass versus Time..................................................... 55 
Figure 3.21: Stress, Width Profiles, and Width Contours for Case 4 ..................................... 56

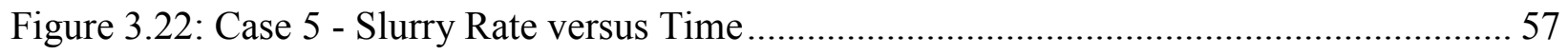

Figure 3.23: Case 5 - Cumulative Slurry Volume versus Time............................................ 57

Figure 3.24: Case 5 - Proppant Rate versus Time ................................................................ 58

Figure 3.25: Case 5 - Cumulative Proppant Mass versus Time................................................ 58

Figure 3.26: Stress, Width Profiles, and Width Contours for Case 5 ...................................... 59

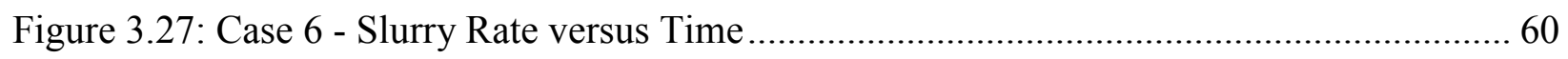

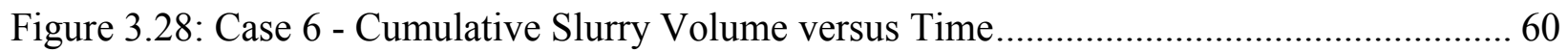

Figure 3.29: Case 6 - Proppant Rate versus Time ............................................................. 61

Figure 3.30: Case 6 - Cumulative Proppant Mass versus Time .............................................. 61

Figure 3.31: Stress, Width Profiles, and Width Contours for Case 6 ...................................... 62

Figure 3.32: Fracture Dimensions for the Base Case Fluid Injection Volume............................ 64

Figure 3.33: Fracture Dimensions for the 50 Percent Case Fluid Injection Volume................... 65

Figure 3.34: Fracture Dimensions for the 150 Percent Case Fluid Injection Volume................. 65

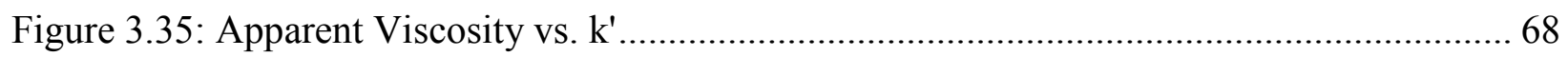

Figure 3.36: Apparent Viscosity vs. Maximum Fracture Height........................................... 69

Figure 3.37: Apparent Viscosity vs. Maximum Fracture Width ........................................... 69

Figure 3.38: Apparent Viscosity vs. Maximum Fracture Length ......................................... 70

Figure 4.1: Case 1 - Heterogeneous Layers with Original Properties ...................................... 73

Figure 4.2: Case 2 - Three Homogenized Layers with Averaged Properties ............................ 74

Figure 4.3: Case 3 - Single Homogenized Layer with Average Properties .............................. 74

Figure 4.4: Width Profiles and Contours for Case 1 ........................................................... 75

Figure 4.5: Width Profiles and Contours for Case 2 .......................................................... 75

Figure 4.6: Width Profiles and Contours for Case 3 ........................................................... 76

Figure 4.7: Fracture Profile and Contours for the Base Case .............................................. 78

Figure 4.8: Width Profiles and Contours for the Modified Stress Case .................................. 80

Figure 4.9: Width Profiles and Contours for Horizontal Stress Gradient $=0.92 \mathrm{psi} / \mathrm{ft} \ldots \ldots \ldots \ldots . . .82$

Figure 4.10: Width Profiles and Contours for Horizontal Stress Gradient $=0.91 \mathrm{psi} / \mathrm{ft} \ldots \ldots \ldots \ldots . .82$

Figure 4.11: Width Profiles and Contours for Horizontal Stress Gradient $=0.9 \mathrm{psi} / \mathrm{ft} \ldots \ldots \ldots \ldots \ldots . . . .33$

Figure 4.12: Width Profiles and Contours for Horizontal Stress Gradient $=0.75 \mathrm{psi} / \mathrm{ft} \ldots \ldots \ldots \ldots . .83$

Figure 4.13: Width Profiles and Contours for Horizontal Stress Gradient $=0.50 \mathrm{psi} / \mathrm{ft} \ldots \ldots \ldots \ldots . .84$ 
Figure 4.14: Width Profiles and Contours for Horizontal Stress Gradient $=0.25 \mathrm{psi} / \mathrm{ft}$..... 84

Figure 4.15: Width Profiles and Contours for Horizontal Stress Gradient $=0.00013134$ psi/ft .. 85

Figure 4.16: Horizontal Stress Gradient in Tully Limestone vs. Fracture Height...................... 86

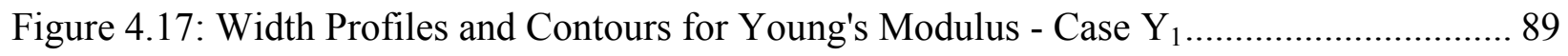

Figure 4.18: Young's Modulus of the Tully Limestone vs. Fracture Height ............................ 90

Figure 4.19: Width Profiles and Contours for Fracture Toughness $=0$ psi-in ${ }^{0.5} \ldots \ldots \ldots \ldots \ldots \ldots \ldots . . . . . . . . . .92$

Figure 4.20: Fracture Toughness of the Tully Limestone vs. Fracture Height.......................... 93

Figure 4.21: Width Profiles and Contours for Fluid Leakoff Coefficient $=0.1 \mathrm{ft} / \mathrm{min}^{0.5} \ldots \ldots \ldots \ldots . . . .95$

Figure 4.22: Leakoff Coefficient of the Tully Limestone vs. Fracture Height.......................... 96

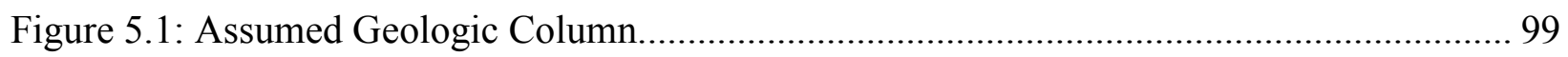

Figure 5.3: Depth to the (Upper) Marcellus shale layer ................................................... 101

Figure 5.4: Thickness of the Marcellus layer (Upper, Lower, and Cherry Valley).................. 101

Figure 5.5: Elastic (Young's) Modulii, Stress Gradients, and Fracture Toughnesses of the Lower

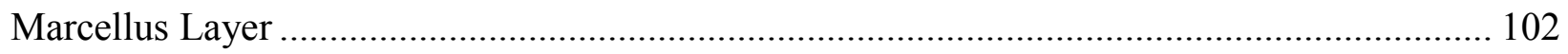

Figure 5.6: Poisson's Ratios, Leakoff Coefficients, and Thicknesses of the Lower Marcellus

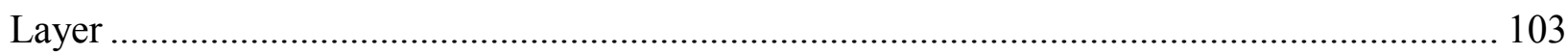

Figure 5.7: Maximum Fracture Height vs. Marcellus Depth.............................................. 104

Figure 5.8: Clearance Depth vs. Marcellus Depth ............................................................... 105

Figure 5.9: Maximum Fracture Half-Length for Each Case ................................................ 105

Figure 5.10: Maximum Fracture Width at Perforations for Each Case ................................... 106

Figure 5.11: Maximum Fracture Height for Each Case..................................................... 106

Figure 5.12: Average Fracture Width for Each Case......................................................... 107

Figure 5.13: Clearance Depth for Each Case .................................................................... 107

Figure 5.14: Fracture Height Propagation above the Marcellus Shale Layer.......................... 108

Figure 5.15: Fracture Height Termination Frequency by Layer.......................................... 108

Figure 5.16: Fracture Height Termination Percentage by Layer .......................................... 109 


\section{LIST OF TABLES}

Table 2.1: Permeability Range for Various Reservoir Types (Modified from King, 2012).......... 7

Table 2.2: Pressure Gradient and Dimensionless Pressure Functions for Various Flow Regimes (radial flow) (Valko \& Economides, 1995) ......................................................................... 13

Table 3.1: Summary of Injection Rate and Proppant Type Cases ......................................... 42

Table 3.2: Summary Table Showing Fracture Heights and Lengths ..................................... 63

Table 3.3: Influence of Fluid Injection Volume on Fracture Dimensions ................................ 66

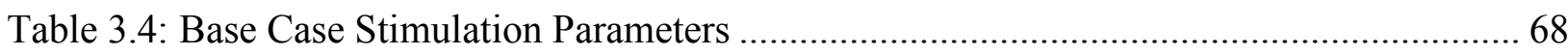

Table 4.1: Layer Homogeneity Influence Case Details ................................................... 72

Table 4.2: Base Case Injection Parameters........................................................................... 73

Table 4.3: Numerical Values of Fracture Dimensions for the Three Cases ............................ 76

Table 4.4: Horizontal Stress Calculations for Each Layer..................................................... 79

Table 4.5: Numerical Fracture Dimensions for the Base and Modified Stress Cases ................ 80

Table 4.6: Horizontal Stress Gradient in Tully Limestone and Computed Fracture Height ........ 86

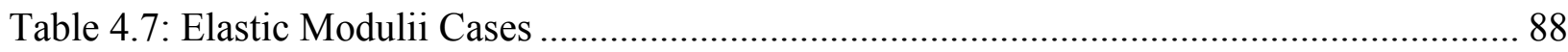

Table 4.8: Young's Modulus of the Tully Limestone vs. Computed Fracture Height................. 90

Table 4.9: Fracture Toughness of the Tully Limestone vs. Computed Fracture Height ............. 93

Table 4.10: Leakoff Coefficient of the Tully Limestone vs. Computed Fracture Height ........... 96 


\section{CHAPTER 1: INTRODUCTION}

\subsection{Background}

Since its beginnings over 60 years ago, hydraulic fracturing has been an important method for extracting oil and natural gas from underground reservoirs (Valko \& Economides, 1995). In the past 15 years, the method has seen increased popularity. There are a number of shale reservoirs in the United States and around the world. In this paper, the Marcellus shale in the United States is the focus. This formation is primarily located in the states of New York, Pennsylvania, Ohio, and West Virginia. Figure 1.1 shows the location and approximate depth range of the Marcellus shale.

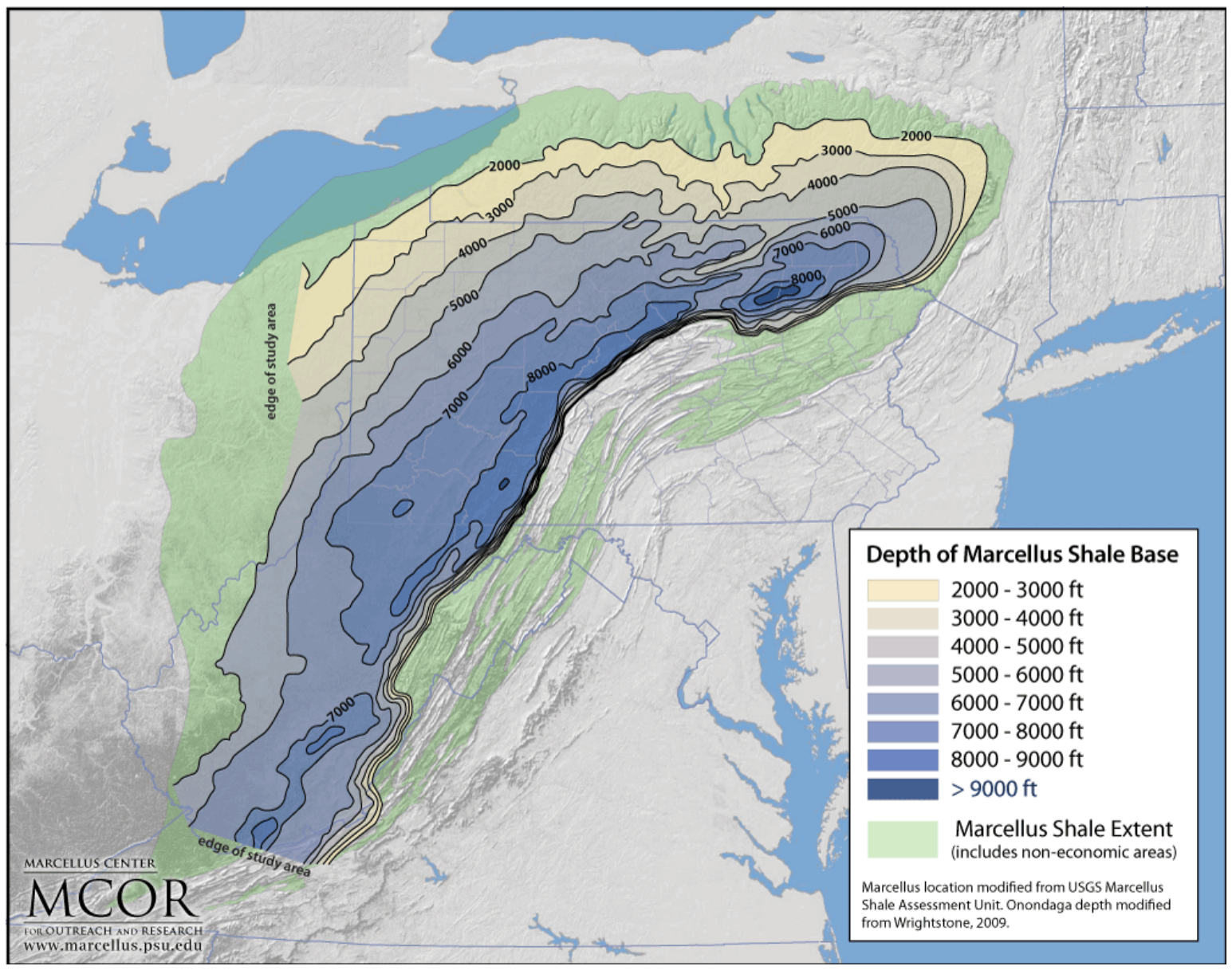

Figure 1.1: Map showing the extent and approximate depth of the Marcellus shale (Marcellus Center for Outreach and Research, www.marcellus.psu.edu, 2010) 
Hydraulic fracturing was developed as a way to extract energy from otherwise unreachable tight reservoirs. Two different well configurations are used to extract gas from formations. The first is a vertical well, which simply goes directly down to the formation without deviating from the vertical plane. Only the thickness of the formation is available to be fractured in this configuration. The second well configuration is a horizontal well. The horizontal well configuration allows for the well to deviate from the vertical plane and go completely horizontal, if necessary, to expose the well to a much larger area of the formation to extract more energy. Figure 1.2 shows both of the well configurations previously described.

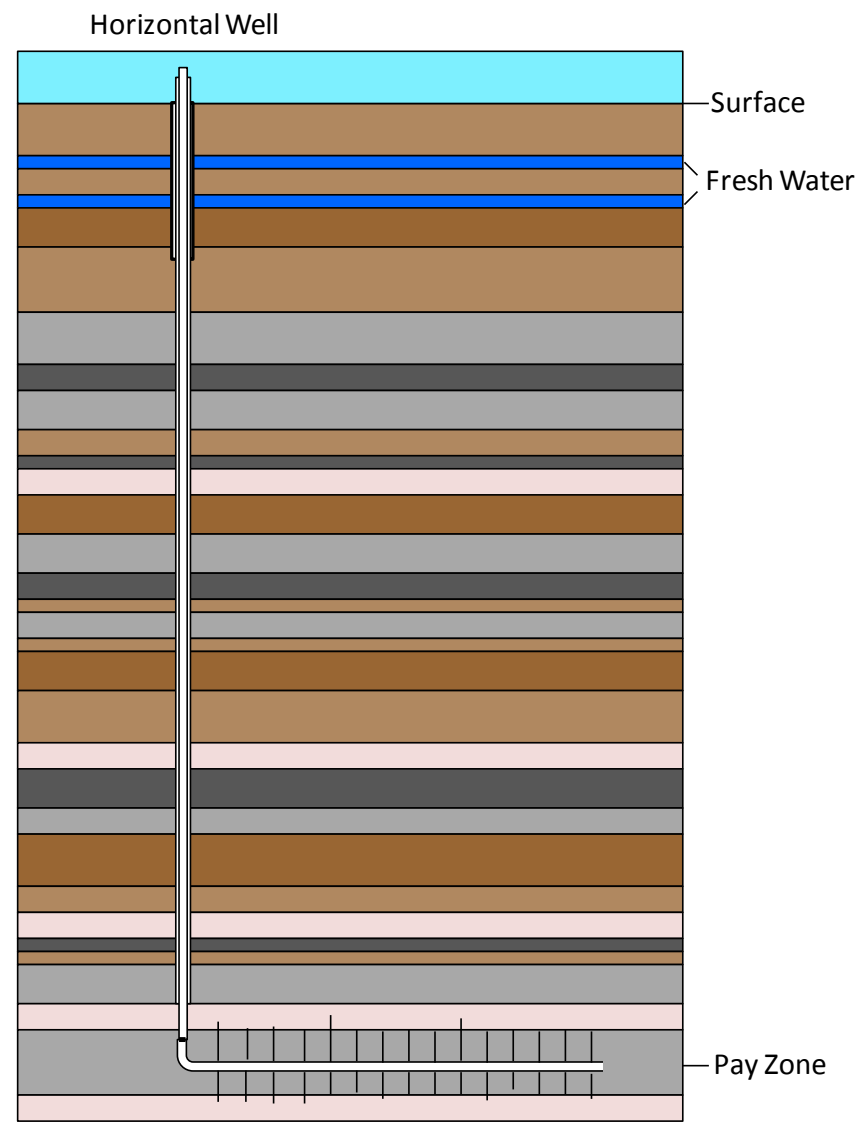

(a) Horizontal Well Configuration

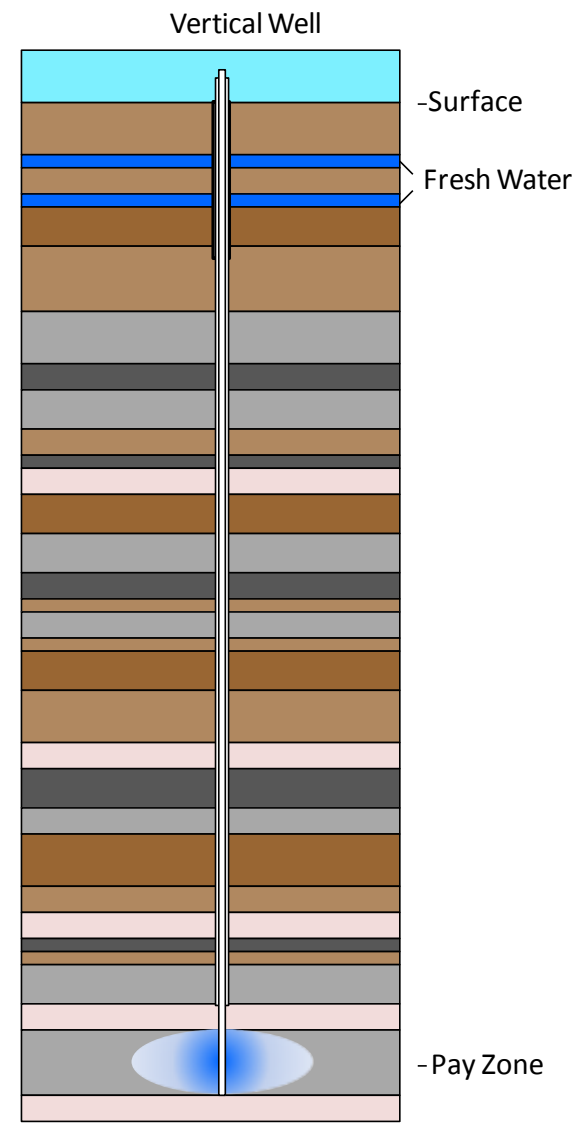

(b) Vertical Well Configuration

Figure 1.2: Horizontal (a) and Vertical (b) Well Configurations 


\subsection{Problem Statement}

- Hydraulic fracturing has received a great deal of attention over the past decade due to its increased energy extraction potential (King, 2012). The Marcellus shale is a primary area of hydraulic fracture activity in the United States, and has a great deal of extractable energy. It is important to establish the range of vertical fracture growth during hydraulic fracturing.

- It is important to determine the potential impacts of this popular energy extraction method on the environment to determine whether or not it is safe to use. Recently, scientists have analyzed 141 drinking wells in northeastern Pennsylvania and found that there is an increase in methane and other gas concentrations in aquifers near hydraulic fracturing operations (Jackson, et al., 2013). In this paper, the focus is on the vertical extent of fractures in areas of the Marcellus formation, with greatest attention focused on the southwestern Pennsylvania region. In order to determine whether or not the fracturing operation is at risk of contaminating groundwater resources from the standpoint of the fractures in the subsurface, it must be determined how high the fractures propagate, and their proximity to groundwater resources. This work aims to determine the extent of fracture propagation in the vertical direction. 


\subsection{Research Objectives}

- Determine the geology of the Marcellus shale and the surrounding layers in the southwestern Pennsylvania region.

- Find the variation of thicknesses and depths of the Marcellus shale and surrounding layers across Pennsylvania and West Virginia to determine an appropriate range which covers most of the formation in the state.

- Determine the effects of treatment parameters, such as injection rate and proppant type, on fracture propagation.

- Determine the effects of geomechanical and fluid flow properties on hydraulic fracture propagation in the Marcellus shale.

- Perform a sensitivity analysis using a statistical method to determine the likely extent of fracture propagation in the Marcellus shale for the selected region. 


\subsection{Scope of Work}

This work will be primarily focused on the Marcellus shale in Pennsylvania and the surrounding states. This work does not go into detail about the Marcellus shale in the shallower depths in locations such as northwestern Pennsylvania and Ohio. Three-dimensional fracture modeling is used to determine the extent of fractures throughout the paper. Conservative fracture design parameters, such as fracture volume and injection rate, were assumed so that the modeling would produce the highest fractures possible for safety purposes. Geomechanical and fluid loss properties were chosen to cover a wide range of values. Conservative values were included in this range to allow for higher fracture growth within the possible range. A review of studies conducted in the past few years is also presented. This paper; however, is related exclusively to the determination of vertical fracture propagation with respect to the ground surface in the Marcellus shale in the regions previously specified. The geomechanical and fluid flow properties which have the greatest impact on fracture propagation will also be identified for clarification purposes. 


\section{CHAPTER 2: OVERVIEW OF HYDRAULIC FRACTURING}

\subsection{Introduction}

The development of alternative energy resources, such as coal beds, tight sands and shales, has been an expanding source of natural gas development in the United States (Arthur, Bohm, \& Layne, 2008). An important reservoir type containing natural gas, which is helping to increase energy reserves throughout the world, is shale. Shale reservoirs are generally very "tight", meaning they have a very low permeability. Thus, it is very difficult to extract trapped natural gas from the formation. Figure 2.1 shows the range of permeability values for various reservoir materials. In this figure, beach sand is one of the most permeable materials, and shale is one of the least permeable materials. Hydraulic fracturing is required to produce in formations with permeabilities less than 1 millidarcy $(\mathrm{mD})$, as seen in the figure. It is important to note that not every shale has adequate permeability to produce gas, even with the aid of hydraulic fracturing (King, 2012). The development of shale gas has been made possible as a result of two critical technology advances - hydraulic fracturing and horizontal drilling (Arthur, Bohm, \& Layne, 2008). In recent years, hydraulic fracturing has moved into the forefront of the American discussion on energy retrieval (King, 2012). Hydraulic fracturing involves the injection of proppant, water (or another fluid), and other additives at high pressures to fracture rock and increase the exposed surface area for natural gas extraction. The emergence of horizontal drilling into shale gas formations has greatly improved the economics and production from tight gas reservoirs. Horizontal drilling involves deviating the wellbore from the vertical position in the subsurface at a "kick-off" point, and proceeding (approximately) horizontally into the targeted formation. This drilling method exposes the wellbore to a greater surface area of the target formation than traditional vertical drilling, as shown in Figure 1.2. The following section contains a review of several recently published studies on hydraulic fracturing. 


\begin{tabular}{|c|c|c|}
\hline Reservoir Type & Permeability Range $(\mathrm{mD})$ & Material Example \\
\hline Conventional & $1-1000$ & Beach Sand \\
\hline TightGas & $0.001-1$ & Brick \\
\hline Unconventional & $0.001-0.000001$ & Shale \\
\hline
\end{tabular}

\subsection{Recent Studies}

Several studies were selected from published literature over the past few years and are presented in this section (Bilgesu \& Yusuf, 2011; Fisher \& Warpinski, 2011; Fontaine, Johnson, \& Schoen, 2008; Jacot, Bazan, \& Meyer, 2010; Keshavarzi, Mohammadi, \& Bayesteh, 2012; Mayerhofer, Stegent, Barth, \& Ryan, 2011; Meyer \& Bazan, 2011; Neuhaus, et al., 2012; Wade \& Bilgesu, 2012).

In a recent study by Bilgesu and Yusuf (2011), simulations were performed to investigate the influence of formation stress levels in various shale formations on the outcome of fracture treatments when the formation contains discrete natural fractures. This study showed that the horizontal stresses which exist in an area can alter the shape and size of a fracture treatment (Bilgesu \& Yusuf, 2011). It was also found that gas production in shale formations can increase with an increased stress difference between layers. This was insignificant for a single fracture treatment, but can be an important economic factor in multi-stage treatments (Bilgesu \& Yusuf, 2011).

Another study used real data from microseismic fracture-mapping taken from thousands of hydraulic fracturing jobs in four different shale formations and showed that hydraulic fracture height growth is well contained (Fisher \& Warpinski, 2011). Hydraulic fracture modeling software often predicts that induced fractures grow higher than those which are directly measured. This is due to the various containment mechanisms which naturally exist in geologic 
strata. Examples of these containment mechanisms are: complex geologic layering, highpermeability layers, formation of fracture networks, high fluid leakoff, natural fractures, and changing material properties between layers (Fisher \& Warpinski, 2011). It was determined in this conference paper that the physics of fractures, the mechanical properties of the formation, the layered geologic strata, and other factors all aid in limiting vertical hydraulic fracture propagation (Fisher \& Warpinski, 2011). These factors allow hydraulic fracturing to take place in tight formations safely and effectively (Fisher \& Warpinski, 2011).

A third study showed the design, execution, and evaluation of a Marcellus shale slickwater stimulation (Fontaine, Johnson, \& Schoen, 2008). Details of fracture treatments from other basins and formations are utilized to aid in making an effective treatment design for the Marcellus shale. One fracture treatment eliminated or reduced near wellbore problems, such as the formation of multiple fractures and tortuosity, through the usage of acids and proppant slugs. This can help in achieving maximum attainable injection rates to effectively transmit the fracturing pressure from the wellbore to the formation, and thus maximize reservoir stimulation. This study also detailed how effective proppant placement in the fractures can be achieved through the use of wellbore sweeps scheduled regularly as part of the treatment schedule. The authors also suggest that the evaluation and analysis of treatment parameters should always be compared to the production response observed in order to improve future designs (Fontaine, Johnson, \& Schoen, 2008).

The importance of technology integration in Marcellus Shale gas wells was described in a recent publication (Jacot, Bazan, \& Meyer, 2010). The technology integration described in the paper brings together the following tools which can enhance production and maximize economics: minifrac analysis, fracture treatment design, microseismic data, and production data. Each of the tools for technology integration was reviewed and the methodology for integration was discussed (Jacot, Bazan, \& Meyer, 2010). The procedure which is given in the paper integrates hydraulic fracture analyses, numerical simulations, minifrac analysis, diagnostic fracture injection testing, after closure analysis, replay pressure history matching, complex fracture geometry, stimulated reservoir volume, and the comparison of numerical fracture propagation simulation with microseismic mapping (Jacot, Bazan, \& Meyer, 2010). Discrete Fracture Networking based simulations were performed for an example well in the Marcellus 
Shale. It is shown through the example that applying this methodology to field work will help provide a systematic approach for designing, analyzing, and optimizing hydraulic fracture designs in horizontal wells (Jacot, Bazan, \& Meyer, 2010).

The behavior of induced hydraulic fractures in an area of pre-existing natural fractures was investigated by Keshavarzi, Mohammadi, \& Bayesteh (2012). In the paper, a new extended finite element method approach was developed in order to account for the interactions between induced and natural fractures, and to determine which parameters were most influential upon the interaction. The paper describes a mechanism called "debonding of natural fracture(s)", which is due to the interaction between the hydraulic and natural fractures. This mechanism was found to be a key factor in explaining almost all the observed behaviors which occur during the interaction between hydraulic and natural fractures. Hydraulic fracture diversion and natural fracture activation was found to begin several stages before the actual intersection. The intersection between hydraulic and natural fractures is controlled by the length and position of the debonded zone along the natural fracture before intersection, the horizontal stress differential, and the orientation of natural fractures. At high angles of approach, hydraulic fracture diversion and natural fracture activation was found to be less than at low angles of approach. When fracturing pressure and angle of approach are kept constant, increasing the horizontal differential stress results in a decrease in hydraulic fracture diversion. Finally, the paper noted that in order to optimize the fracture treatment, more focus should be put on hydraulic fracture diversion and natural fracture activation before intersection prior to starting the fracturing job, in order to prevent failure caused by changes or diversion in the path of the hydraulic fractures (Keshavarzi, Mohammadi, \& Bayesteh, 2012).

The benefits of integrating fracture diagnostics with engineering data in the Marcellus shale was recently reported (Mayerhofer, Stegent, Barth, \& Ryan, 2011). This paper integrated microseismic fracture mapping, diagnostic fracture injection tests, downhole pressure gauges, post-fracture pressure transient analysis, non-toxic chemical tracer data, and production data in order to gain valuable insight into fracture propagation. Results showed that post-fracture pressure buildup tests do not give a clear interpretation of the effectiveness of the stimulation and the quality of the reservoir (Mayerhofer, Stegent, Barth, \& Ryan, 2011). Additional diagnostic data is required to avoid potential incorrect interpretations and conclusions. Communication was 
seen between two wells spaced at approximately 1,000 feet. The paper suggests that reservoir simulation software (in general) could be used to determine gas recovery factors using history matching of actual well production and the forecasting of well performance in order to determine the appropriate well spacing to avoid communication between wells. The study concludes that the integration of various forms of diagnostic data is vital in shortening the learning curve in shale play development and optimization (Mayerhofer, Stegent, Barth, \& Ryan, 2011).

A solution methodology and mathematical formulation for an induced hydraulic discrete fracture network numerical simulator was presented in the literature (Meyer \& Bazan, 2011). The paper made several important conclusions, which have implications for hydraulic fracturing jobs in naturally fractured reservoirs. The paper formulated a discrete fracture network model, which is most applicable to naturally fractured formations with complex fracture networks. It was also found that the fracture aperture for closely spaced parallel or transverse fractures will be greatly impacted by the mechanical interaction between multiple parallel fractures. This mechanical interaction has a greater effect on the interior of the fractures as compared to the exterior or edge fractures. Fracture efficiency of the dominant fracture was found to have a significant influence on proppant transport and placement. Fracture efficiency could be extremely small for larger discrete fracture networks or stimulated reservoir volumes and screenouts may occur if all of the proppant is assumed to remain within the dominant fracture. Because screen-outs are not commonly observed in the far field, it may mean that significant volumes of proppant are being transported into secondary fracture networks. Microseismic fracture mapping was also said to be a useful tool for calibrating the discrete fracture network model. Finally, the authors concluded that the application of the technology described in the paper will provide oil and natural gas operators with a systematic approach for designing, analyzing, and optimizing multi-stage/multi-cluster transverse discrete fracture network hydraulic fractures in horizontal wellbores (Meyer \& Bazan, 2011).

Neuhaus et al. (2012) conducted a study on using microseismic monitoring technology for field optimization of hydraulic fracture treatments in the Marcellus Shale. 101 permanently installed geophones, which covered an area of 18 square miles and five wellpads, were used to provide high resolution stimulation monitoring. There was little to no variation in terms of the treatment parameters for all five wells and all their respective stages. Variability was found in the 
observed microseismic response to fracture treatments, and this can be attributed to geological factors, as the treatment parameters were relatively the same. The in-situ stress state in the reservoir is a normal faulting tectonic regime with the vertical stress being the maximum principal stress. However, during the hydraulic fracture treatment, the in-situ stress local to the wellbore changes and becomes a strike-slip faulting tectonic regime with the maximum horizontal stress being the maximum principal stress. Microseismic mapping and analysis were shown to provide a characterization of the reservoir stimulation, which can be used to model future production. Hydraulic fracture simulation modeling of discrete fracture networks based on microseismicity was able to predict the behavior observed in the field (Neuhaus, et al., 2012). It was also able to validate the stress conditions which were interpreted from obtained data and show that microseismicity originates mainly from the reactivation of the natural ( $\mathrm{J} 1$ and $\mathrm{J} 2$ ) joint sets (Neuhaus, et al., 2012).

Wade and Bilgesu (2012) analyzed and predicted the maximum stress around a wellbore for a horizontal well in the Marcellus shale formation. Data was gathered on the formation and a model was created to simulate reservoir production coupled with a geomechanics model, which analyzed the maximum stress near the wellbore. It was determined that the final maximum stress values and stress distributions in a Marcellus gas reservoir differ because of differences in fracture permeability and the fracture treatments. Stresses which were created in the wellbore in the short-term, following treatment, can be attributed to the hydraulic fractures, and account for approximately half of the total stress during 20 years of gas production. Wells with shorter halflengths had greater stress at the beginning of production, while wells with longer fracture halflengths had greater stress in the long-term, because of the resulting increased production. Longterm increased stress in the wellbore can be attributed to increased production. Increased fracture permeability leads to higher production, and thus higher stress. Finally, the paper states that if the wellbore does not fail during the first year of production, it will most likely not fail during the life of the well (Wade \& Bilgesu, 2012). 


\subsection{Fluid Flow through Porous Media}

The flow of fluids through a porous medium (such as a shale gas reservoir) is important in understanding how natural gas or oil is able to travel from inside a formation to a wellbore. The ability of a fluid to flow through a porous medium is critical in determining the amount of natural gas or oil which can be extracted through fracturing. A porous medium is defined as, in this context, a geologic formation which contains voids (pores). The ratio of the volume of the pores in the formation to the bulk volume of the formation is known as the porosity (denoted $\phi)$. The sizes of these pores typically range from about $10^{-7}$ meters to $10^{-4}$ meters. As for porosities, these values generally range from less than 0.10 to 0.40 (very high) in some carbonate formations. Porosity is very important in terms of determining the oil or gas in place in a reservoir. The permeability $(k)$, describes the ability of fluids to flow through the reservoir. Permeability ranges of typical reservoir and other materials can be seen in Figure 2.1. Permeability relates the pressure gradient $(\Delta \mathrm{p})$ and the macroscopic fluid velocity $(u)$ through the following relation:

$$
u \propto k \Delta p
$$

Darcy's law is a fundamental equation which is used to describe the flow of a fluid (such as gas or oil) through a porous medium. This law relates the volumetric flow rate, fluid viscosity, and pressure gradient over a given length. Darcy's law is given in radial coordinates in the following equation (Valko \& Economides, 1995):

$$
q=\frac{2 \pi r k h}{\mu} \frac{d p}{d r}
$$

where $q$ is the volumetric flow rate, $r$ is the radial distance, $k$ is the permeability, $h$ is the reservoir thickness, and $\mu$ is the viscosity. The following important points should be noted from the relation shown in Darcy's law:

- If no pressure gradient exists over a distance, no fluid flow will occur (hydrostatic conditions) 
- If there is a pressure gradient, fluid will flow from a high pressure zone to the lower pressure zone

- the larger the pressure gradient, the larger the fluid flow rate

The constant rate and constant pressure solutions of the previous equation are of interest for hydraulic fracturing purposes. The general form of the constant rate solution is given as follows (Valko \& Economides, 1995):

$$
q=\frac{2 \pi k h \Delta p}{\mu p_{D}}
$$

where $p_{D}$ is the dimensionless pressure function. $p_{D}$ can be defined by three different flow mechanisms: transient, with an infinite-acting behavior, steady-state, which has a constant outer boundary pressure $\left(p_{e}\right)$, and psuedosteady-state, which has a no-flow outer boundary condition. Table 2.1 shows the pressure gradient and dimensionless pressure functions for the different flow regimes (radial flow).

Table 2.2: Pressure Gradient and Dimensionless Pressure Functions for Various Flow Regimes (radial flow) (Valko \& Economides, 1995)

\begin{tabular}{|c|c|c|}
\hline Flow Regime & $\Delta \mathbf{p}$ & $p_{D}$ \\
\hline Transient & $p_{i}-p_{b h f}$ & $-\frac{1}{2} E^{i}\left(-\frac{1}{4 t_{D}}\right)$ \\
\hline Steady State & $p_{a v g}-p_{b h f}$ & $t_{D}=\frac{k t}{\phi \mu c_{t} r_{w}^{2}}$ \\
\hline Pseudosteady State & $p_{e}-p_{b h f}$ & $\ln \frac{r_{e}}{r_{w}}$ \\
\hline
\end{tabular}


In Table 2.1, $E^{i}$ is the Exponential integral, $p_{i}$ is the initial reservoir pressure, $p_{e}$ is the outer boundary constant pressure, $p_{a v g}$ is the average reservoir pressure, $p_{b h f}$ is the flowing bottom-hole pressure, $r_{e}$ is the outer boundary radius, and $r_{w}$ is the well radius.

As can be seen from Equation 2.3, for steady state flow and pseudosteady state flow the pressure gradient driving the flow is proportional to the logarithm of the radial distance. This means that the same amount of pressure gradient is used in the first meter as in the next 10 meters, 100 meters, 1000 meters, etc. So, changing the permeability of the reservoir around the wellbore is clearly critical to increasing production from the well, especially in reservoirs with very low natural permeabilities (tight formations).

It is common in almost all drilling operations that there are some permeability-altering occurrences which decrease the permeability near the wellbore. This decrease in permeability near the wellbore is referred to as "damage", and is taken into account using a dimensionless skin effect coefficient, $s$. The dimensionless skin coefficient is simply added to the dimensionless pressure function in Equation 2.3 as follows (Valko \& Economides, 1995):

$$
q=\frac{2 \pi k h \Delta p}{\mu\left(p_{D}+s\right)}
$$

The dimensionless skin effect coefficient is determined through well pressure transient testing. Large positive values indicate that the permeability has been severely decreased due to possible mechanical problems. A value of zero indicates no permeability change due to near wellbore damage. A negative value is rare, but possible, and indicates that the permeability was increased in the near wellbore zone due to possible reactions of the formation with injected stimulation fluids (such as acids reacting with carbonate rock). If a negative value is found for the dimensionless skin effect coefficient, matrix stimulation may be performed through chemical treatments to the near wellbore zone, as opposed to hydraulic fracturing. Hydraulic fracturing may be performed for cases where matrix stimulation cannot be carried out in an economic fashion (Valko \& Economides, 1995). 


\subsection{Hydraulic Fracture Design and Execution}

In order to successfully design a hydraulic fracture treatment for a given reservoir, the post-treatment production should be maximized and the treatment costs minimized. The economic principle known as the "Net Present Value" (or NPV) was established for the purpose of ensuring that the maximum benefit is gained from the reservoir stimulation (Valko \& Economides, 1995). Maximum NPV corresponds to the optimal fracture size. Designs are typically begun with a fracture size using the fracture half-length (fracture wing length). The hydraulic fracture propagation model then defines the fracture width and height. The required fracture volume is determined by calculating the estimated created fracture volume and determining the amount of fluid which may be lost to leakoff into the formation (Valko \& Economides, 1995). In order to calculate the required mass of proppant to keep the created fractures open, a "ramped proppant schedule" is commonly used (Nolte, 1986). The required fluid volume, proppant mass, and time of injection are the main components which factor into the cost of the treatment. After subtracting these costs from the expected present value of the incremental revenue, the NPV is found for the specified fracture half-length. The process of finding the main components for various fracture-half lengths and the corresponding NPV for each half-length is repeated. The ideal fracture half-length is the one which corresponds to the maximum NPV.

Today's hydraulic fracturing operations require large amounts of fluid, proppant, and pumping power. Fracturing operations can inject over 500,000 U.S. gallons of fluids, 1,000,000 lbm of proppant, and can use over 20 pumping units, each of which can produce over $2000 \mathrm{hhp}$ (hydraulic horse power) (Valko \& Economides, 1995). Figure 2.1 shows an illustration of a simple drilling area used for hydraulic fracturing operations (Note: this is not a complete list of all components used in the hydraulic fracturing process. Mud refers to the fracturing fluid mixture.). The following paragraphs briefly explain the fracturing fluids and proppants used in hydraulic fracturing. 


\section{Drilling Rig Components}

1. Crown Block and Water Table

2. Catline Boom and Hoist Line

3. Drilling Line

4. Monkeyboard

5. Traveling Block

6. Top Drive

7. Mast

8. Drill Pipe

9. Doghouse

10. Blowout Preventer

11. Water Tank

12. Electric Cable Tray

13. Engine Generator Sets

14. Fuel Tanks

15. Electric Control House

16. Mud Pump

17. Bulk Mud Components Storage

18. Mud Pits

19. Reserve Pits

20. Mud Gas Separator

21. Shale Shaker

22. Choke Manifold

23. Pipe Ramp

24. Pipe Racks

25. Accumulator

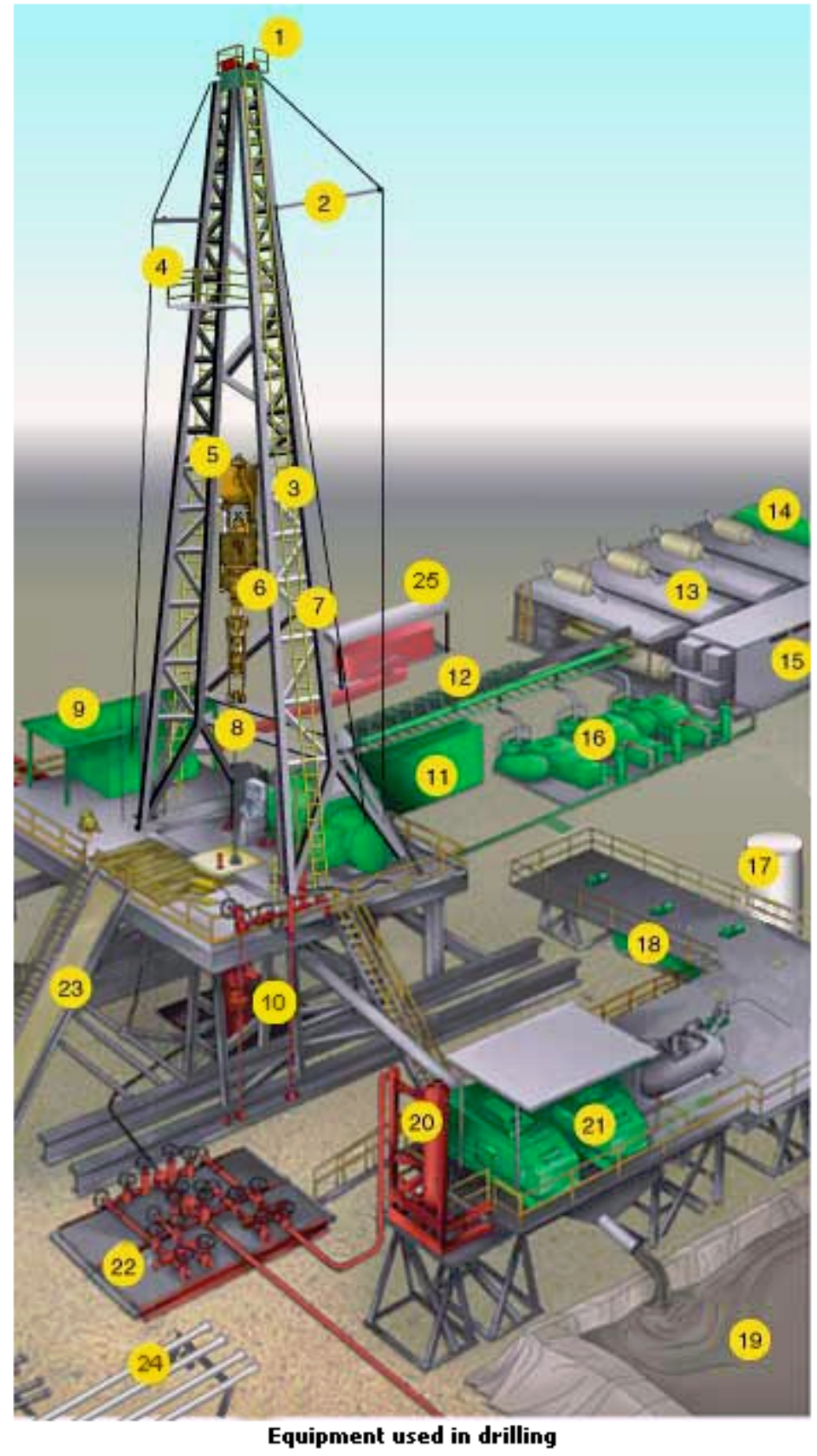

This figure was taken from

https://www.osha.gov/SLTC/etools/oilandgas/illustrated_glossary.html, 2013.

Figure 2.1: Drilling Rig Components (OSHA, 2013) 
There are four main objectives of a good fracturing fluid (Valko \& Economides, 1995). The first is to allow the fracture to initiate the breakdown of the formation and propagate through the formation. The second is to facilitate proppant transport by allowing the proppant to flow adequately into the created fractures so that they may keep a sufficient fracture area open. The third objective is to minimize fluid leakoff into the formation. If too much fluid leaks into the formation, a valuable resource is lost and adequate proppant transport and fracture propagation may not be achieved. The final primary objective of the fracturing fluid is to avoid damage to the proppant as it is being placed in the fractures. Damage to the proppant may reduce the designed permeability of the proppant pack and decrease production from the formation.

Viscosity is an essential property which helps the fracturing fluid create adequate fracture dimensions. While travelling through the wellbore, the fluid should have a low viscosity. The lower the viscosity, the less friction pressure is created in the wellbore. This lower friction pressure allows the fluids to be pumped at lower treating pressures and allows for less energy to be used in powering pumping devices. However, when the fluid enters the fractures in the formation, a higher viscosity is required. This is to allow for the creation of wider fractures and adequate proppant transport (Valko \& Economides, 1995). After the fractures are created and the treatment process has ended, the high viscosity that was required for fracture creation is now detrimental to production fluids leaving the formation and going back into the wellbore. To incorporate these necessary viscosity changes to the fluid as it goes through the wellbore, into the formation, and flows back after production, various chemicals are added to the injected fluid to help achieve viscosity changes. To achieve the higher viscosity in the fractures, delayed crosslinkers can be used (Valko \& Economides, 1995). These chemicals do not increase the viscosity in the wellbore, and are delayed until the fluid reaches the formation, when higher viscosity is needed.

Fracturing fluids are also commonly foamed using nitrogen or carbon dioxide (Valko \& Economides, 1995). Foaming works to minimize the damage to the filtrate and to help with the flowback by ensuring that cleanup occurs in the fracture. Foam qualities, gas volume percentages, of 50 to $90 \%$ have been used (Valko \& Economides, 1995). After injection, it is important to ensure that the polymer chains in the proppant pack are broken down so that the 
permeability is not decreased. In order to break down such polymer chains, oxidizers, enzymes, or sometimes chemicals called encapsulated breakers are added into the fracturing fluids.

After injecting the fracturing fluids and creating fractures in a reservoir, the natural pressure in the reservoir acts to close the fractures and reduce the widths back to zero. In order to keep the fractures created by the fluids open, it is thus necessary to inject a solid along with the fluids to prop the fractures open following injection. The solids injected along with the fluids are called proppants and are usually sands, which may be coated in a resin or other material. The main criteria in selecting proppants is by their strength and size. There are three main categories of proppant as follows: low, intermediate and high strength. Low strength proppants are usually natural sands which fall into the 12/20 mesh to 20/40 mesh range (average particle diameters ranging from $0.2 \mathrm{~mm}$ to $0.1 \mathrm{~mm}$ ) (Valko \& Economides, 1995). These proppants are generally used at depths below 2000 meters, because of lower formation stresses. Intermediate and high strength proppants are used at greater depths (3000 to 5000 meters) and are usually coated with resin (Valko \& Economides, 1995). The resin coating helps proppant fragments to stick together, maintain higher permeability in the fracture, and perform under higher formation stresses (Valko \& Economides, 1995). 


\subsection{Data Acquisition and Evaluation Methods for Hydraulic Fracturing}

To adequately predict fracture propagation and conductivity through simulation modeling, data must be collected from the site where stimulation will occur. There are three

primary techniques for obtaining data for numerical models. These techniques are well log measurements, core measurements, and well testing. Seismic techniques are sometimes used, but are very costly and primarily used in critical cases (King, 2012). Well log measurements are meant to obtain mechanical properties of rocks in the target and surrounding formations (King, 2012). The primary data acquired from this test is the stress values in the formation and the stress contrast between layers (Valko \& Economides, 1995). Devices called acoustic televiewers are lowered into drilled boreholes to send out sonic waves and measure their travel time and amplitude when they return to the device to determine mechanical properties within the rock (Valko \& Economides, 1995). Core measurements are done by collecting core samples from the target reservoir. As stress is applied to the core, fissures may appear or disappear, and by counting the number of fissures in the sample it is possible to determine the stress anisotropy of the sample (Valko \& Economides, 1995). The final data acquisition method of well testing is done while a well is in operation (not for hydraulic fracturing yet). The well can be analyzed for pressure and flow rate data when the well is in operation and fluid is flowing (called drawdown), when the well is shut-in and not actively pumping fluids (called buildup), or when the well is being observed by another well (called interference). This analysis allows for the determination of important reservoir properties. These properties include, but are not limited to: skin effect, reservoir permeability, permeability anisotropy, and types and locations of boundaries and formation heterogeneities. This testing can determine whether or not the formation is suitable for hydraulic fracturing, matrix stimulation, or no treatment. Also, after hydraulic fracturing is performed, a well test can allow for the determination of fracture half-length and conductivity (Valko \& Economides, 1995). 


\subsection{Overview of Fracturing Models}

In this chapter, three hydraulic fracture propagation models and their formulae are presented. Over the past half century, many 2-D as well as 3-D hydraulic fracturing simulators have been developed, which take into account the various complex processes which occur during the fracturing process. The two primary 2-D models which are used in hydraulic fracturing simulators are known as PKN and GDK. The PKN model was developed by Perkins and Kern (Perkins \& Kern, 1961), as well as Nordgren (Nordgren, 1972). The GDK model was developed by Geertsma and de Klerk (Geertsma \& de Klerk, 1969). A comparison of the various 2-D models and their underlying assumptions can be found elsewhere (Geertsma \& Haafkens, 1979). The 3-D model formulae which are presented in this chapter are based on a penny shape type fracture (Meyer, 1986).

The "(2-D) formulae are based on asymptotic behavior of more comprehensive solutions for the limiting cases of no fluid loss $(\eta=1)$ and large leak-off $(\eta \rightarrow 0) "$ (Meyer, 1986). 3-D formulae are also shown for cases of large and no confining stresses, as these are the asymptotic limits for validation of the model. The equations presented in this chapter which govern mass conservation and fracture propagation are based on Meyer's (1985) methodology. All equations take into account a single wing fracture, as the fracture is assumed to have two symmetric wings (See Figure 2.2).

Plane strain is an adequate assumption in simplified hydraulic fracturing analysis. The GDK model assumes plane strain in the horizontal plane. The PKN model assumes plane strain in the vertical plane. For long fractures with short height and a small width, plane strain can be assumed in the vertical plane (PKN). For short fractures with higher fracture heights and a small width, plane strain can be assumed in the horizontal plane (GDK). For more information on plane strain assumptions in the PKN and GDK models see Valko and Economides (1995), Sneddon (1973), Perkins and Kern (1961), Nordgren (1972), and Geertsma and deKlerk (1969). 


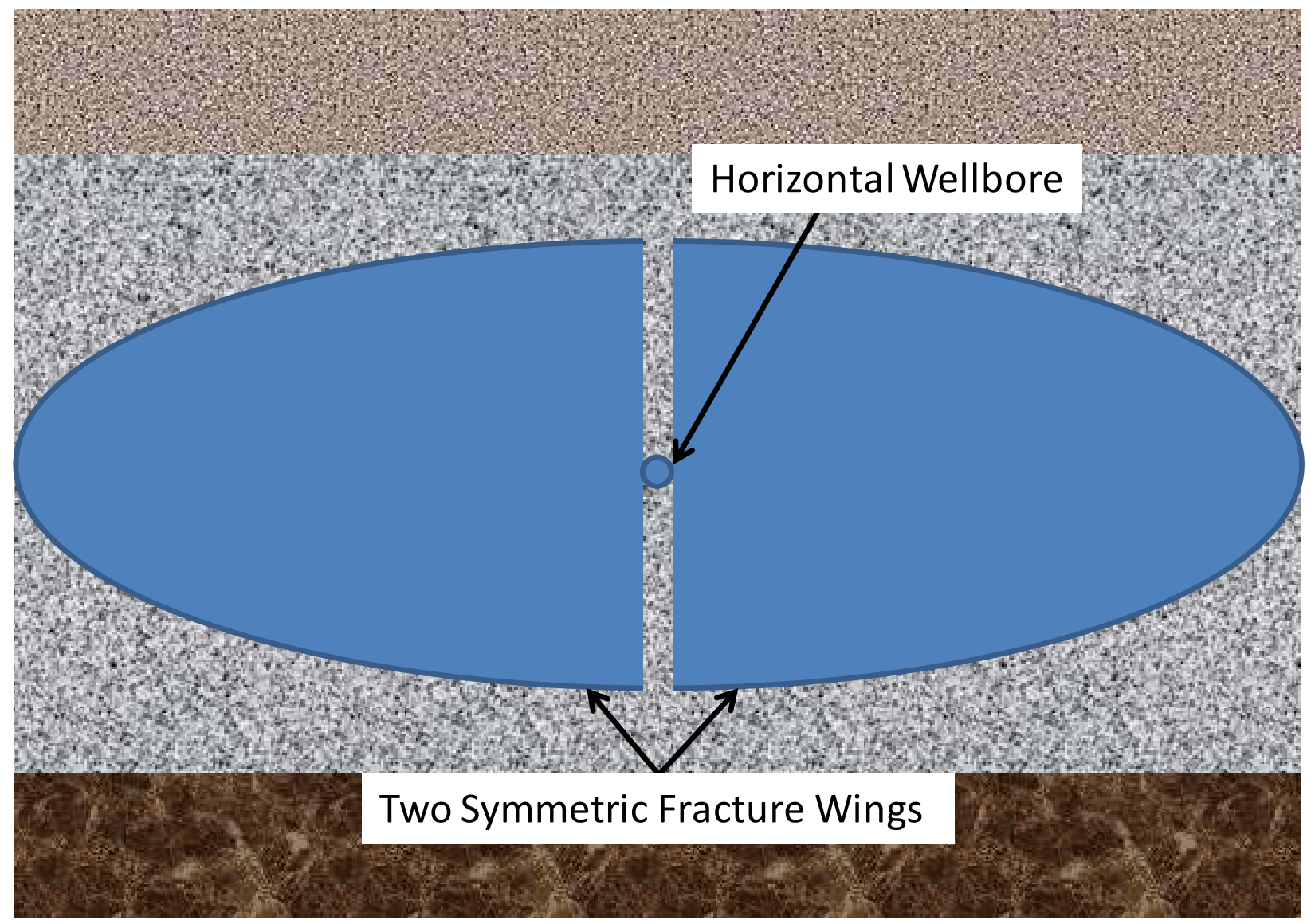

Figure 2.2: Symmetric Fracture Wing Diagram

For the conservation of mass in any incompressible slurry injection into a fracture, it is required that the following equation is satisfied (Meyer, 1986):

$\int_{0}^{t} q(\tau) d \tau-V_{f}(t)-V_{l}(t)-V_{s p}(t)=0$ 
where:

$$
\begin{aligned}
& V_{f}(t)=\tau_{v}(t) W_{W}(t) H_{W} L(t) \cdots G D K \\
& V_{f}(t)=\Gamma_{v}(t) W_{W}(t) H_{W} L(t) \cdots P K N
\end{aligned}
$$

$V_{f}(t)=2 \Gamma_{v}(t) W_{W}(t) R(t)^{2} \cdots$ Penny

$V_{l}(t)=2 \int_{0}^{t} \int_{0}^{A} \frac{C(A, t)}{\sqrt{t-\tau(A)}} d A d t$

$V_{s p}(t)=2 S_{p} A(t)$

$\tau(A)=t[A / A(t)]^{1 / l_{a}}$

$t$ is time

$q$ is the single-wing flow rate

$\tau$ is the fluid loss delay time

$V_{f}$ is the single-wing fracture volume

$V_{l}$ is the volume loss due to leak-off

$V_{s p}$ is the volume loss due to spurt

$\tau_{v}$ and $\Gamma_{v}$ are fracture volume coefficients 
$W_{W}$ is the maximum wellbore width

$H_{W}$ is the total wellbore height

$L$ is the fracture half-length

$R$ is the fracture radius

$A$ is the leak-off area of a single face

$C$ is the total leak-off coefficient

$S_{p}$ is the spurt loss coefficient

$l_{a}$ is the leak-off area propagation parameter

Equation 2.5 states that the amount of fluid injected must equal the amount of fluid in the fracture, along with the fluid lost. That is, the total volume of slurry injected minus the volume of slurry in the fracture, the volume of fluid lost to the formation through leak-off, and the volume of spurt loss must equal zero in order to conserve mass. This basically states that what you put in must equal what comes out and what stays in the fracture (Meyer \& Bazan, 2011).

The following equations will set the stage for defining the PKN, GDK, and 3-D (penny) models in the coming sub-sections. First, in order to define the limiting cases for the PKN, GDK, and 3-D models, the fracture efficiency parameter must be defined. This parameter is defined as the ratio of fracture volume to total slurry volume injected. This relationship is shown in the following equation (Meyer, 1986):

$$
\eta(t)=V_{f} / \int_{0}^{t} q(\tau) d \tau
$$


$=V_{f} / q t \longrightarrow q$ is constant

Fracture length, $(\mathrm{L}(\mathrm{t})$, and fracture radius, $\mathrm{R}(\mathrm{t})$, for the 2-D (GDK and $\mathrm{PKN})$ and 3-D (penny) models are given in Equations 2.13, 2.14, and 2.15 (Meyer, 1986) for a constant injection rate and no leak-off (or a fracture efficiency of 1 ).

$$
\begin{aligned}
& L(t)=\frac{q t}{\tau_{v}(t) W_{W}(t) H_{W}} \longrightarrow G D K \\
& L(t)=\frac{q t}{\Gamma_{v}(t) W_{W}(t) H_{W}} \longrightarrow P K N \\
& R(t)=\left[\frac{q t}{2 \Gamma_{v}(t) W_{W}(t)}\right]^{0.5} \longrightarrow 3-D(\text { penny })
\end{aligned}
$$

where $R$ is the fracture radius (for the 3-D (penny) model).

For situations with large leak-off volumes $(\eta \rightarrow 0)$ with constant leak-off coefficients and no spurt loss, the fluid loss volume equation is given as follows (Meyer, 1986):

$$
\begin{aligned}
V_{l}(t) & =2 C \int_{0}^{t} \frac{A}{t^{0.5}} \int_{0}^{1} \frac{1}{\sqrt{1-\lambda^{2}}} d \lambda d t \\
& =\pi C A t^{0.5}
\end{aligned}
$$

where $l_{a}=1 / 2($ when $\eta=0)$

Finally, for the 2-D models (PKN and GDK) and the 3-D (penny) fractures, the total leak-off area for one face where leak-off only occurs in the pay zone is given by the following (Meyer, 1986): 


$$
\begin{aligned}
& A=H_{p} L(t) \longrightarrow 2-D \\
& A=\frac{\pi R(t)^{2}}{2} \longrightarrow 3-D(\text { penny }) \longrightarrow R<\frac{H_{p}}{2} \\
& A=H_{p} R(t) \longrightarrow 3-D(\text { penny }) \longrightarrow R>>\frac{H_{p}}{2}
\end{aligned}
$$

where $H_{p}$ is the height of the pay zone. 


\subsubsection{PKN Model}

The Perkins-Kern/Nordgren (PKN) fracture propagation model incorporates a constant height fracture along with an ellipsoidal shaped width profile along the length of the fracture (Perkins \& Kern, 1961). The width profile of a PKN fracture can be seen in Figure 2.3 (a) (Meyer, 1986). The length profile for the PKN model can be seen in Figure 2.4. The distinctive feature of the PKN model is the fact that the net pressure increases with time for a constant injection rate (Meyer, 1986). The PKN model is most appropriate for use when the total fracture length is greater than the total fracture height (Meyer \& Bazan, 2011). For the PKN model, the width of the fracture at any position ( $\xi$ ) in PKN model is given by (Meyer, 1986):

$$
W(x, \xi, t)=W_{w}(x, 0, t)\left(1-\xi^{2}\right)^{1 / 2}
$$

where

$W(x, \xi, t)$ is the width at any position $\xi,\left(\xi=\frac{z}{H}\right)$

$W(x, 0, t)$ is the maximum width at any position ' $\mathrm{x}$ '. 


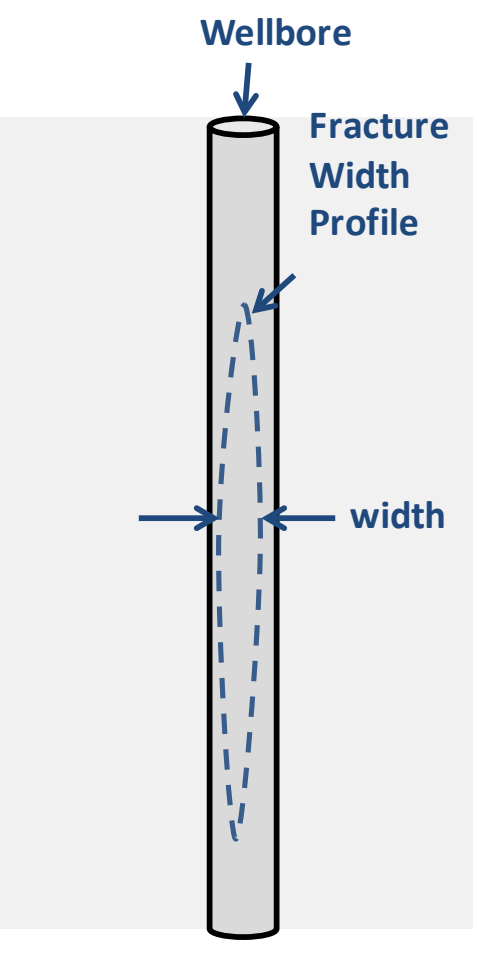

PKN Model Width Profile

(a) PKN Width Profile

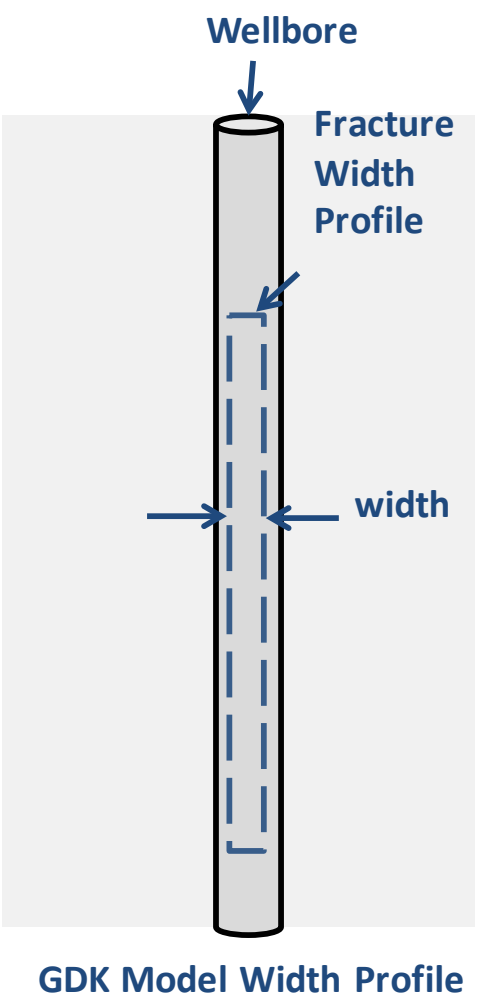

(b) GDK Width Profile

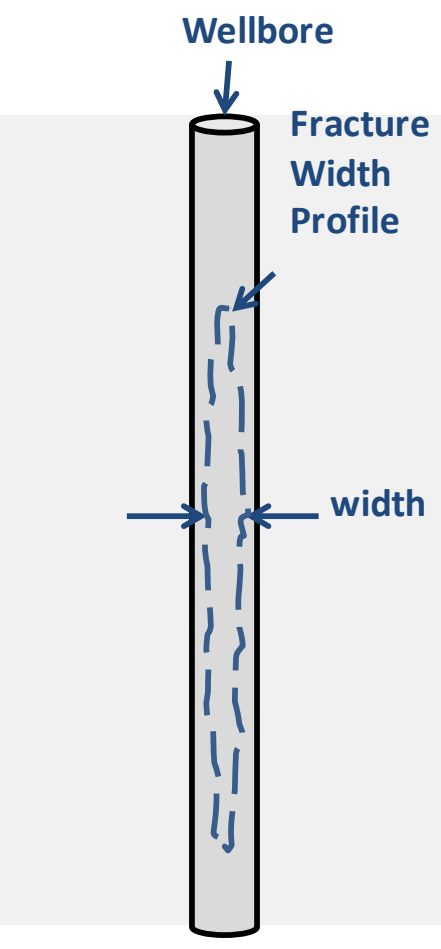

3D Model Width Profile

(c) 3D Width Profile

Figure 2.3: Fracture Model Width Profiles (Meyer, 1986)

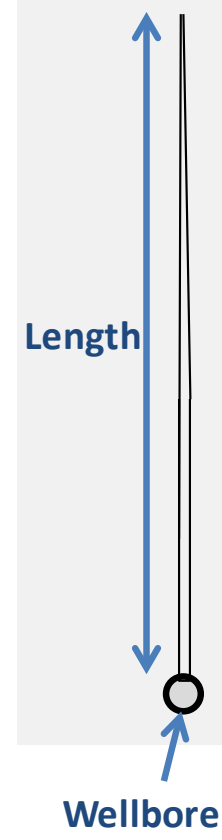

Figure 2.4: Length Profile for PKN, GDK, and 3D Fracture Models (Meyer, 1986) 
The width-opening pressure relationship for the PKN model is given by the following equation (Meyer, 1986):

$$
W_{w}(x, 0, t)=\frac{\tau_{w 0}(1-v)}{G} H_{w} \Delta P(x, t)
$$

The length and width equations for cases with no leak-off coefficient are presented below (Meyer, 1986):

$L(t)=b\left[\frac{\frac{G}{(1-v) K_{a}}\left(\frac{Q}{H_{w}}\right)^{n^{\prime}+2}}{H_{w}}\right]^{\frac{1}{2 n^{\prime}+3}} t^{\frac{2 n^{\prime}+2}{2 n^{\prime}+3}}$

$W_{w^{\prime}}(t)=a\left[\frac{1-v}{G} K_{a}\left(\frac{Q}{H_{w}}\right)^{n^{\prime}+2} L(t)^{2}\right]^{\frac{1}{2 n^{\prime}+3}} \frac{1}{2 n^{\prime}+3}$

where

$$
\begin{aligned}
& a=\left[5^{n^{\prime}} \Gamma_{w 0} /\left(\Gamma_{f} \Gamma_{p} \Gamma_{v}\right)\right]^{\frac{1}{2 n^{\prime}+3}} \\
& b=\left[\Gamma_{f} \Gamma_{p} /\left(8 * 12^{n^{\prime}} \Gamma_{w 0} \Gamma_{v}^{2 n^{\prime}}\right)\right]^{\frac{1}{2 n^{\prime}+3}} \\
& \Gamma_{w 0}=1.0
\end{aligned}
$$




$$
\begin{aligned}
& \Gamma_{p} \cong 1 /\left(2 n^{\prime}+2\right) \\
& \Gamma_{f} \cong 3 \pi / 16 \\
& \Gamma_{v} \cong \pi / 4\left(2 n^{\prime}+2\right) /\left(2 n^{\prime}+3\right)
\end{aligned}
$$

The length and width for the PKN case with leak-off coefficient is shown below (Meyer, 1986):

$$
\begin{gathered}
L(t)=\frac{Q t^{1 / 2}}{2 \pi C H_{p}} \\
W_{w}(t)=a\left[\frac{1-v}{G} K_{a}\left(Q / H_{w}\right)^{n^{\prime}}\left(Q H_{w} / C H_{p}\right)\right]^{\frac{1}{2 n^{\prime}+2}} \frac{1}{t^{\prime}+4}
\end{gathered}
$$

where

$$
\begin{aligned}
& a=\left[3^{n^{\prime}} \Gamma_{w 0} /\left(\Gamma_{p} \Gamma_{f} \pi\right)\right]^{1 /\left(2 n^{\prime}+2\right)} \\
& \Gamma_{w 0}=1.0 \\
& \Gamma_{p} \cong 1 /\left(2 n^{\prime}+2\right) \\
& \Gamma_{f} \cong 3 \pi / 16 \\
& \Gamma_{v} \cong \pi / 4\left(2 n^{\prime}+2\right) /\left(2 n^{\prime}+3\right)
\end{aligned}
$$




\subsubsection{GDK model}

The Geertsma-deKlerk (GDK) model assumes a constant fracture height along with a vertically constant fracture width (Geertsma \& de Klerk, 1969). Figure 2.3 (b) shows the GDK fracture width profile (Meyer, 1986). Figure 2.4 shows the length profile for the GDK model. There is, however; slip along the vertical geometry at the upper and lower extremities (Meyer, 1986). One way in which this model differs from the PKN model is that the net pressure decreases with time. The GDK model is preferred for use when the total fracture length to fracture height ratio is less than 1 (Meyer \& Bazan, 2011). Typically, this model predicts greater wellbore widths and shorter fracture lengths than the PKN model does when the ratio of total fracture length to fracture height is greater than 1 (Meyer \& Bazan, 2011). Another difference between the PKN and GDK models is the width-opening pressure relationship which is shown below (Meyer \& Bazan, 2011):

$W_{w} \propto \Delta p L / E \rightarrow G D K$

$W_{w} \propto \Delta p H / E \rightarrow P K N$

For the GDK model, the width of the fracture at any position ( $\xi$ ) in GDK model is given by the following equation (Meyer, 1986):

$$
W(\xi, t)=W_{w}(t)\left(1-\xi^{2}\right)^{1 / 2}
$$

where

$W(\xi, t)$ is the width at any position $\xi\left(\xi=\frac{x}{L(t)}\right)$

$W_{w}(t)$ is the maximum wellbore width $\left(W_{w}(t)=W(0, t)\right)$ 
The primary difference between the PKN and GDK models is the width-opening pressure relationship (Meyer, 1986). More details on this difference can be found in the literature (Meyer, 1986; Meyer and Hagel, 1989). The width-opening pressure relationship for the GDK fracture propagation model is given as follows (Meyer, 1986):

$$
W_{w}(t)=\frac{2 \tau_{w 0}(1-v)}{G} L(t) \Delta P(0, t)
$$

The length and width equations for the GDK propagation model case with no leak-off coefficient $(\eta=1)$ are shown below (Meyer, 1986):

$$
\begin{aligned}
W_{w}(t) & =a\left[\frac{1-v}{G} K_{a}\left(\frac{Q}{H_{w}}\right)^{n^{\prime}+2}\right]^{\frac{1}{2\left(n^{\prime}+2\right)}} \frac{1}{\left.t n^{\prime}+2\right)} \\
L(t) & =b\left[\frac{G}{(1-v) K_{a}}\left(\frac{Q}{H_{w}}\right)^{n^{\prime}+2}\right] \frac{1}{2\left(n^{\prime}+2\right)} \frac{n^{\prime}+1}{t^{\prime}+2}
\end{aligned}
$$

where:

$$
\begin{aligned}
& a=\left[3^{n^{\prime}} \tau_{w 0} /\left(\tau_{f} \tau_{p} \tau_{v}^{2}\right)\right]^{\frac{1}{2\left(n^{\prime}+2\right)}} \\
& b=\left[\tau_{f} \tau_{p} /\left(16^{*} 12^{n^{\prime}} \tau_{w 0} \tau_{v}^{2 n^{\prime}+2}\right)\right]^{\frac{1}{2\left(n^{\prime}+2\right)}} \\
& K_{a}=K^{\prime}\left(\frac{2 n^{\prime}+1}{3 n^{\prime}}\right) n^{\prime}
\end{aligned}
$$




$$
\begin{aligned}
& G=\frac{E}{2(1+v)} \\
& Q=2 q ; \text { two-wing injection rate } \\
& \tau_{w 0} \cong 0.785 \\
& \tau_{p} \cong 0.7046 \\
& \tau_{v}=\pi / 4 \\
& \tau_{f}=1.0
\end{aligned}
$$

The length and width equations for the GDK propagation model case with a leak-off coefficient $(\eta=0)$ are presented below (Meyer, 1986):

$$
\begin{gathered}
L(t)=\frac{Q t^{1 / 2}}{2 \pi C H_{p}} \\
W_{w}(t)=a\left[\frac{1-v}{G} K_{a}\left(\frac{Q}{H_{w}}\right)^{n^{\prime}+2}\left(\frac{Q}{C H_{p}}\right)^{2}\right]^{\frac{1}{2\left(n^{\prime}+2\right)}} \frac{1}{t^{2 n^{\prime}+2}}
\end{gathered}
$$

where

$$
a=\left[\frac{3^{n^{\prime}} \tau_{w 0}}{\left(\tau_{p} \tau_{f} \pi^{2}\right)}\right]^{\frac{1}{\left(2 n^{\prime}+2\right)}}
$$




\subsubsection{D Ellipsoidal Fracture Model}

The 3D ellipsoidal fracture model uses a variable fracture height and includes different features of both the PKN and GDK models (Geertsma \& de Klerk, 1969; Perkins \& Kern, 1961; Meyer, 1986). Figure 2.3(c) shows the 3D ellipsoidal fracture width profile (Meyer, 1986). Figure 2.4 shows the length profile for the $3 \mathrm{D}$ ellipsoidal fracture model. The model takes into account fracture propagation in both the horizontal and vertical directions as well. If the ellipsoidal aspect ratio (the ratio of the total fracture length to the total fracture height) is greater than 1, the solution of the model approaches that of the PKN model; otherwise, the model approaches the GDK propagation model solution (Meyer \& Bazan, 2011). More details on this model can be found in the literature (Meyer, 1986; Meyer, 1989; Meyer and Hagel, 1989). Equation 2.28 below shows the fracture with at any position, r (Meyer, 1986):

$$
W(r, t)=W(0, t)\left[1-(r / R)^{2}\right]^{1 / 2}
$$

where:

$W(r, t)$ is the width at any position, $\mathrm{r}$

$W(0, t)$ is the maximum wellbore width

$\mathrm{R}$ is the facture radius at any time, $\mathrm{t}$

The width and radius for the 3D Ellipsoidal fracture model case with no leak-off coefficient are shown below (Meyer, 1986): 


$$
\begin{aligned}
& W_{w}(t)=a\left[\frac{1-v}{G} K_{a} Q^{\frac{2+n^{\prime}}{2}}\right]^{\frac{2}{3 n^{\prime}+6}} \frac{2 n^{\prime}+2}{3 n^{\prime}+6} \\
& R(t)=b\left[\frac{G}{(1-v) K_{a}} Q^{n^{\prime}+2}\right]^{\frac{1}{3 n^{\prime}+6}} \frac{2 n^{\prime}+2}{t^{\prime} n^{\prime}+6}
\end{aligned}
$$

where

$$
\begin{aligned}
& a=\left[3^{n^{\prime}} \Gamma_{w 0} /\left(\Gamma_{f} \Gamma_{p} \Gamma_{v}^{1-n^{\prime} / 2}\right)\right]^{\frac{2}{3 n^{\prime}+6}} \\
& b=\left[\Gamma_{f} \Gamma_{p} /\left(4^{3} 24^{n^{\prime}} \Gamma_{w 0} \Gamma_{v}^{2 n^{\prime}+2}\right)\right]^{\frac{1}{3 n^{\prime}+6}}
\end{aligned}
$$

The width and radius for the 3D Ellipsoidal fracture model case with a leak-off coefficient $(\eta=0)$ are shown as follows for two possible cases (Meyer, 1986):

$$
R<H_{p} / 2:
$$




$$
\begin{aligned}
& W_{w}(t)=\left[a \frac{1-v}{G} K_{a} Q^{\frac{n^{\prime}+2}{2}} C^{\frac{n^{\prime}-2}{2}}\right]^{\frac{1}{2 n^{\prime}+2}} \frac{2-n^{\prime}}{t^{8 n^{\prime}+8}} \\
& R(t)=\left[\frac{Q t^{1 / 2}}{\pi^{2} C}\right]^{1 / 2}
\end{aligned}
$$

where

$$
a=\left[\frac{4(3 / 2)^{n^{\prime}} \Gamma_{w 0}}{\Gamma_{f} \Gamma p^{2-n^{\prime}}}\right]^{\frac{1}{2 n^{\prime}+2}}
$$

$R>>H_{p} / 2$ :

$$
\begin{gathered}
W_{w}(t)=a\left[\frac{1-v}{G} K_{a} Q^{n^{\prime}}\left\{\frac{Q}{C H_{p}}\right\}^{2-n^{\prime}}\right]^{\frac{1}{2 n^{\prime}+2}} t^{\frac{2-n^{\prime}}{4 n^{\prime}+4}} \\
R(t)=\frac{Q t^{1 / 2}}{2 \pi C H_{p}}
\end{gathered}
$$

where 


$$
a=\left[\frac{3^{n^{\prime}} \Gamma_{w 0}}{\Gamma_{f} \Gamma_{p} \pi^{2-n^{\prime}}}\right]^{\frac{1}{2 n^{\prime}+2}}
$$




\subsection{Stresses in Formations}

Most formations which are candidates for hydraulic fracturing are located at significant depths below the ground surface. Thus, these formations experience a significant amount of stress due to overburden rock. Stresses are also caused by tectonic events, which have occurred in the geologic media over the millennia. The drilling of a well into a rock formation creates near-wellbore stress concentrations which may be much more complicated than those in the farfield. As previously mentioned, the stress at a given point is determined by dividing the force by the area upon which it acts. Stresses are vectors, and vectors may be infinite in number at any given point, as there are varying magnitudes and angles at which they may occur. Any stress which is applied on a surface at any angle may be broken down into three vectors. These vectors are a normal stress, and two shear stresses. Figure 2.5 below shows two normal stresses, $\sigma_{\mathrm{x}}$ and $\sigma_{y}$, acting upon the $\mathrm{x}$ and $\mathrm{y}$ planes, respectively. $\tau_{\mathrm{xy}}$ and $\tau_{\mathrm{yx}}$ are the shear forces acting on those planes, and are equivalent to one another, as previously explained. Forces acting at any other angle, $\theta$, to the $y$ axis would result in normal and shear stresses. These stresses are shown in the two equations below (Valko \& Economides, 1995):

$$
\begin{gathered}
\sigma=\sigma_{x} \cos ^{2} \theta+2 \tau_{y x} \sin \theta \cos \theta+\sigma_{y} \sin ^{2} \theta \\
\tau=\frac{1}{2}\left(\sigma_{y}-\sigma_{x}\right) \sin (2 \theta)+\tau_{y x} \cos (2 \theta) \ldots \ldots
\end{gathered}
$$




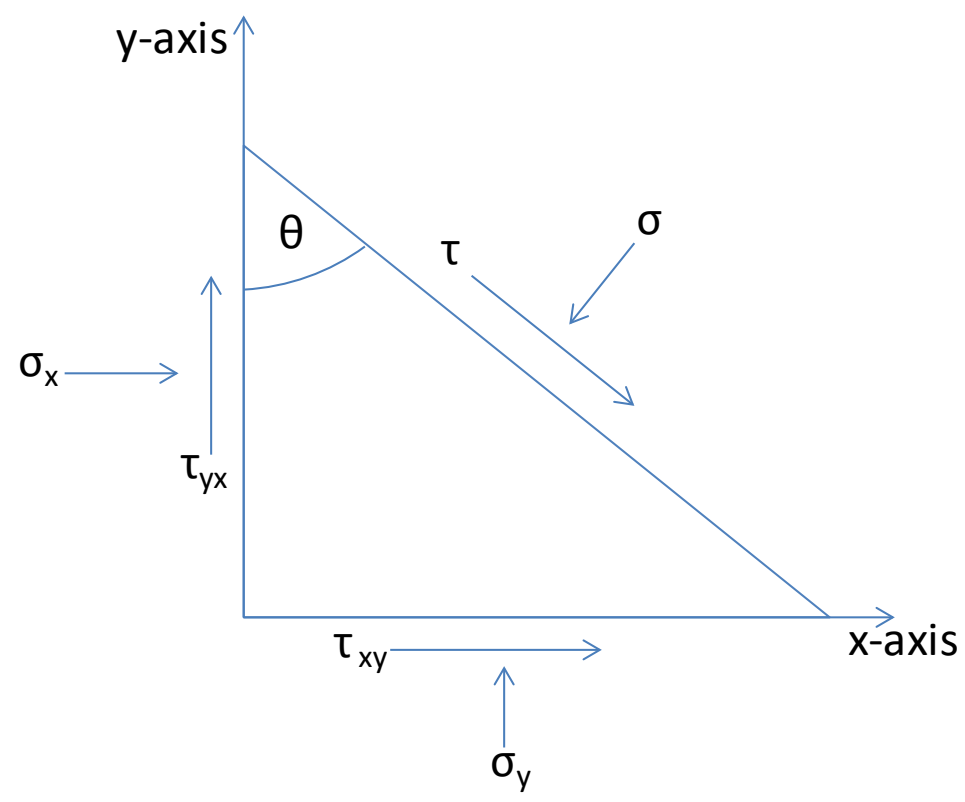

Figure 2.5: Normal and Shear Stress Example

By looking at the two equations above, it can be concluded that there must exist an angle where the shear stress goes to zero. By setting the shear stress to zero in Equation 2.34 and solving for the angle, the following result is obtained (Valko \& Economides, 1995):

$$
\theta=\frac{1}{2} \tan ^{-1}\left(\frac{2 \tau_{y x}}{\sigma_{x}-\sigma_{y}}\right)
$$

When Equation 2.35 is input into Equation 2.33, the following equation is obtained (Valko \& Economides, 1995):

$$
\sigma_{\max , \min }=\frac{1}{2}\left(\sigma_{x}+\sigma_{y}\right) \pm \sqrt{\tau_{y x}^{2}+\frac{1}{4}\left(\sigma_{x}-\sigma_{y}\right)^{2}}
$$

The maximum and minimum stresses in the above equation are calculated by adding and subtracting, respectively. These stresses are known as the maximum and minimum principal stresses. At these principal stresses, the shear stresses are zero. At all other angles, there are shear stress components. 
Formations are subjected to three primary principal stresses. These are the vertical stress, minimum horizontal stress, and maximum horizontal stress. All of these stresses are considered to be in the far-field. An analysis of the effects of these stresses in hydraulic fracturing was performed by Hubbert and Willis (Hubbert \& Willis, 1957). Consider a formation at some depth $\mathrm{H}$. To find the absolute vertical stress acting on that formation, the following equation can be used:

$$
\sigma_{v}=g \int_{0}^{H} \rho d H
$$

where $\sigma_{\mathrm{v}}$ is the absolute vertical stress, $\mathrm{g}$ is the acceleration due to gravity, and $\rho$ is the density of the overlying rock. Density logs can be used to provide the engineer with density values of all rock material from the surface to the formation depth. After integrating the data obtained from the log, the absolute vertical stress can be found.

As previously stated, the stress in Equation 2.37 above is absolute. The effective stress is found by subtracting the pore stress from the absolute vertical stress. This effective stress is what the formation ultimately feels in the vertical direction. The absolute stress is reduced by the grains and fluid within the pores of the porous rock media. The poroelastic constant, $\alpha$, known as Biot's constant, was introduced to account for the reduction in stress due to the grains and fluids in rock pores (Biot, 1956). The effective stress equation using Biot's constant is written as follows (Valko \& Economides, 1995):

$$
\sigma_{v}^{\prime}=\sigma_{v}-\alpha p
$$

where $\mathrm{p}$ is the pore pressure, and $\sigma_{\mathrm{v}}^{\prime}$ is the effective vertical stress.

The in-situ, or natural, stress conditions in the rock may be changed in their magnitude and orientation by the drilling of a well. Stresses induced by the drilling of a well into a rock formation often result in changes in the stress field. When drilling a cylindrical well into rock, stresses can be noted in cylindrical coordinates. 


\subsection{Measurement of Stresses}

Stresses in formations are measured using several common measuring procedures and techniques. Four common stress measurement methods will be covered in this section. One important value of interest in the hydraulic fracturing process (apart from the four stress measurement methods to be covered) is the closure pressure. Closure pressure was first defined by Nolte to be the minimum fluid pressure required to keep a pre-existing facture open (Nolte, 1988).

The first stress measurement method is that of small interval fracture injection testing. This method involves the isolation of small intervals of the given formation, and injecting small volumes of fluid. After injection, the well is shut-in (meaning it stops injecting and is closed for injection and extraction) and the instantaneous shut-in pressure is taken from monitoring devices. This instantaneous shut-in pressure is taken at the very moment that the well is shut-in. This pressure is estimated to be the minimum horizontal stress for a vertical fracture in a single layer. More information on this stress measurement method can be found in the literature: (Hubbert \& Willis, 1957; Haimson \& Fairhurst, 1967; Haimson \& Fairhurst, 1969; Haimson, 1978; Haimson, 1981).

The second method used for stress measurement is acoustic measuring. Acoustic waves are sent through the rock formation in question and cause very slight deformations within the rock. The deformation of the rock results in a change in speed of the acoustic wave. This change in speed is detected by the measuring device and can be used to measure the Poisson's ratio and Young's modulus of the rock. Stress information can be interpreted from the Poisson's ratio and Young's modulus values. The equations relating the acoustic wave speed, Poisson's ratio, and Young's modulus can be found elsewhere (Jaeger \& Cook, 1979). More information on this stress measurement method can be found in the literature: (Howard \& Fast, 1970; and Newberry et. al., 1985).

The third method used for stress measurement is the determination of the closure pressure. Determining the closure pressure can help to determine the net pressure in the fracture as previously discussed. The closure pressure is commonly found by using a step-rate injection 
test. Small injection rates are used and gradually stepped up after each time step. The bottomhole injection pressure is recorded and plotted against the injection rate. The point on the graph where the slope changes is known as the fracture extension pressure. This pressure is the maximum value which the closure pressure may reach. Following the step-rate injection test, a flow-back test is usually performed. After the injection test has ended, well flow-back occurs. The bottomhole pressure decline is recorded and plotted against time. The inflection point on the graph will show the closure pressure. This test is usually run several times to ensure that the value is reproducible. More information on this stress measurement technique can be found in the literature: (Nolte, 1988; Smith, 1985; Mayerhofer et. al., 1995).

The last method for measuring stress in formations which will be discussed is the measurement of core stress samples. The measurement of stress in this fashion requires a significant amount of lab equipment. Various techniques used to measure the stress include the following: Differential Wave Velocity Analysis, Anelastic Strain Recovery, and Differential Strain Curve Analysis. These techniques are interested in finding the strain relaxation in the core sample. This is related to the stored energy in the sample and is assumed to be proportional to the present state of stress in the rock. More information on this stress measurement technique can be found in the literature: (Friedman, 1972; and Obert \& Duvall, 1967). 


\section{CHAPTER 3: INFLUENCE OF TREATMENT PARAMETERS ON HYDRAULIC FRACTURE PROPAGATION}

\subsection{Influence of Injection Rate (Constant versus Variable) and Proppant Type}

In order to determine the effects of treatment parameters on the propagation of hydraulic fractures, models were established based on simple treatment parameters. These parameters were chosen to investigate the effects of two treatment parameters: the rate of injection (constant and varied), and the proppant type used (none, smaller, and larger). Six cases were formulated with these parameters being combined in different ways. Case 1 is a constant injection rate case with no proppant. Case 2 is a constant injection rate case with a larger proppant size used. Case 3 is a constant injection rate case with a smaller proppant size used. Case 4 is a variable injection rate case with no proppant. Case 5 is a variable injection rate case with a larger proppant size used. Finally, Case 6 is a variable injection rate case with a smaller proppant size used. See Table 3.1 for a summary of the six cases.

Table 3.1: Summary of Injection Rate and Proppant Type Cases

\begin{tabular}{|c|c|c|c|}
\hline Case & Injection Rate & Proppant Type & Figures \\
\hline 1 & Constant & None & $3.2-3.6$ \\
\hline 2 & Constant & Larger & $3.7-3.11$ \\
\hline 3 & Constant & Smaller & $3.12-3.16$ \\
\hline 4 & Variable & None & $3.17-3.21$ \\
\hline 5 & Variable & Larger & $3.22-3.26$ \\
\hline 6 & Variable & Smaller & $3.27-3.31$ \\
\hline
\end{tabular}


There are six primary layers that are involved in these cases presented in this chapter. There are a series of overburden and underburden layers, which do not come into effecting the propagating fractures in these cases. The Tully Limestone is the bounding layer as shown in Figure 3.1. Figure 3.1 shows the geologic column used in this chapter. The layer below the Tully is the Hamilton shale, followed by the Upper Marcellus, Cherry Valley Limestone, Lower Marcellus Shale, and the Onondaga Limestone. These formations have unique properties, found in literature, which influence the shape of propagating hydraulic fractures.

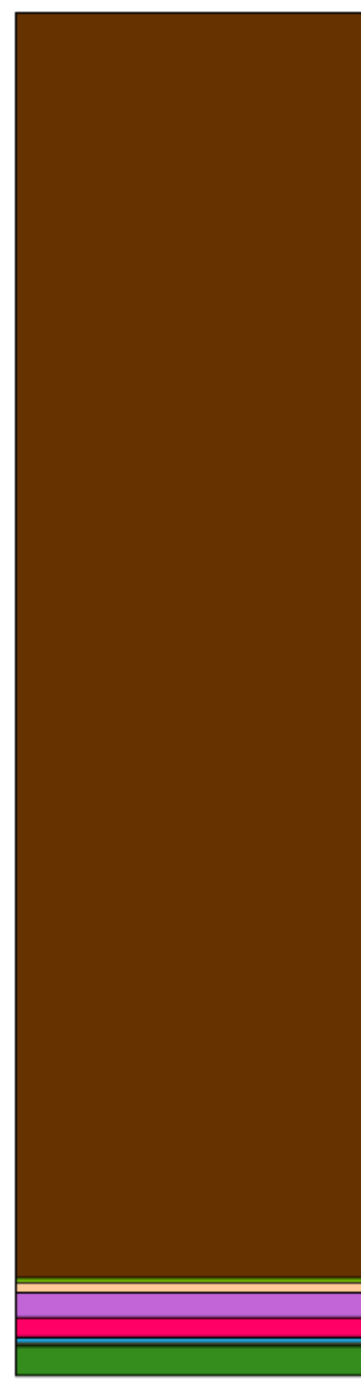

\section{Legend}

Overburden

Burkett Shale

Tully Limestone

Hamilton Shale

Upper Marcellus

Cherry Valley

Lower Marcellus

Onondaga Limestone

Huntersville Chert

Figure 3.1: Geologic Column used for the Six Cases 
Figures 3.2 through 3.31 show proppant and slurry treatment parameters and fracture propagation results for all six cases. Treatment parameter plots are shown in Figures 3.2, 3.3, 3.4, and 3.5 for Case 1. The width profile and contour for Case 1 is shown in Figure 3.6. The height was found to be approximately 310 feet and the length was around 1524 feet.

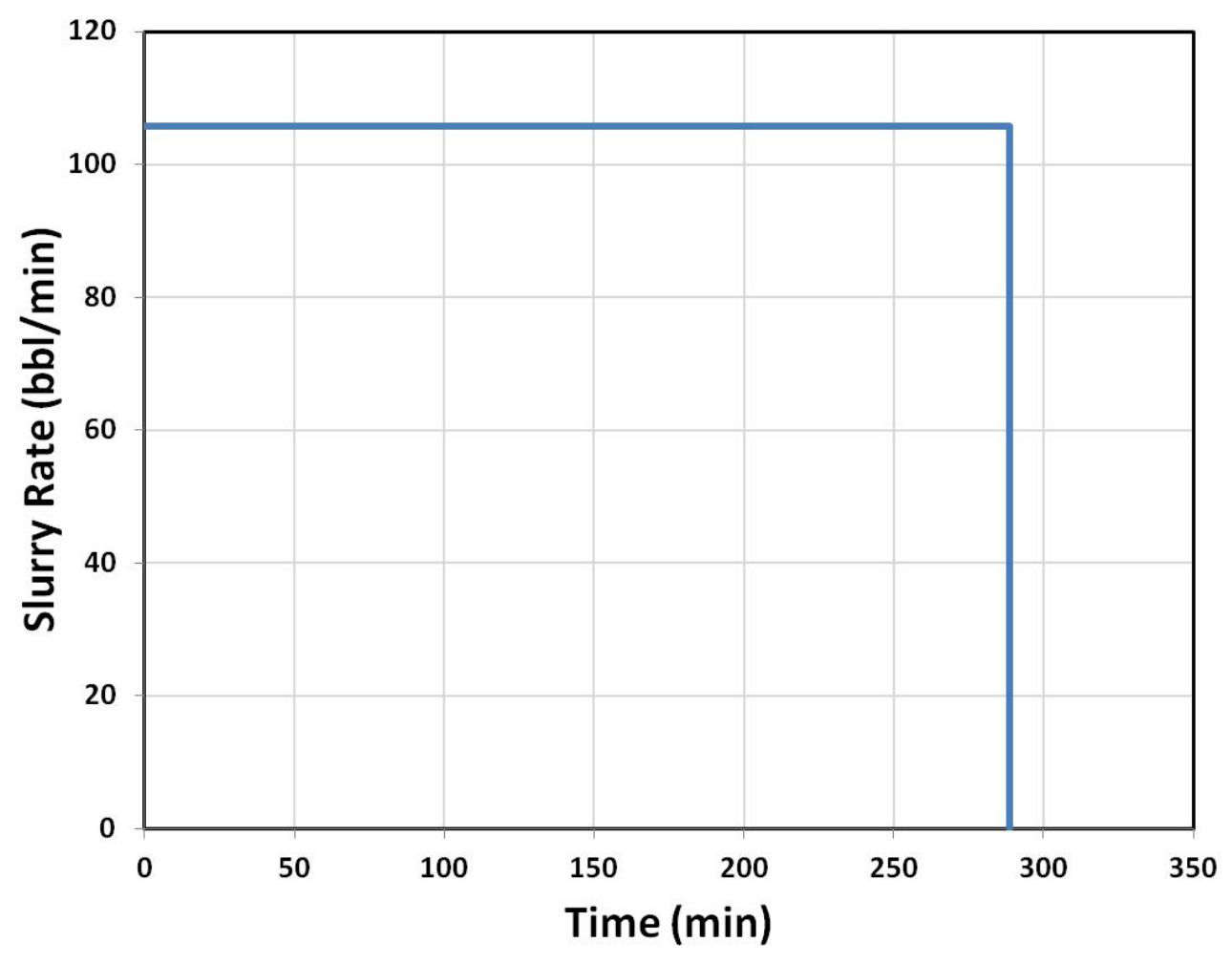

Figure 3.2: Case 1 - Slurry Rate versus Time 


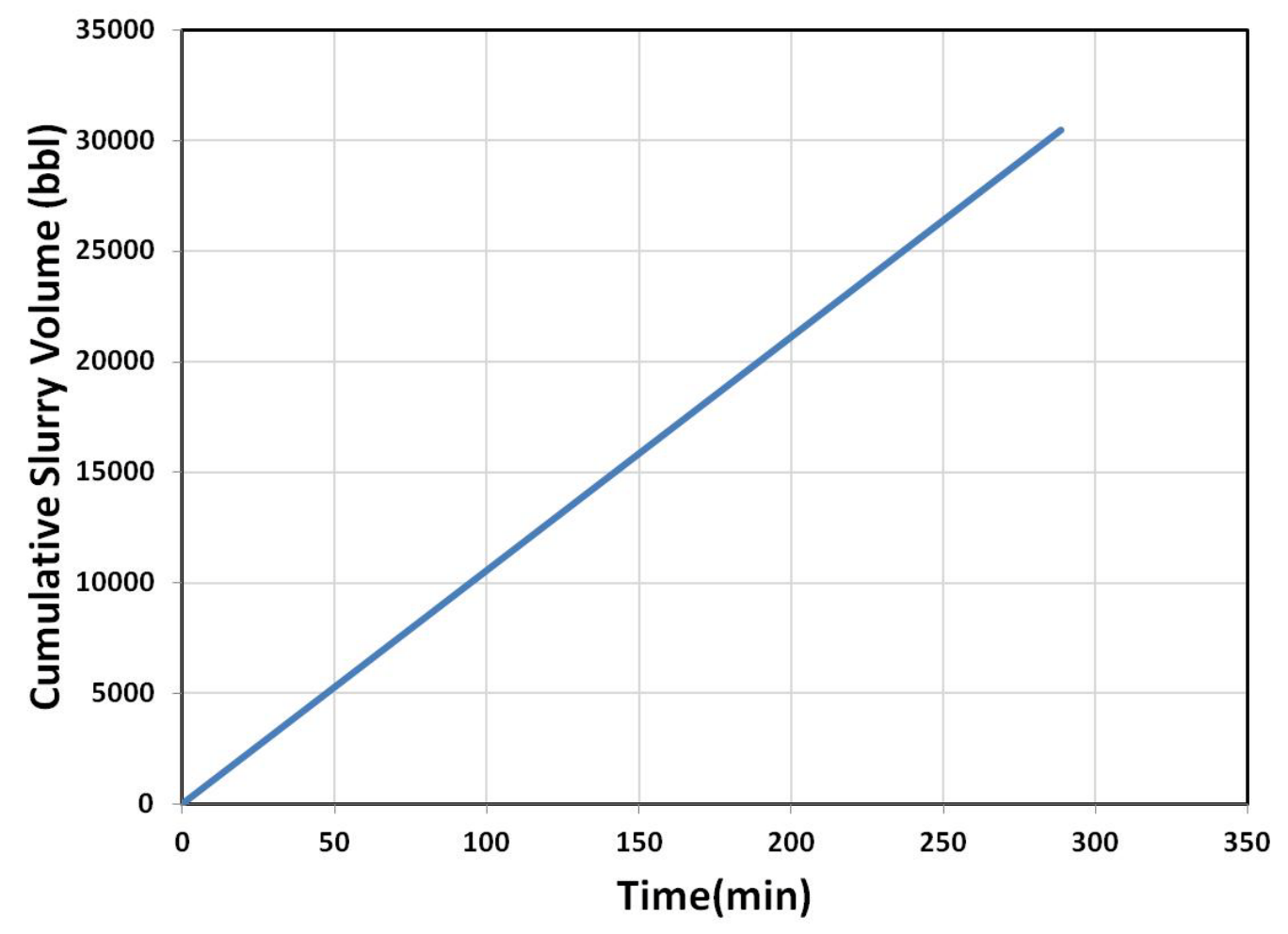

Figure 3.3: Case 1 - Cumulative Slurry Volume versus Time

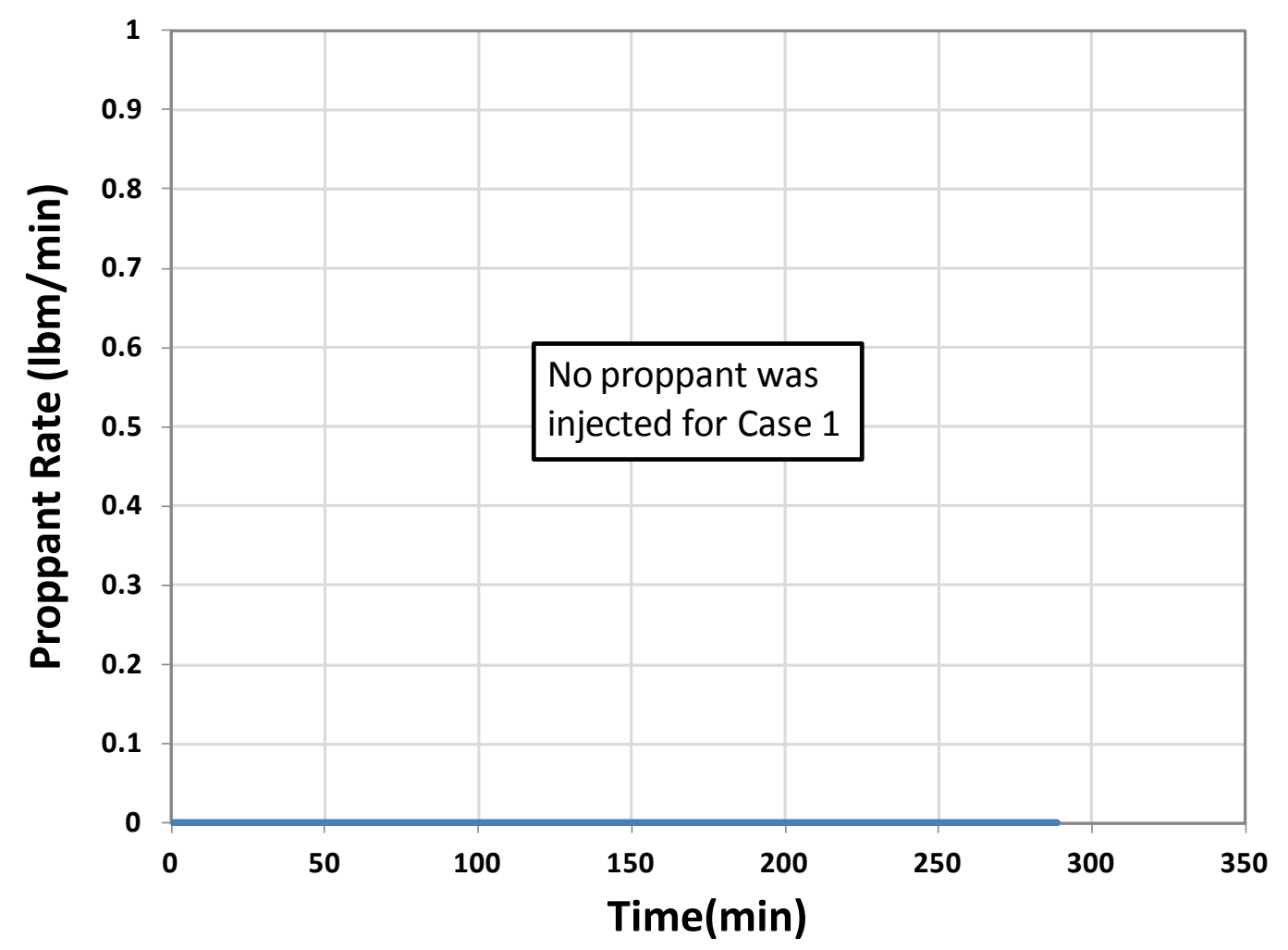

Figure 3.4: Case 1 - Proppant Rate versus Time 


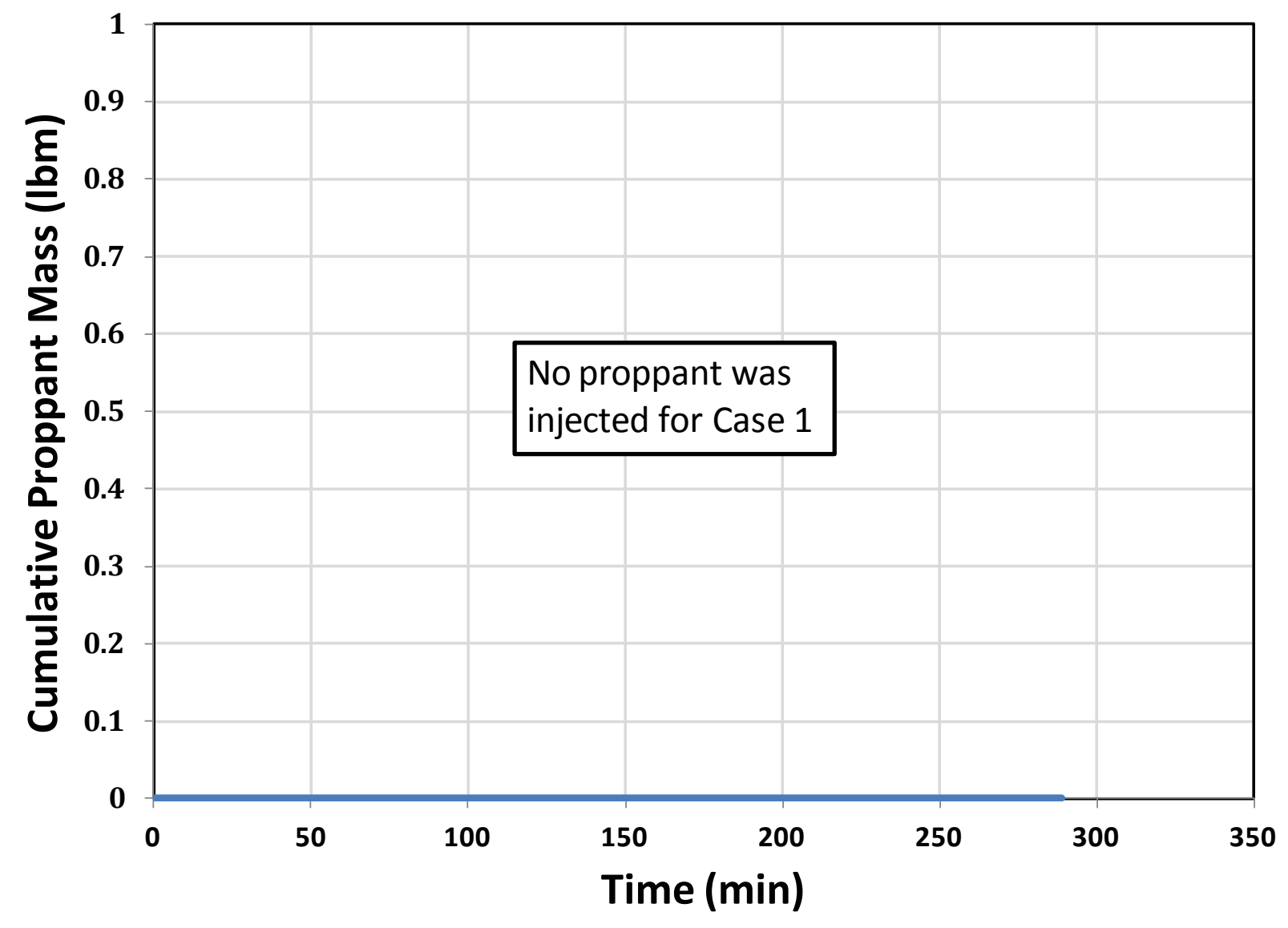

Figure 3.5: Case 1 - Cumulative Proppant Mass versus Time 

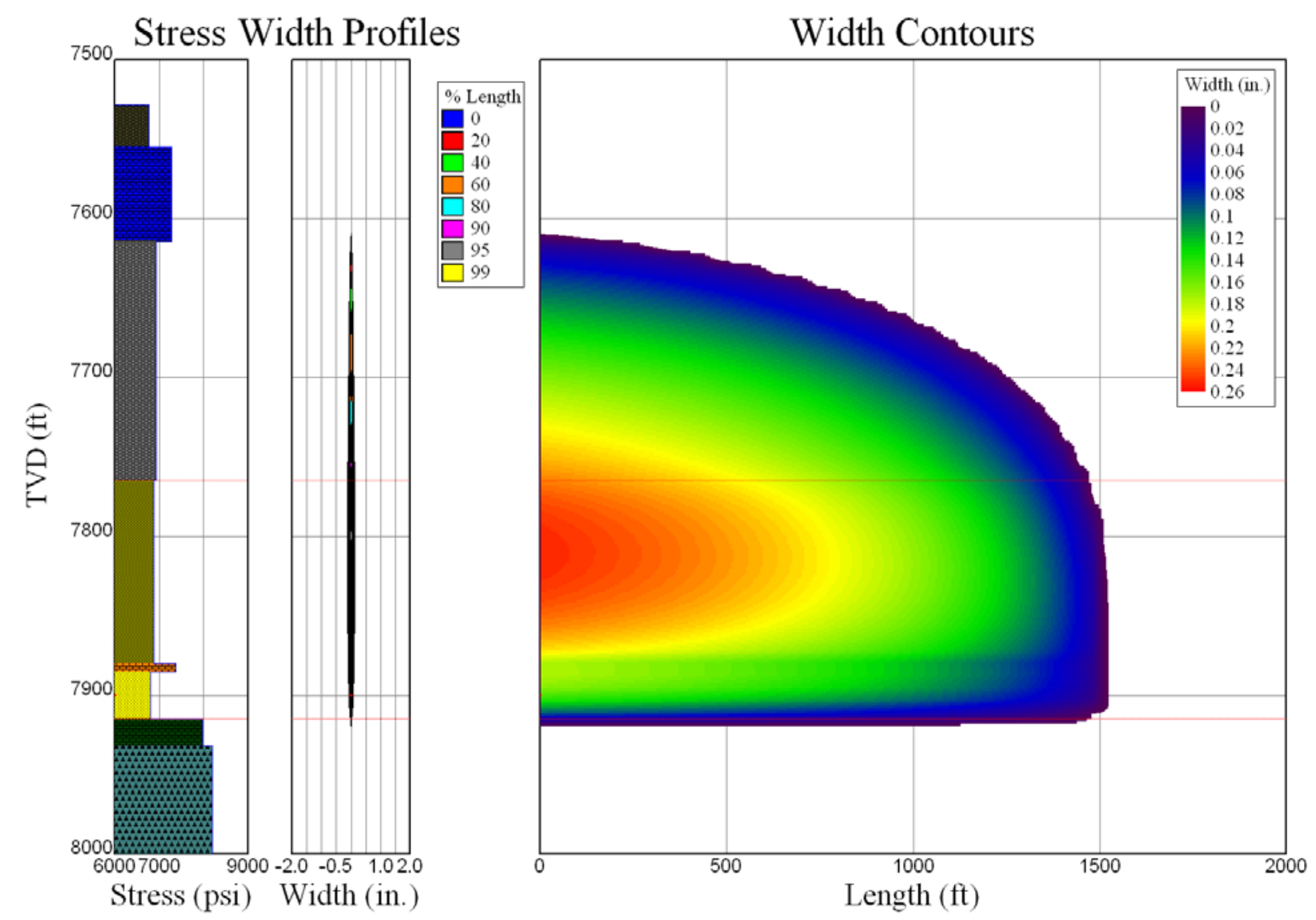

Figure 3.6: Stress, Width Profiles, and Width Contours for Case 1

Treatment parameter plots are shown in Figures 3.7, 3.8, 3.9, and 3.10 for Case 2. The width profile and contour for Case 2 is shown in Figure 3.11. The height was found to be approximately 307 feet and the length was around 847 feet. 


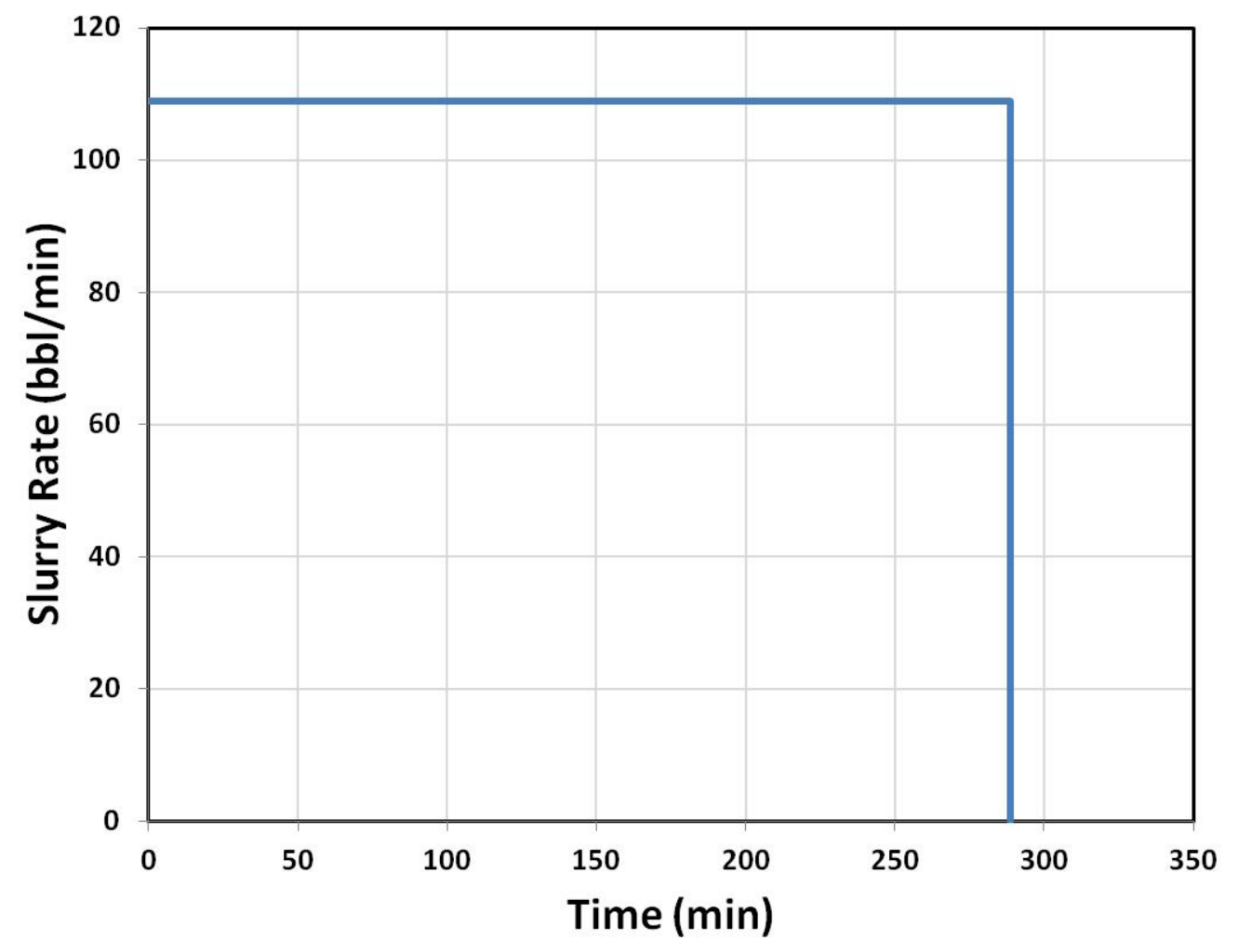

Figure 3.7: Case 2 - Slurry Rate versus Time

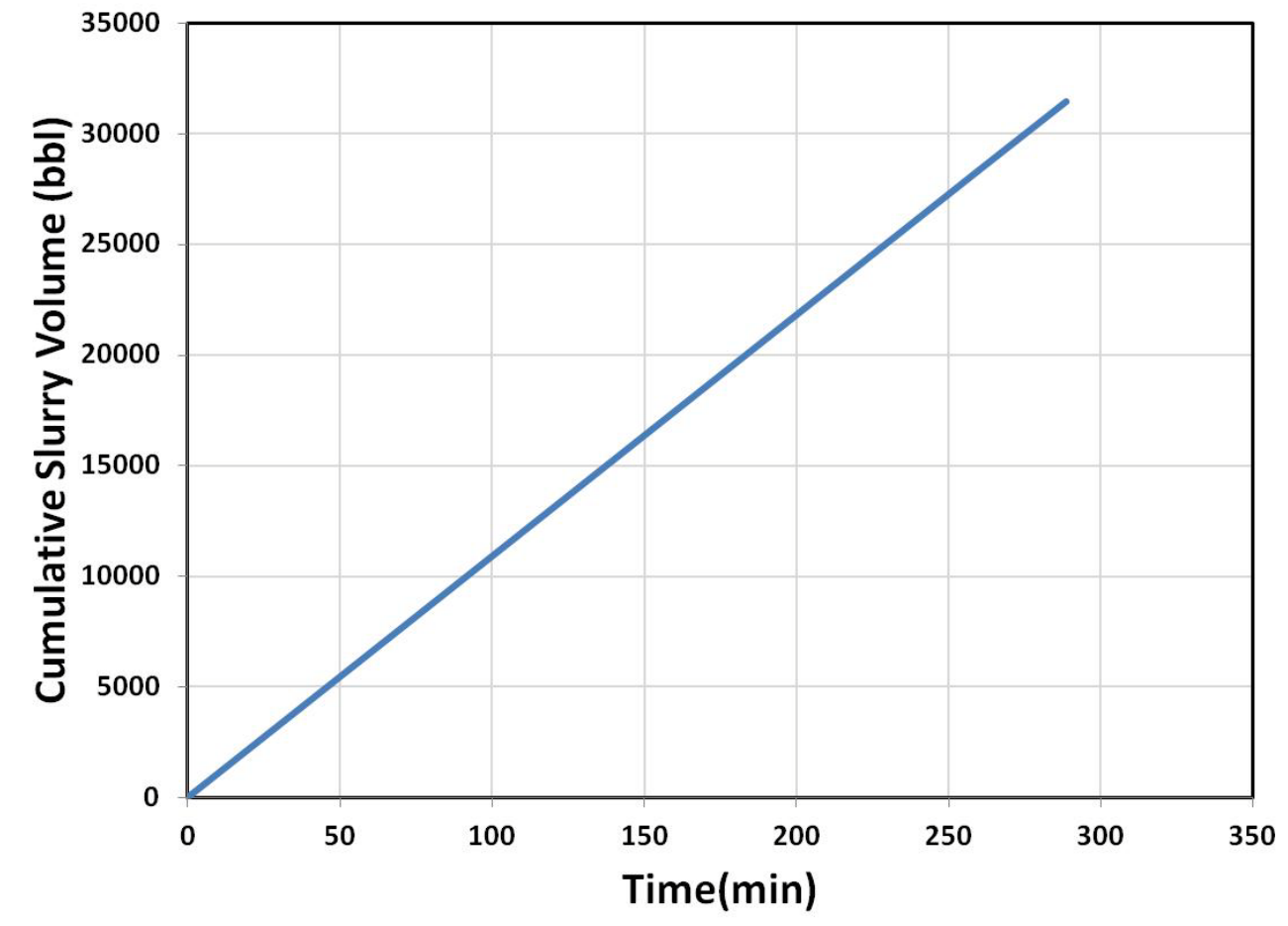

Figure 3.8: Case 2 - Cumulative Slurry Volume versus Time 


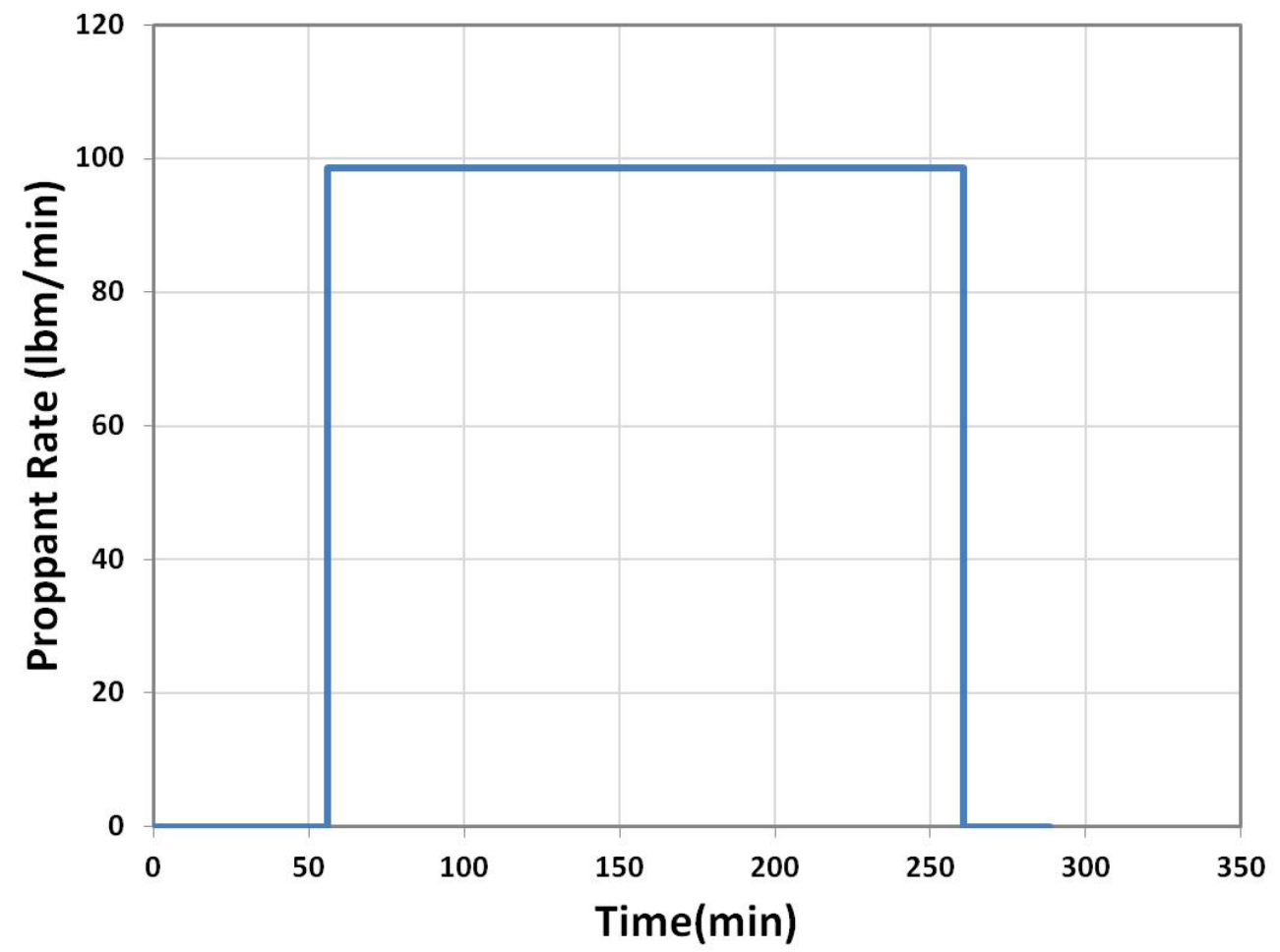

Figure 3.9: Case 2 - Proppant Rate versus Time

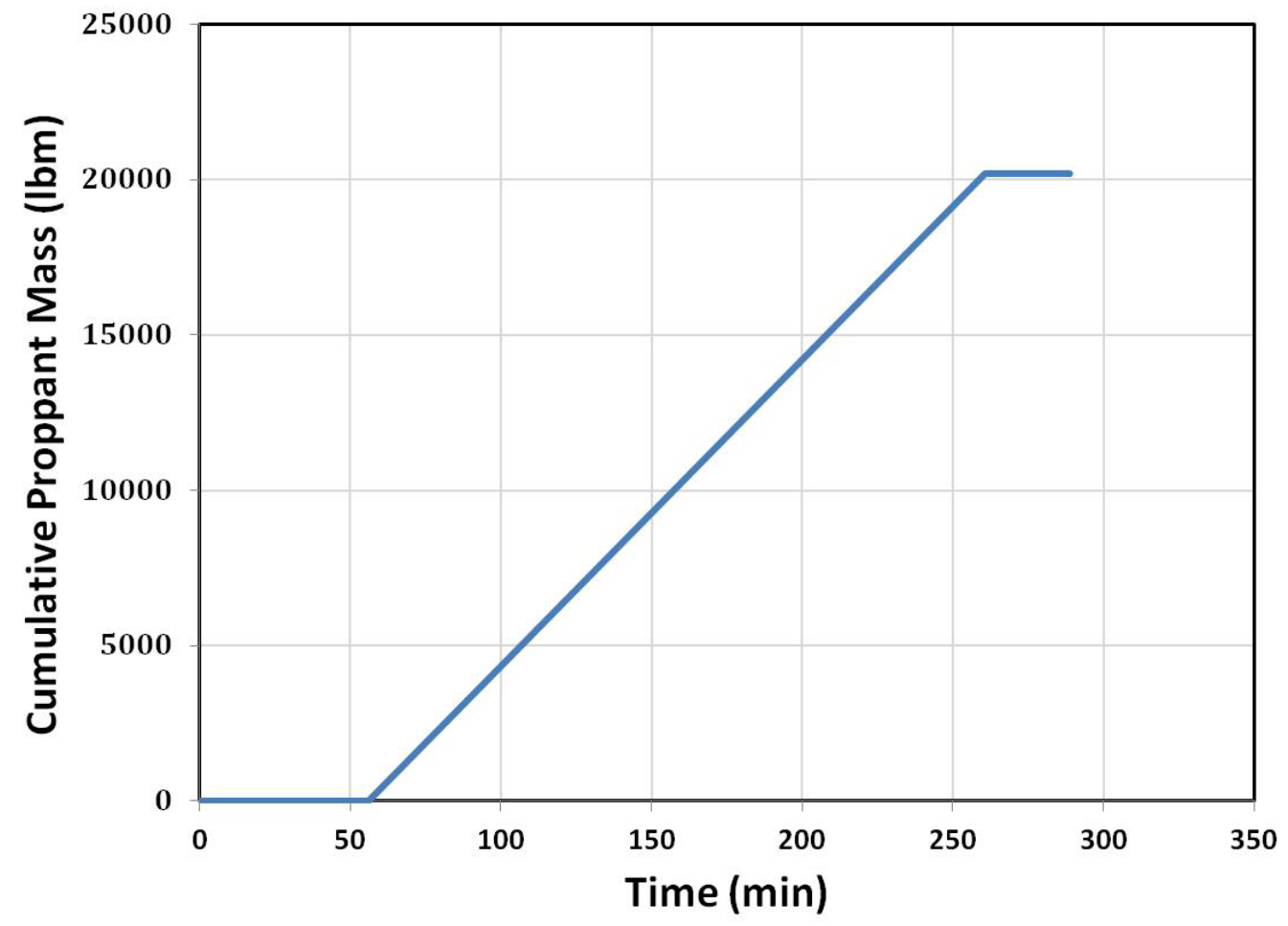

Figure 3.10: Case 2 - Cumulative Proppant Mass versus Time 

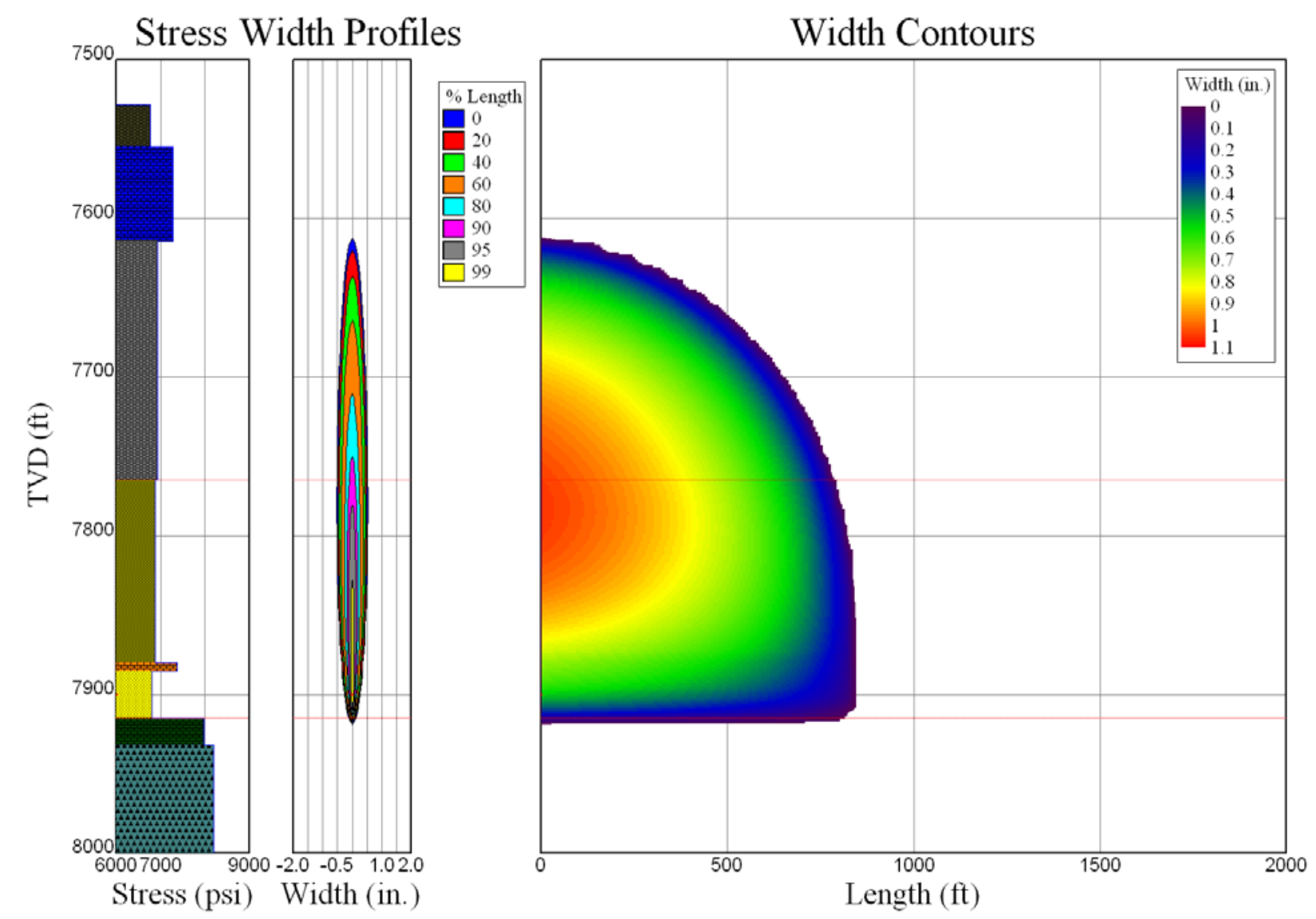

Figure 3.11: Stress, Width Profiles, and Width Contours for Case 2

Treatment parameter plots are shown in Figures 3.12, 3.13, 3.14, and 3.15 for Case 3. The width profile and contour for Case 3 is shown in Figure 3.16. The height was found to be approximately 307 feet and the length was around 852 feet. 


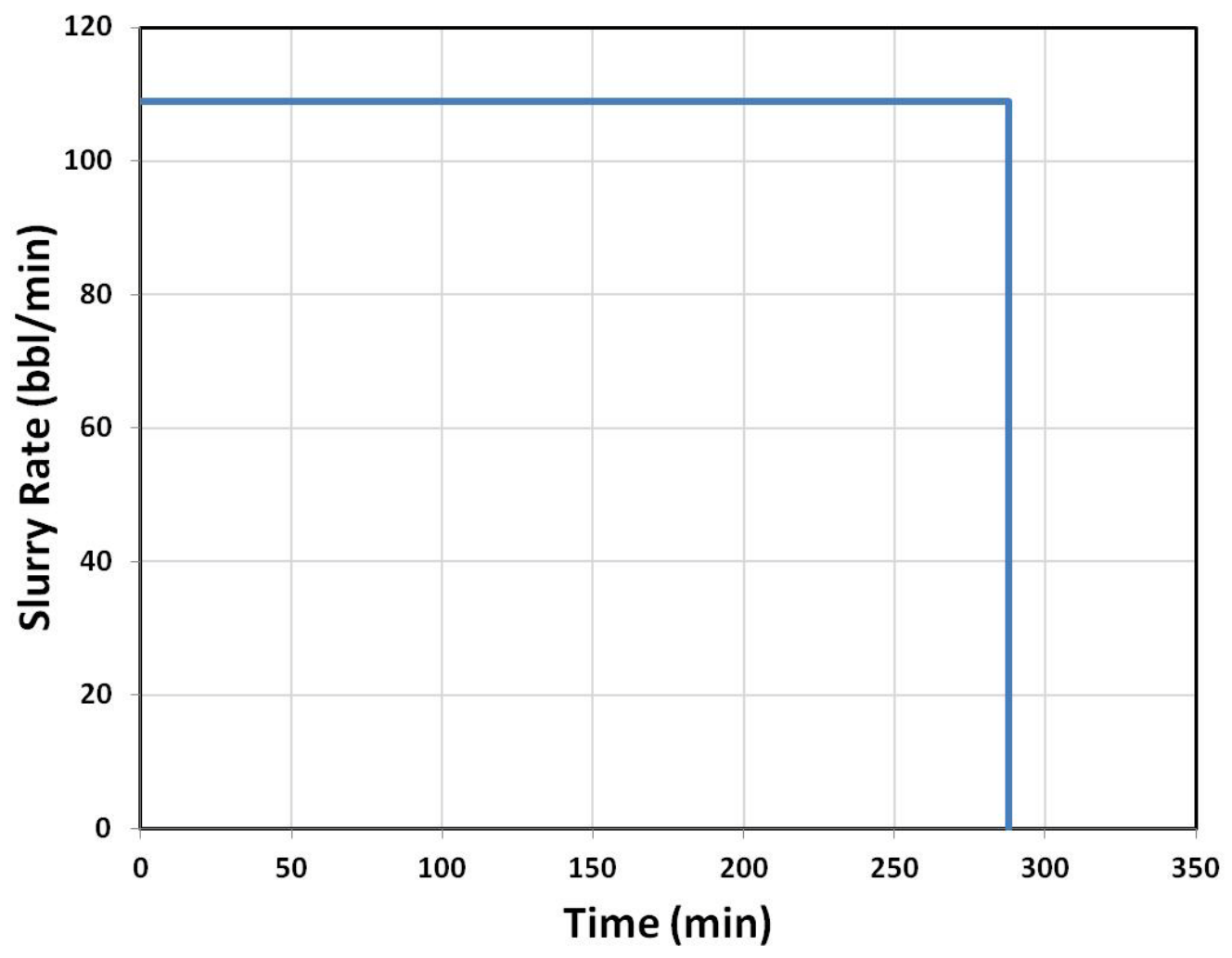

Figure 3.12: Case 3 - Slurry Rate versus Time

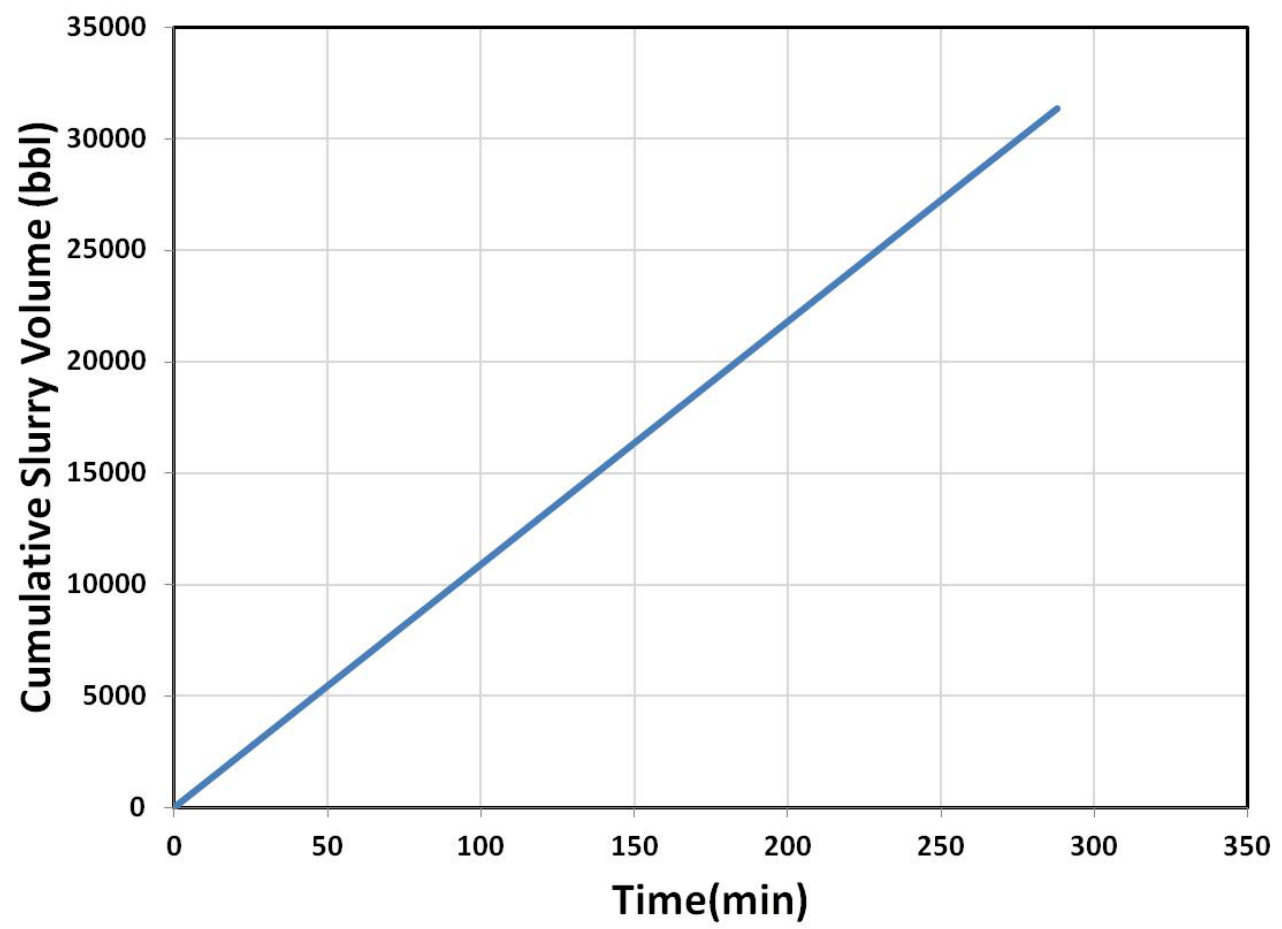

Figure 3.13: Case 3 - Cumulative Slurry Volume versus Time 


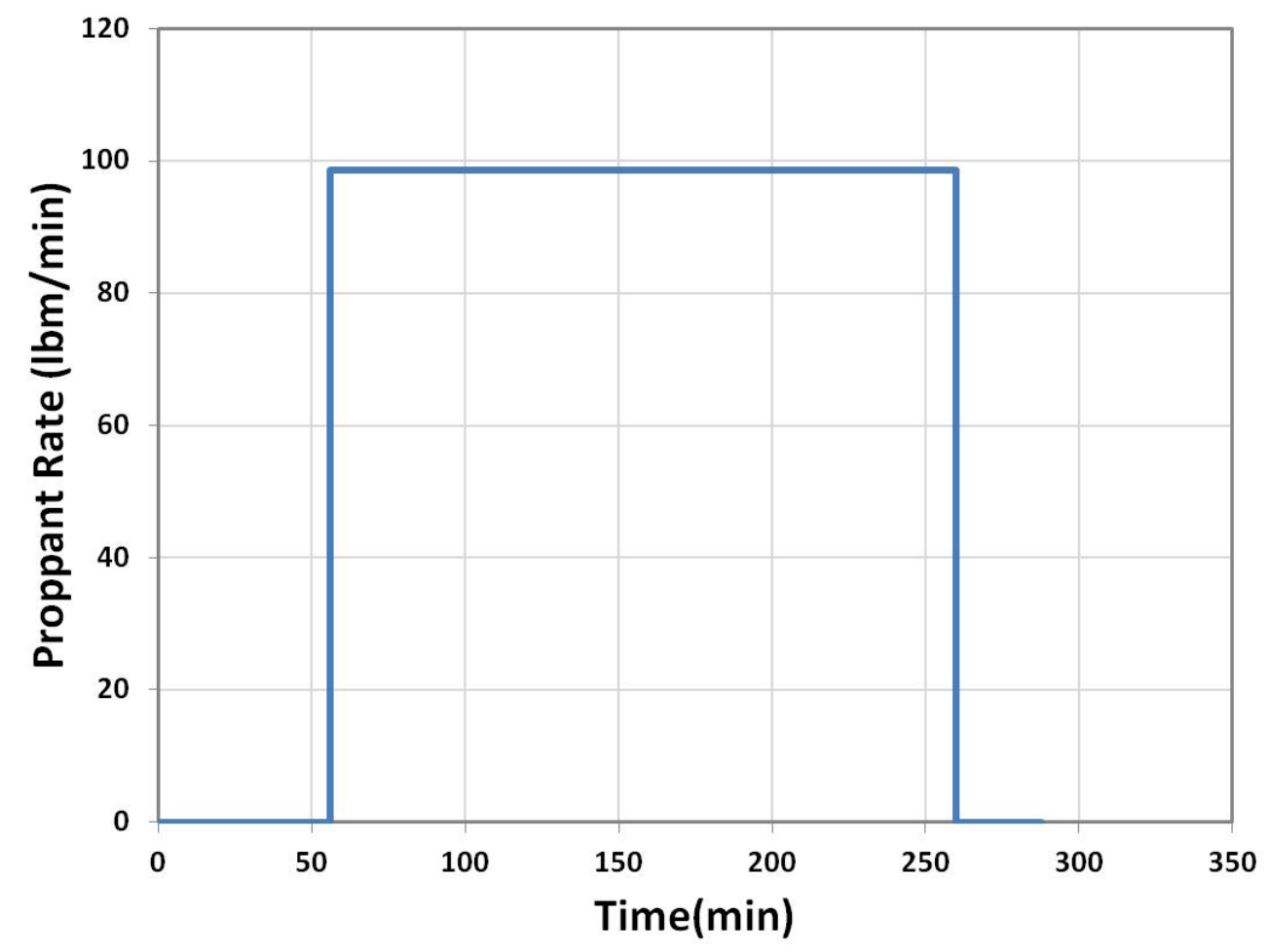

Figure 3.14: Case 3 - Proppant Rate versus Time

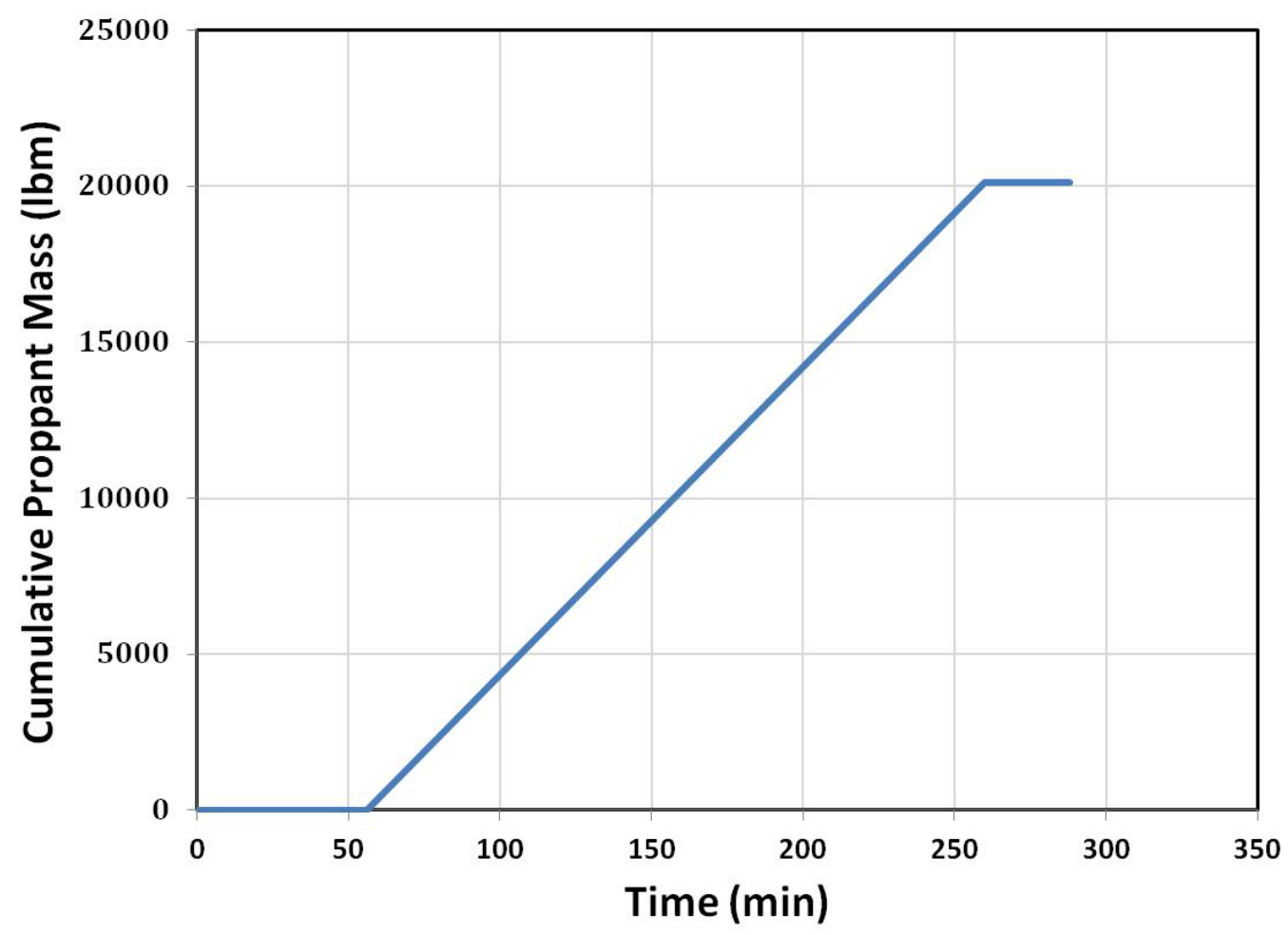

Figure 3.15: Case 3 - Cumulative Proppant Mass versus Time 

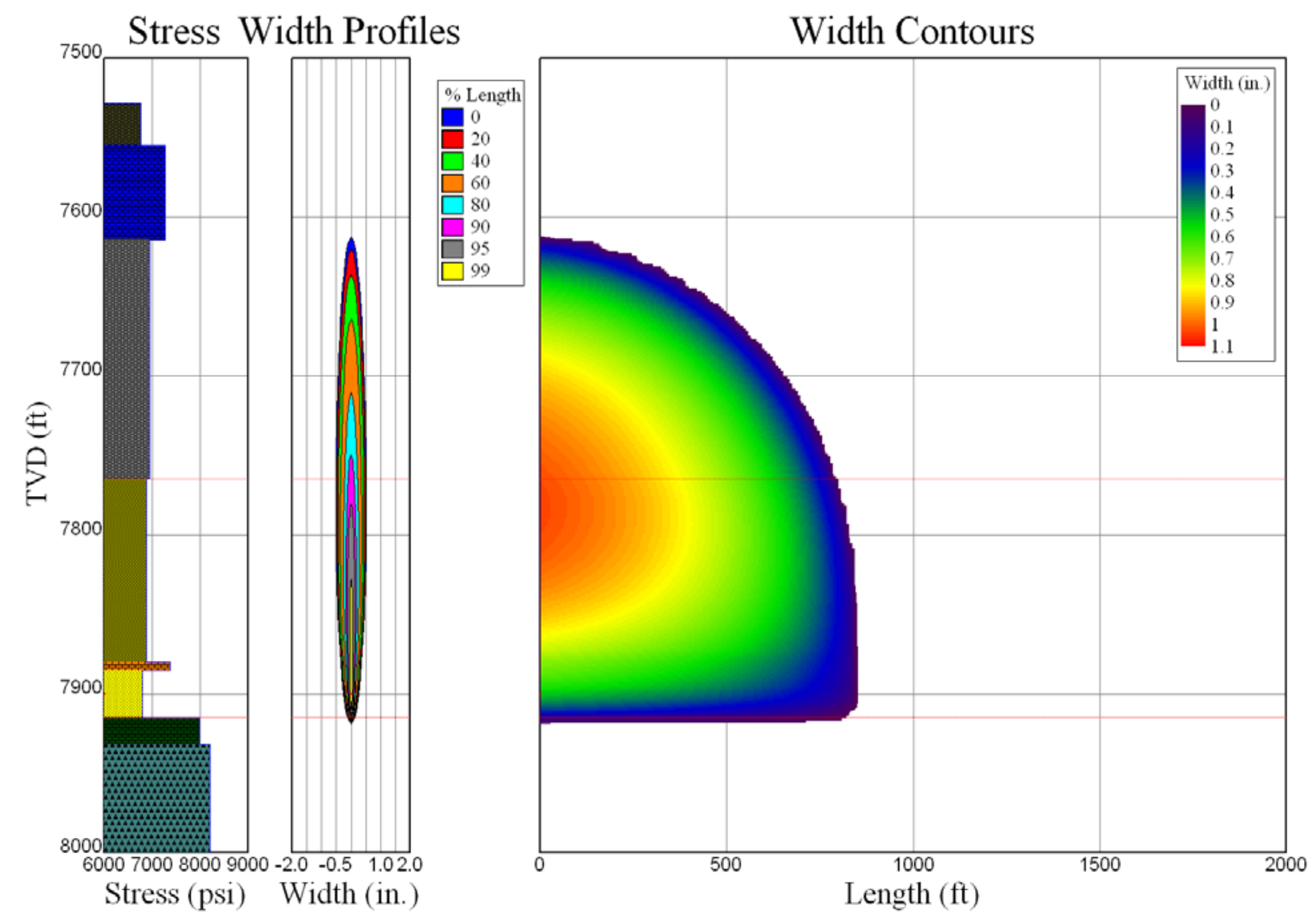

Figure 3.16: Stress, Width Profiles, and Width Contours for Case 3

Treatment parameter plots are shown in Figures 3.17, 3.18, 3.19, and 3.20 for Case 4. The width profile and contour for Case 4 is shown in Figure 3.21. The height was found to be approximately 311 feet and the length was around 1591 feet. 


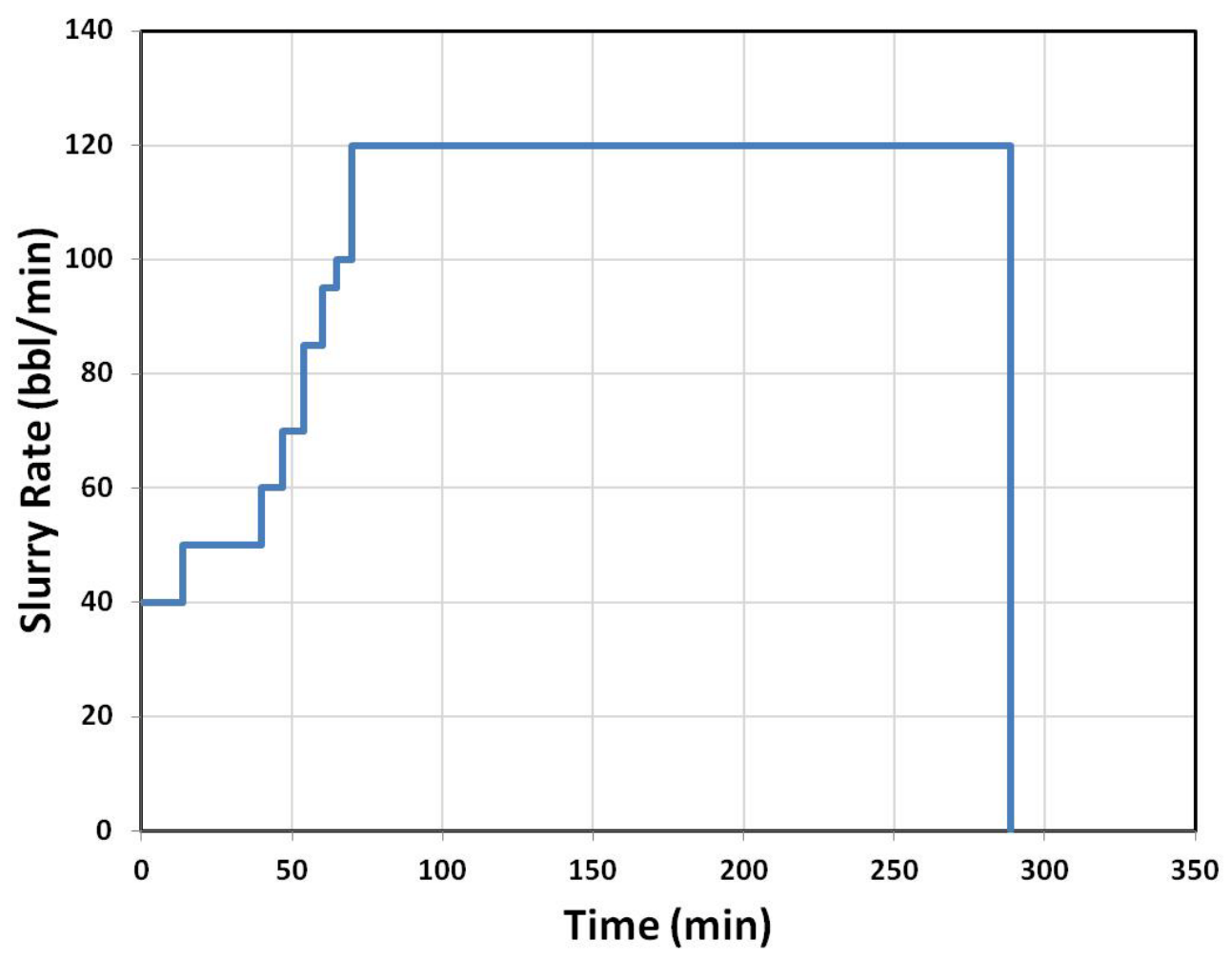

Figure 3.17: Case 4 - Slurry Rate versus Time

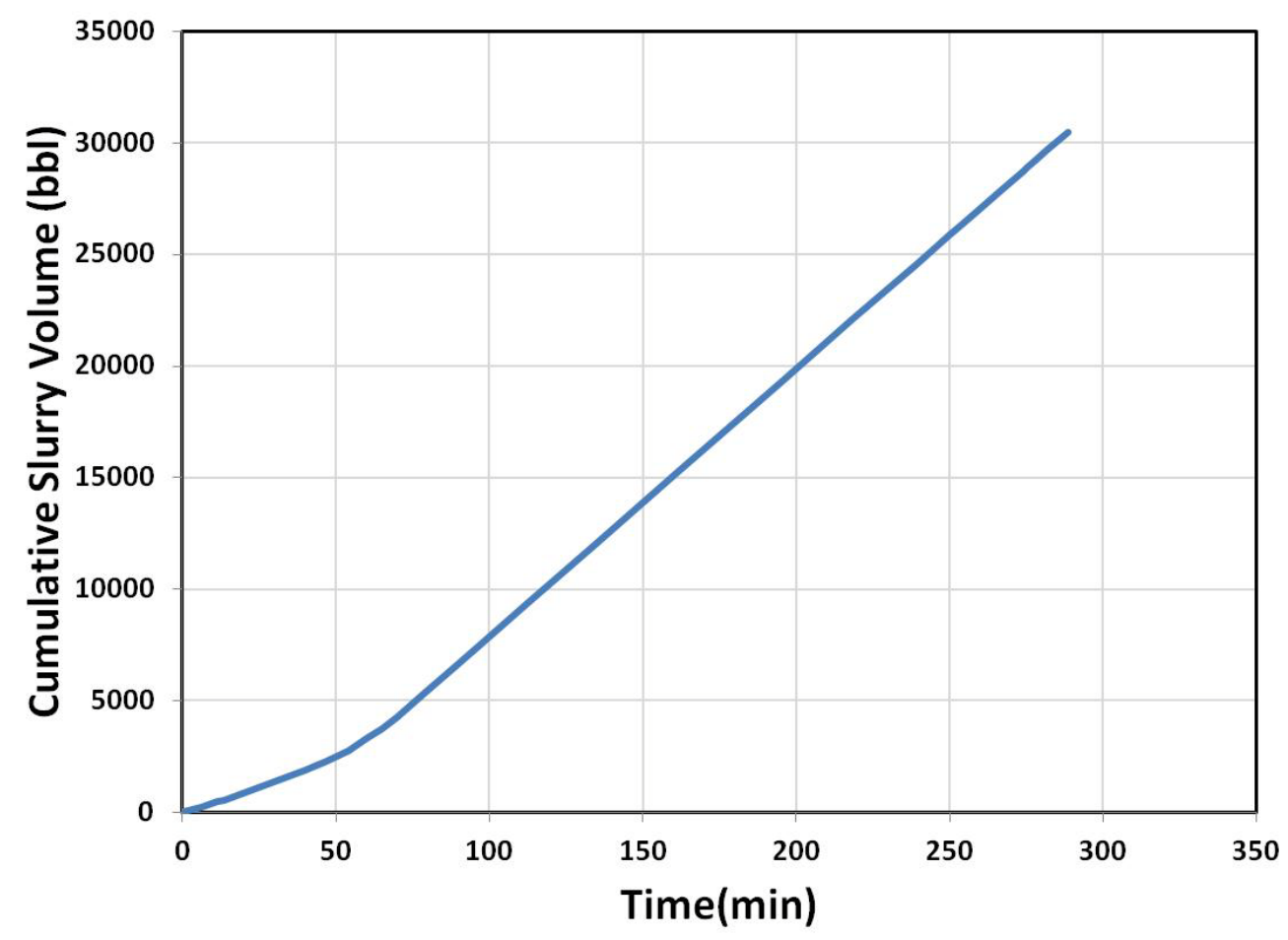

Figure 3.18: Case 4 - Cumulative Slurry Volume versus Time 


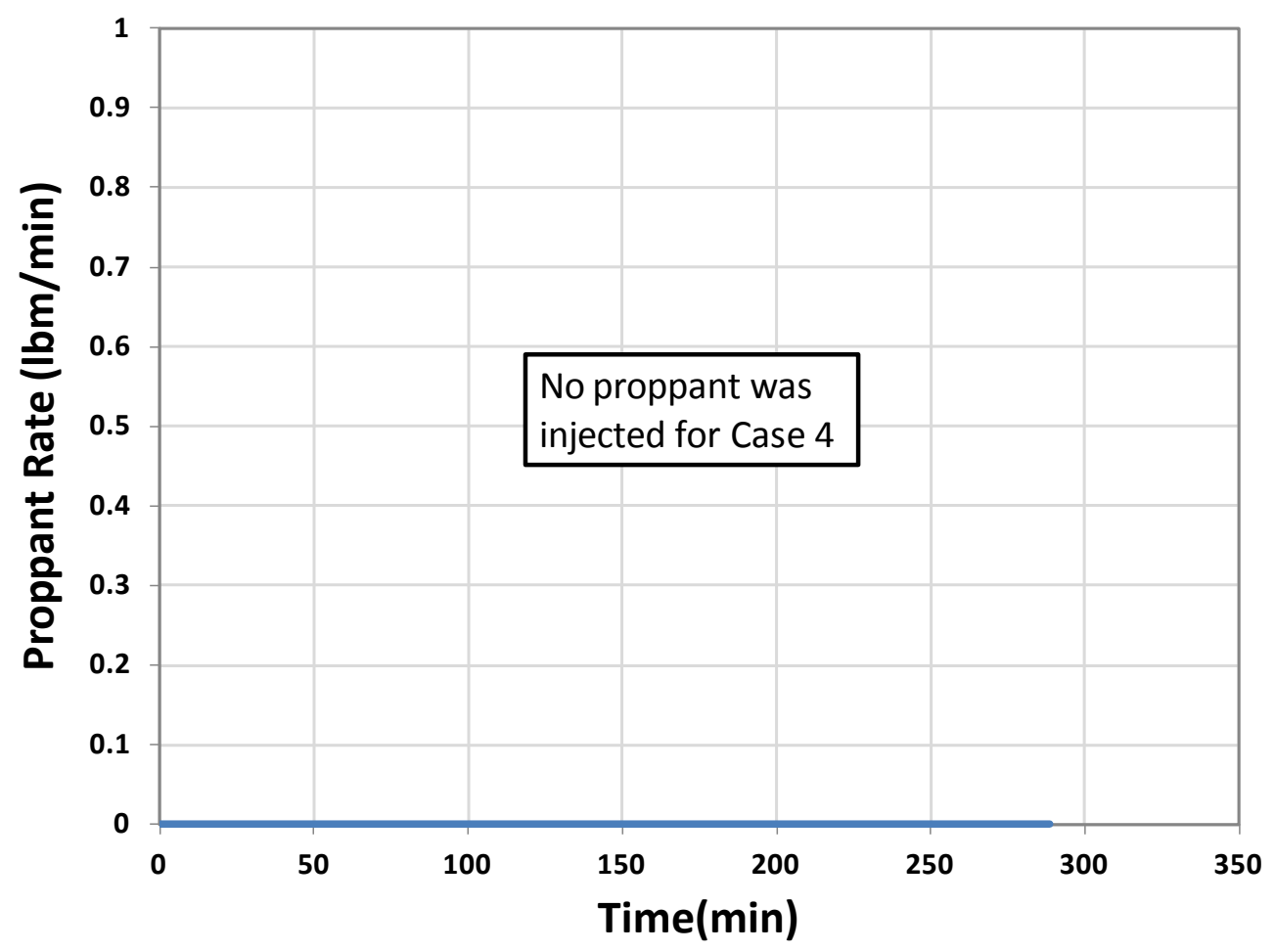

Figure 3.19: Case 4 - Proppant Rate versus Time

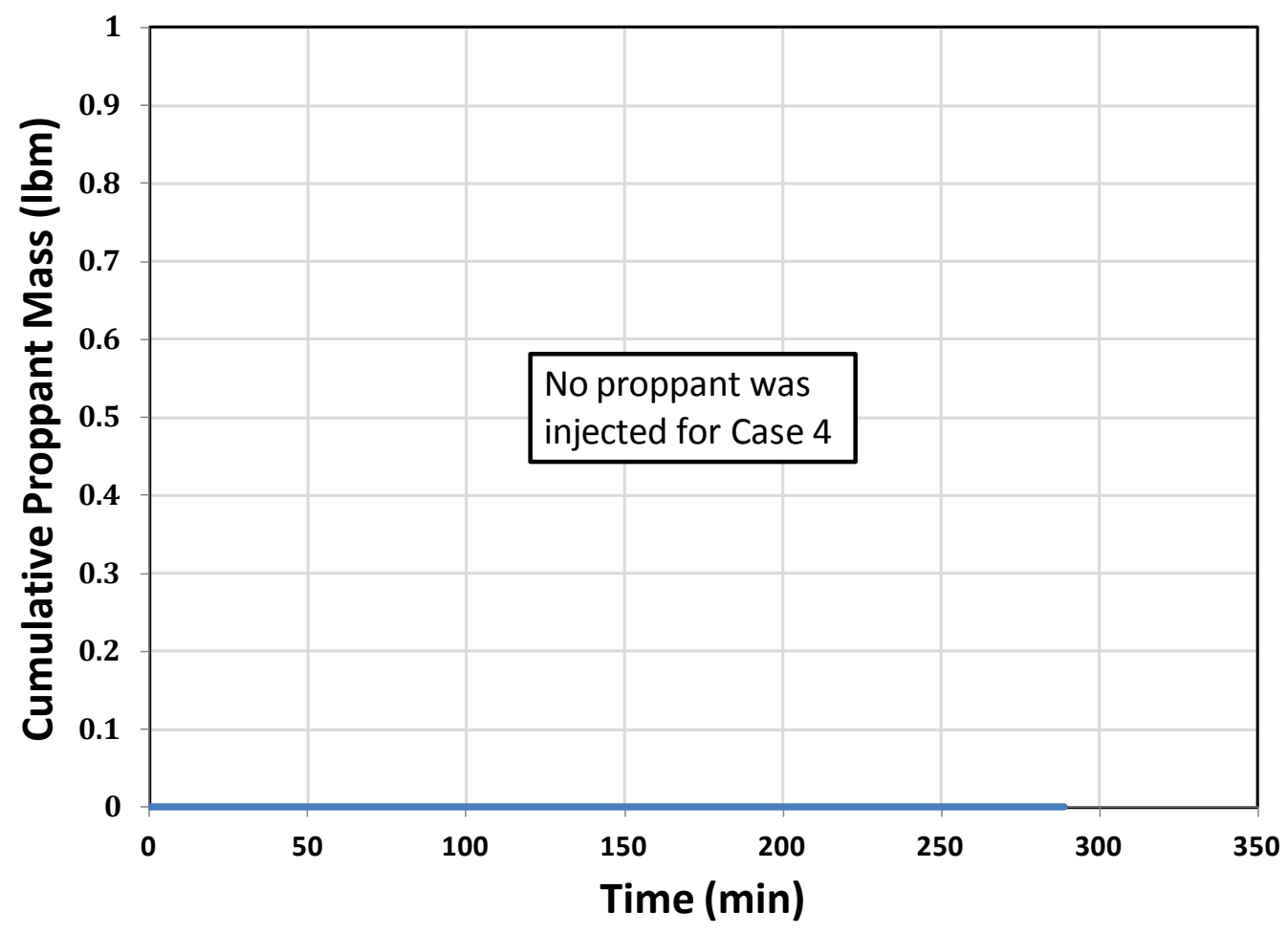

Figure 3.20: Case 4 - Cumulative Proppant Mass versus Time 

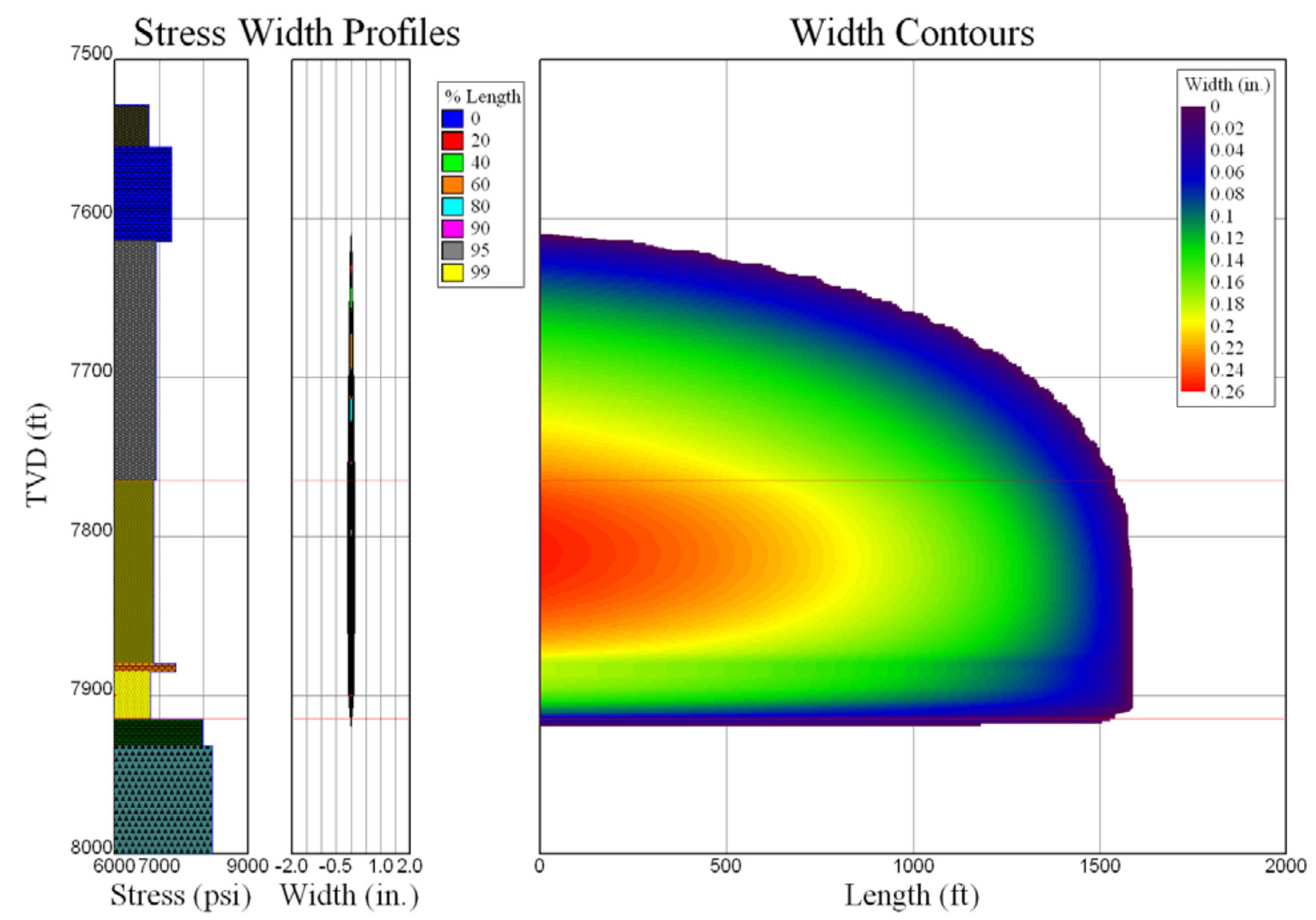

Figure 3.21: Stress, Width Profiles, and Width Contours for Case 4

Treatment parameter plots are shown in Figures 3.22, 3.23, 3.24, and 3.25 for Case 5. The width profile and contour for Case 5 is shown in Figure 3.26. The height was found to be approximately 271 feet and the length was around 665 feet. 


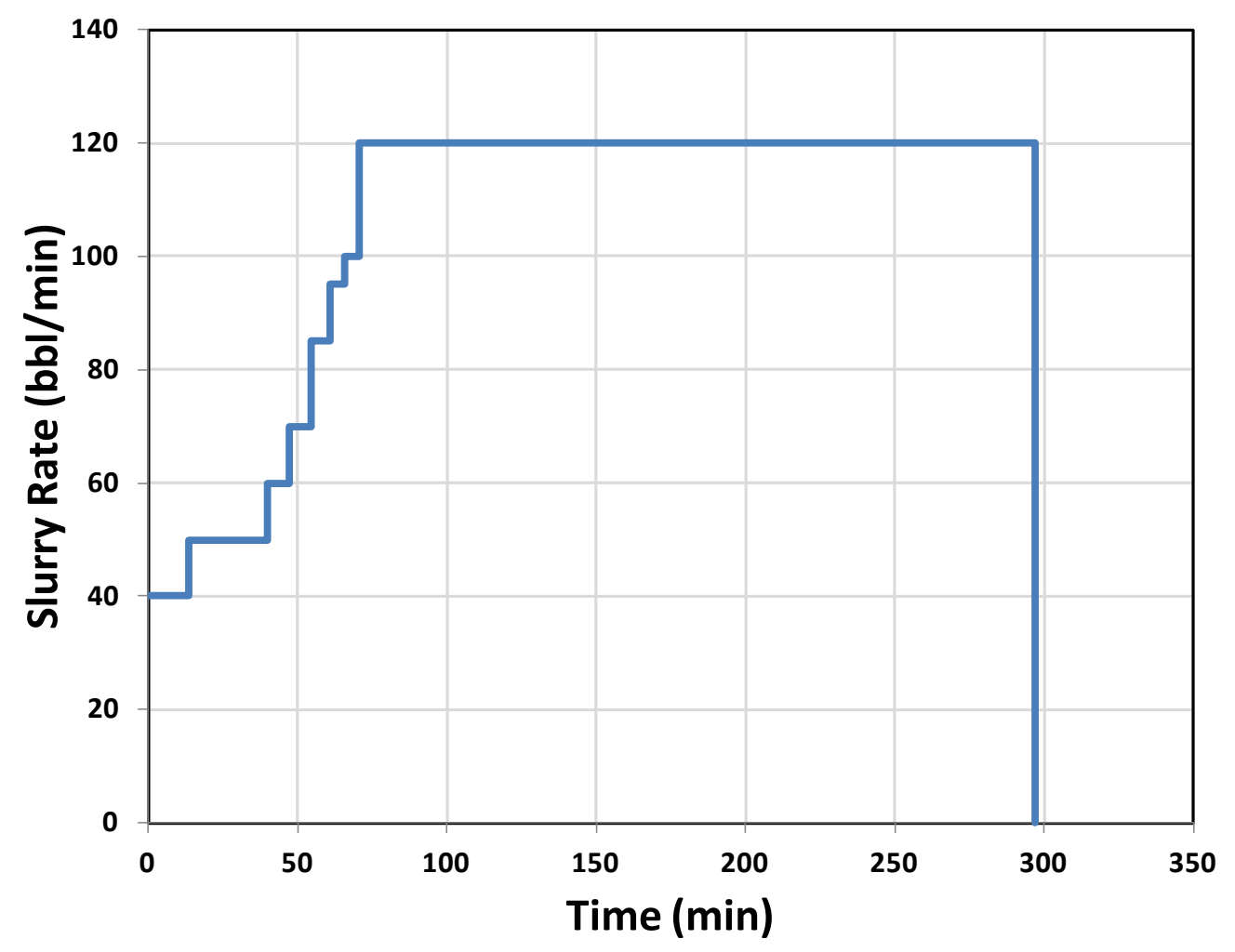

Figure 3.22: Case 5 - Slurry Rate versus Time

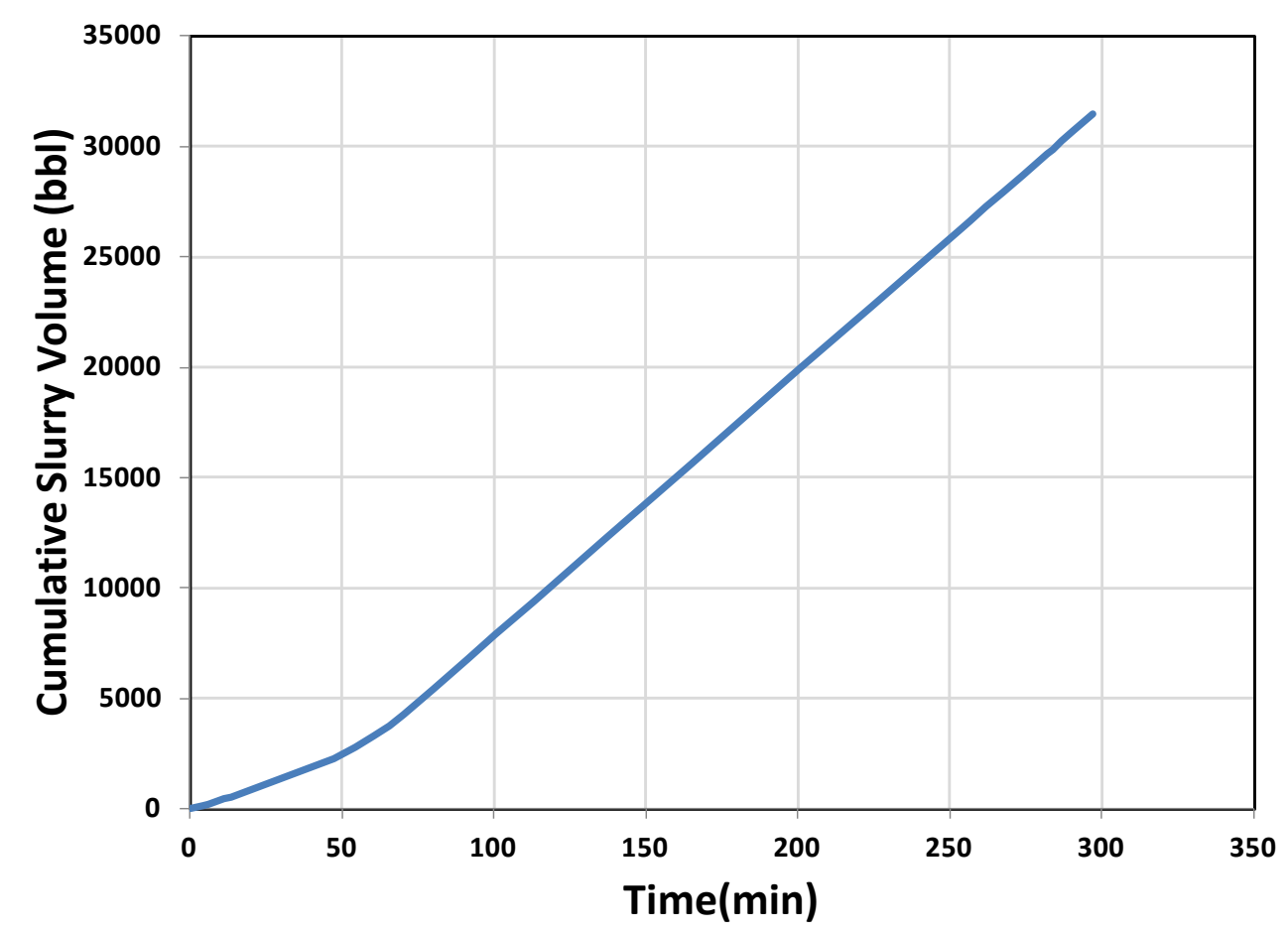

Figure 3.23: Case 5 - Cumulative Slurry Volume versus Time 


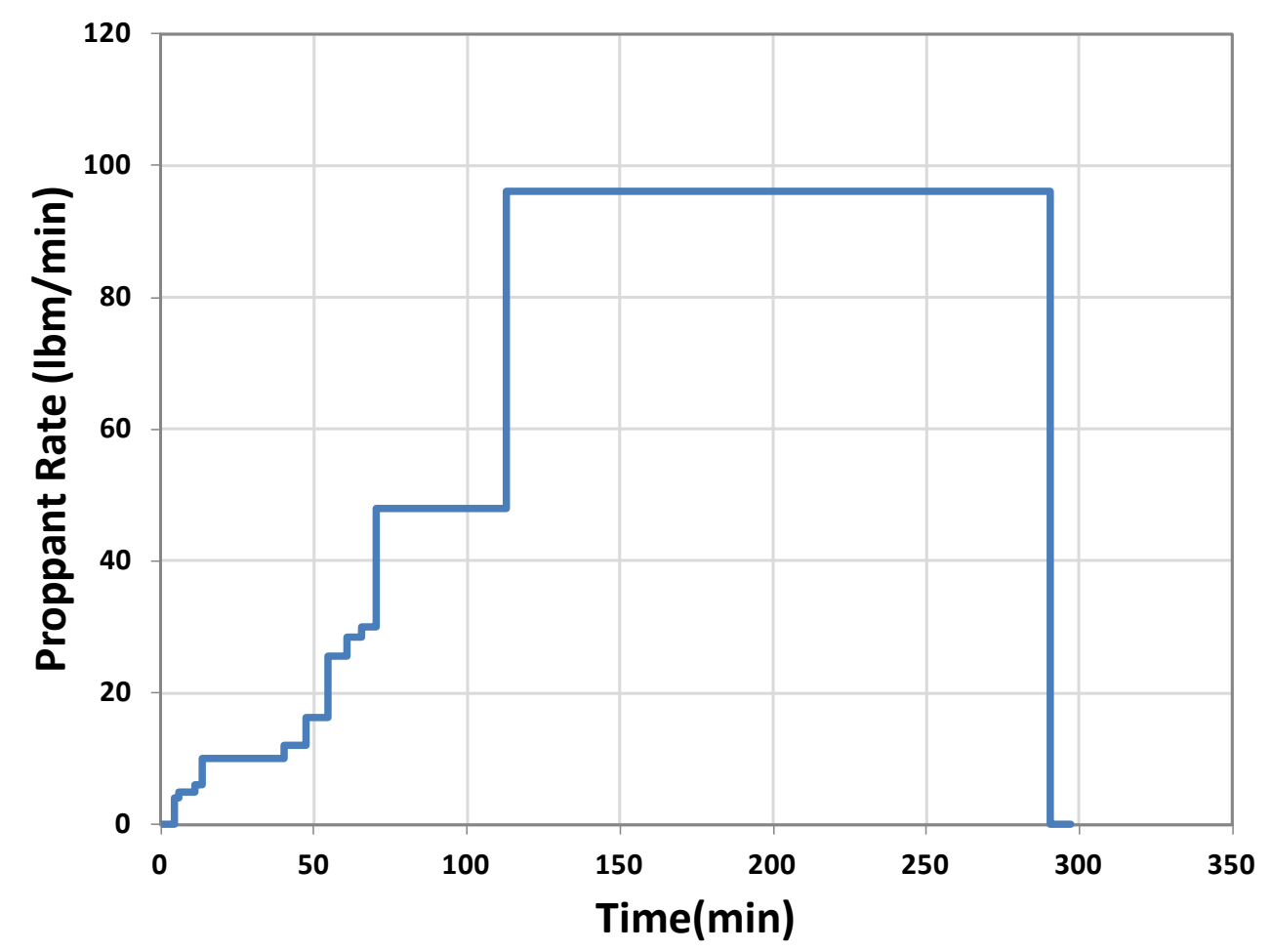

Figure 3.24: Case 5 - Proppant Rate versus Time

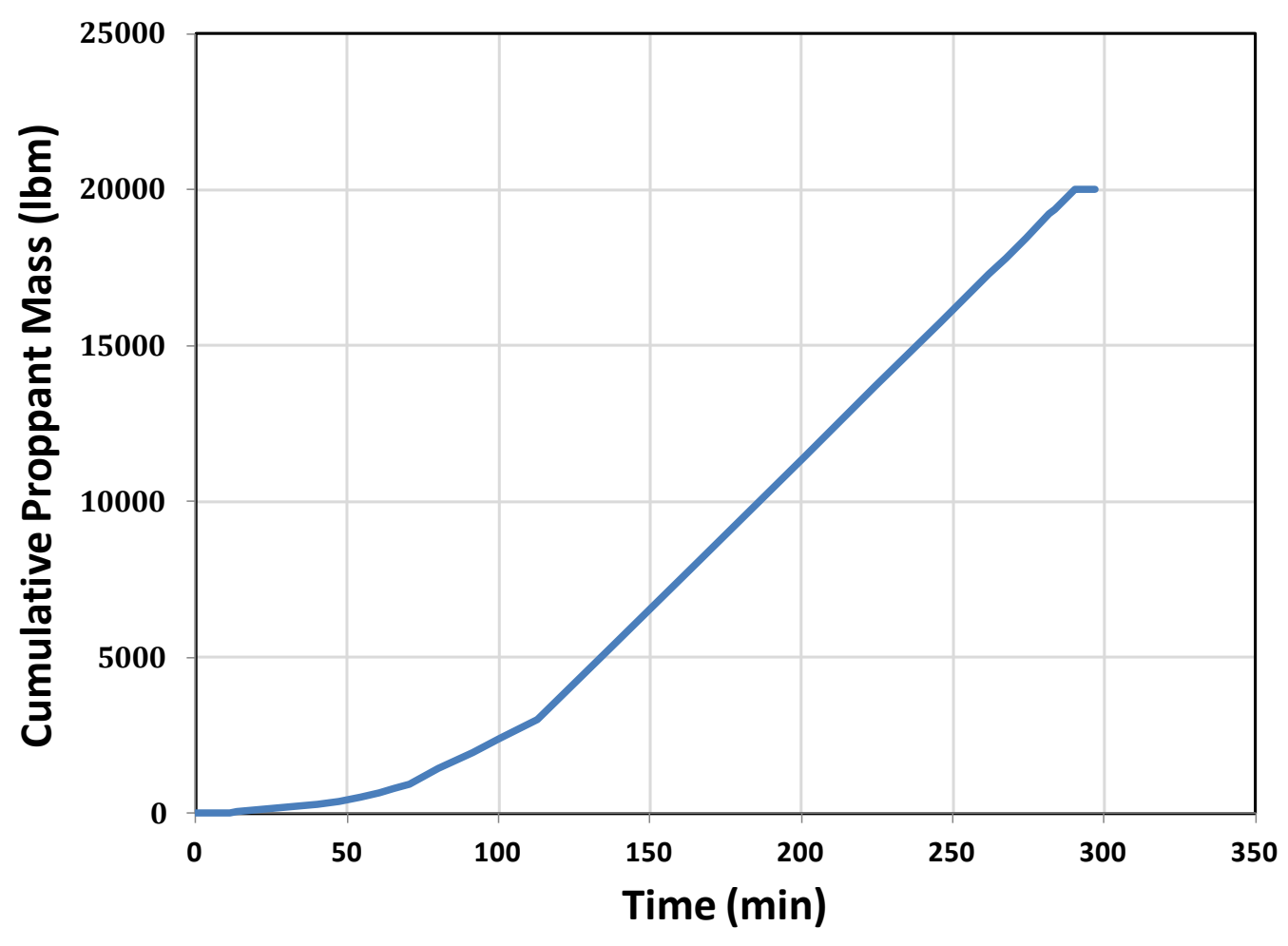

Figure 3.25: Case 5 - Cumulative Proppant Mass versus Time 

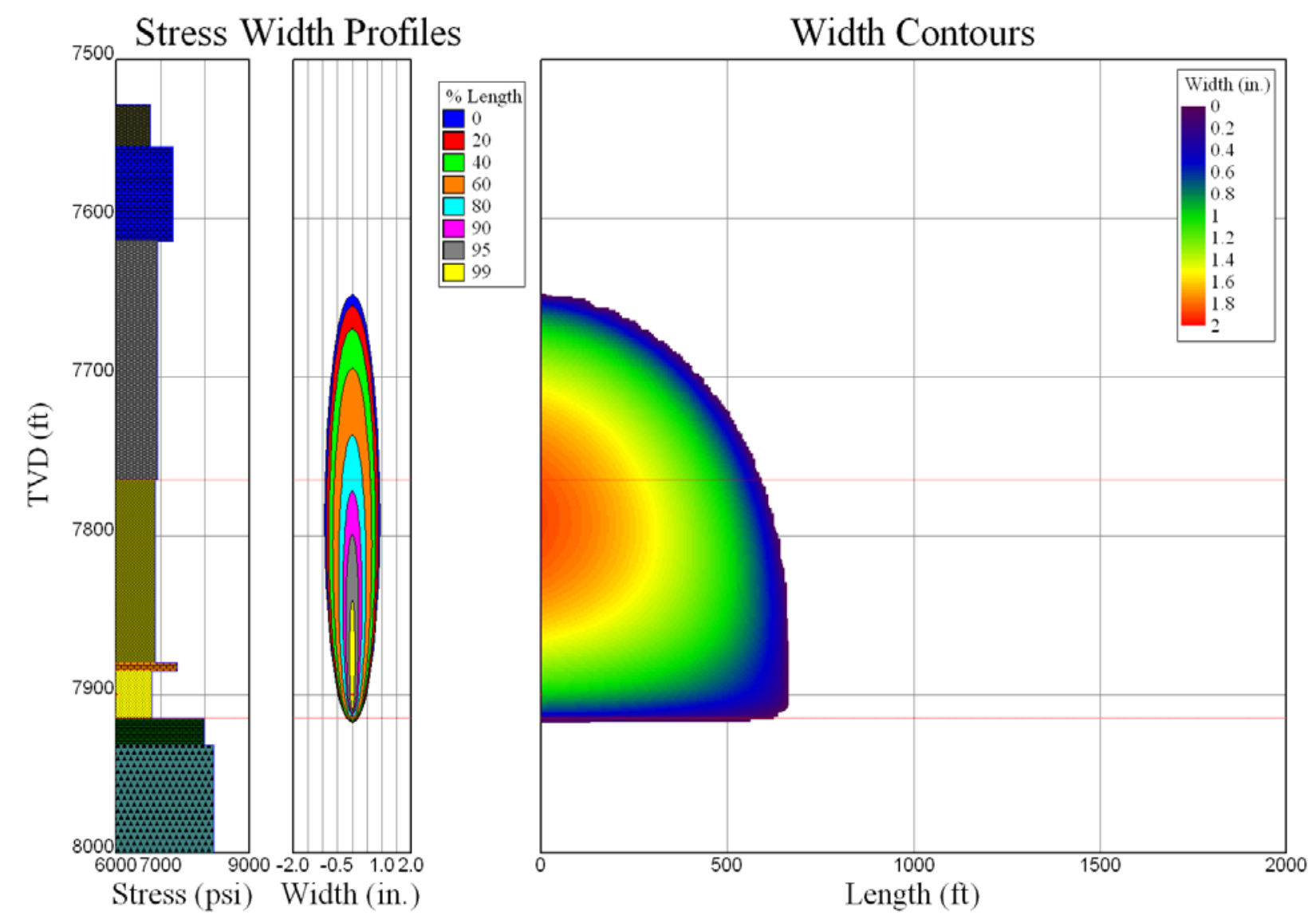

Figure 3.26: Stress, Width Profiles, and Width Contours for Case 5

Treatment parameter plots are shown in Figures 3.27, 3.28, 3.29, and 3.30 for Case 6. The width profile and contour for Case 6 is shown in Figure 3.31. The height was found to be approximately 272 feet and the length was around 672 feet. 


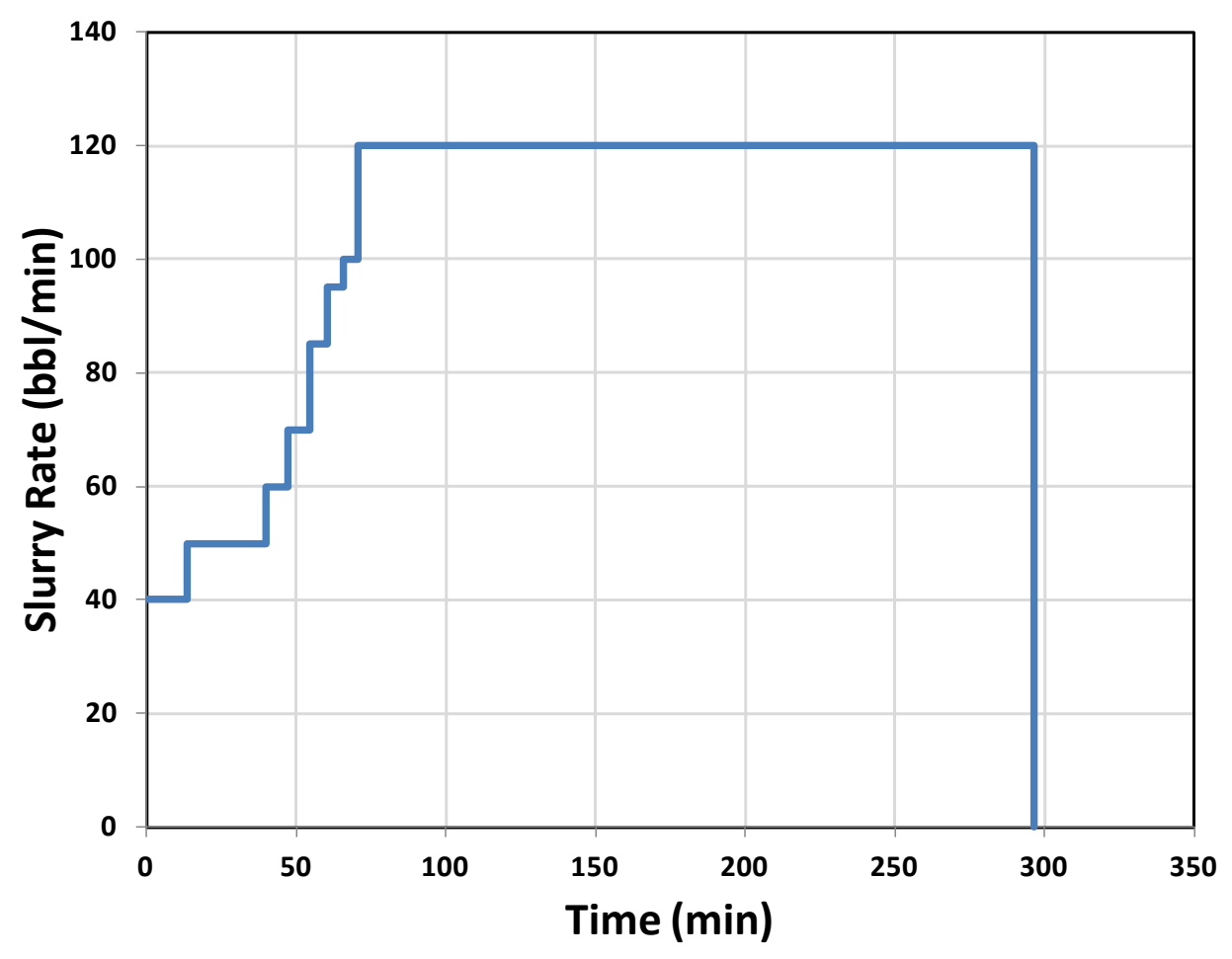

Figure 3.27: Case 6 - Slurry Rate versus Time

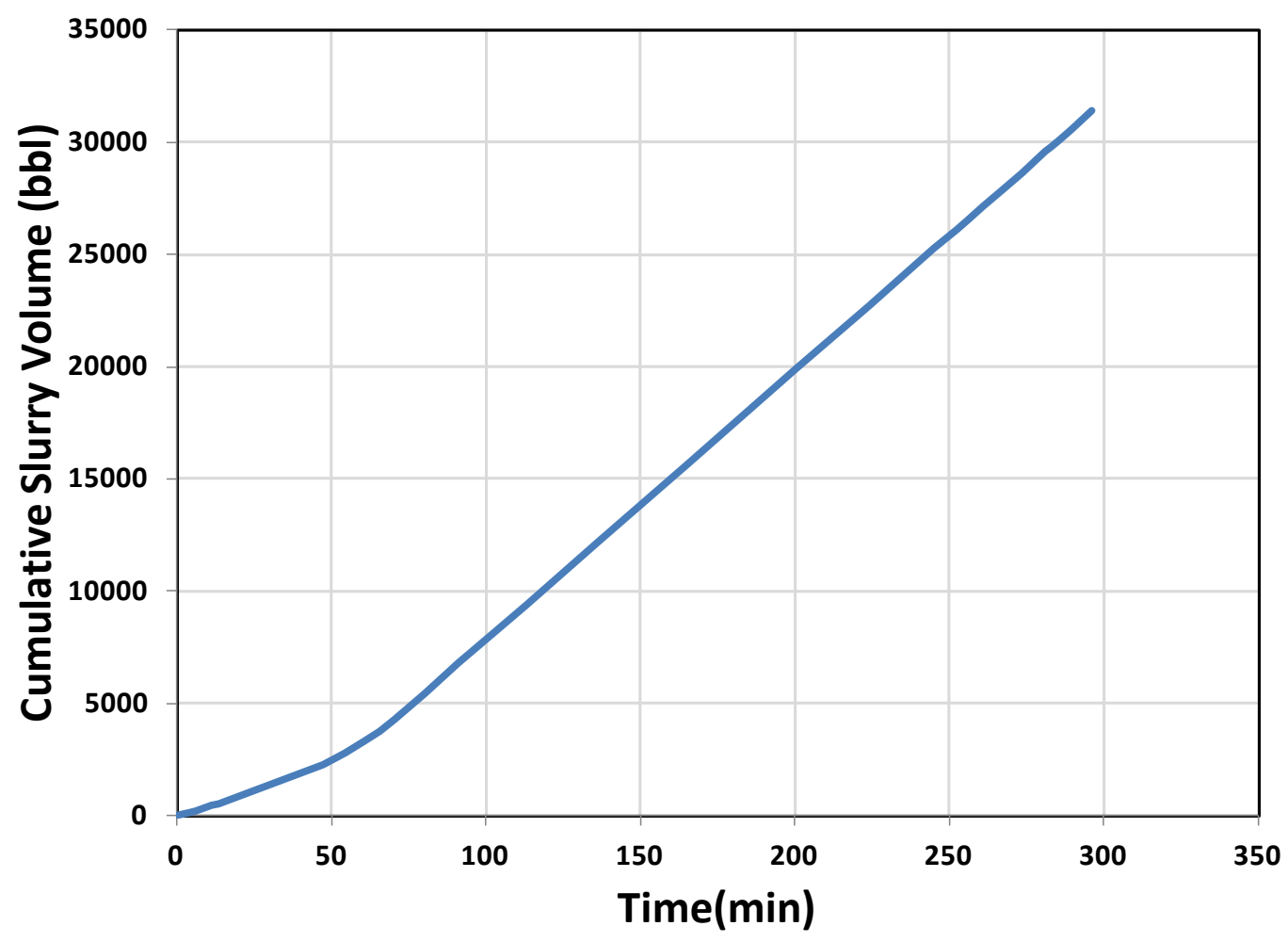

Figure 3.28: Case 6 - Cumulative Slurry Volume versus Time 


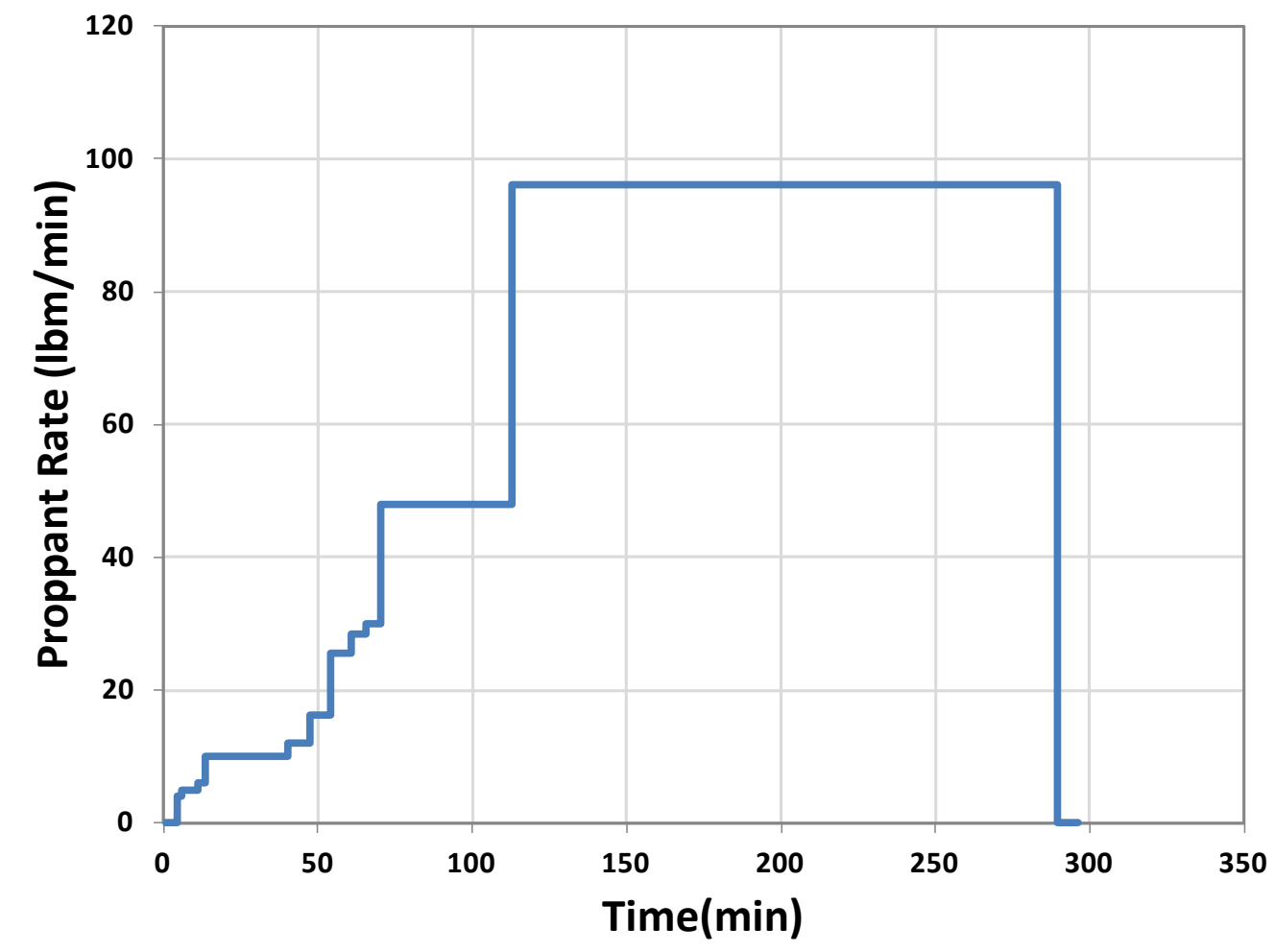

Figure 3.29: Case 6 - Proppant Rate versus Time

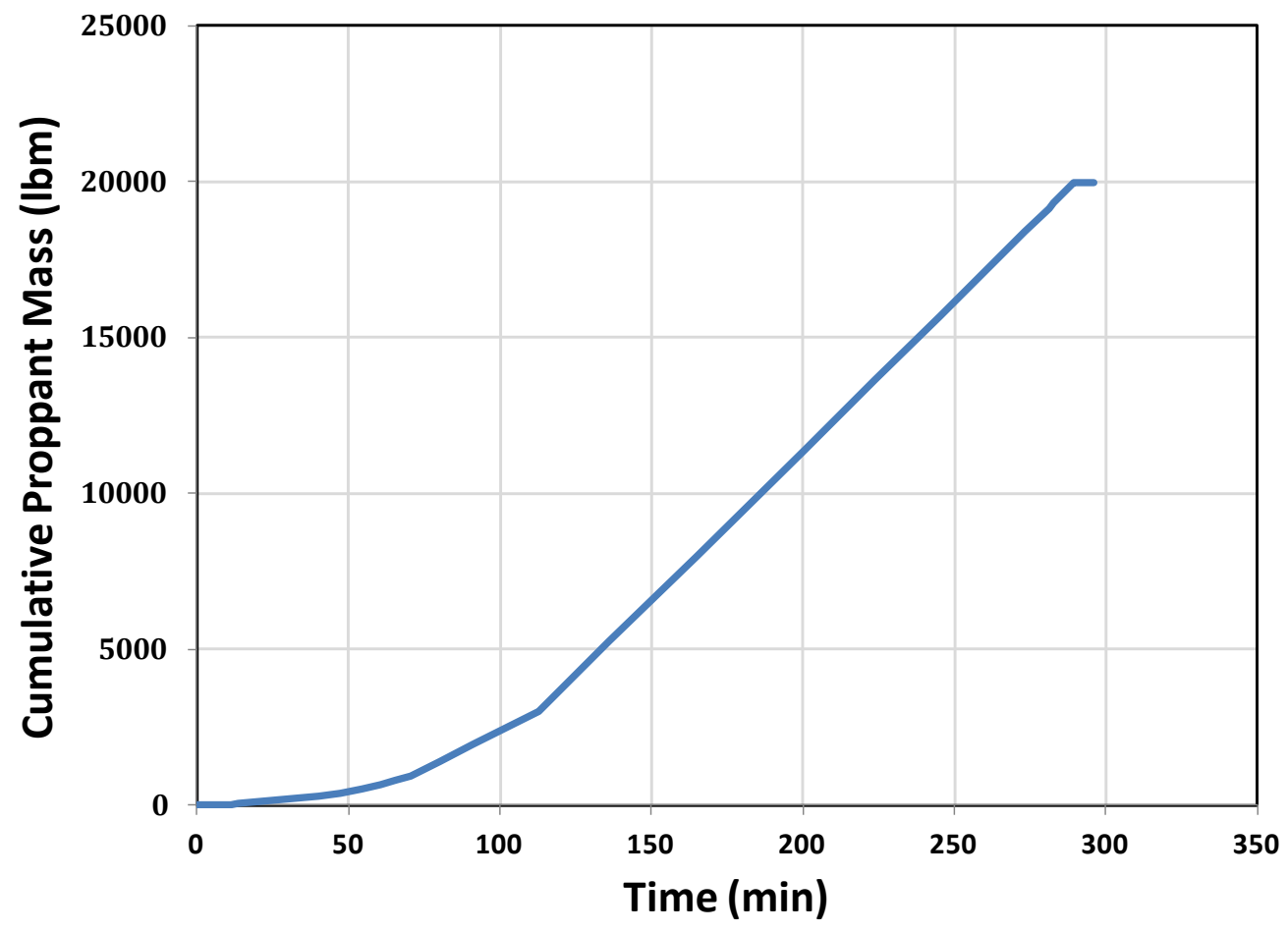

Figure 3.30: Case 6 - Cumulative Proppant Mass versus Time 

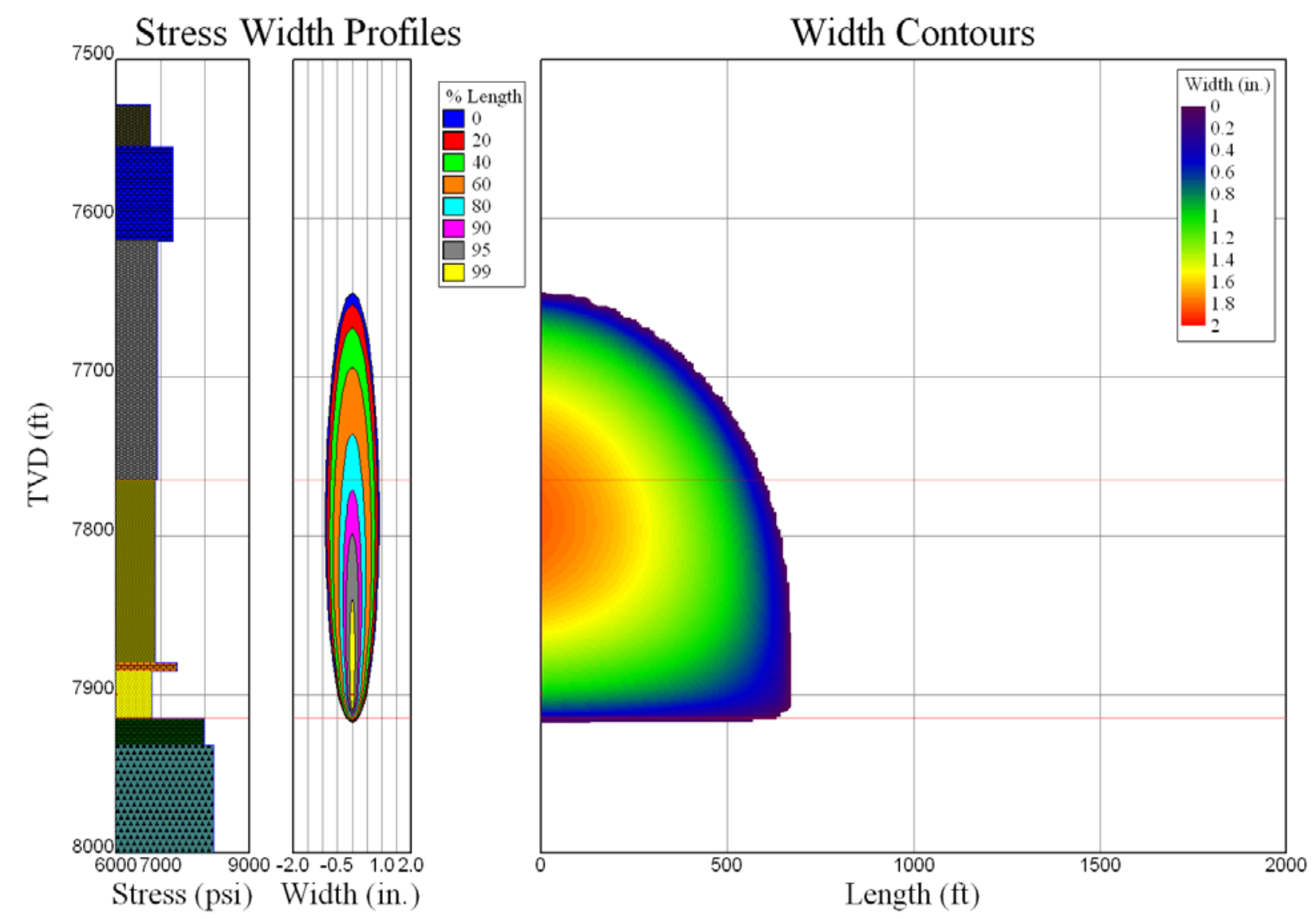

Figure 3.31: Stress, Width Profiles, and Width Contours for Case 6 
Results from the above six cases showing maximum fracture heights and lengths are shown in Table 3.2 below.

Table 3.2: Summary Table Showing Fracture Heights and Lengths

\section{Case \# Fracture Height (ft) Fracture Length (ft) Figure}

\begin{tabular}{|c|c|c|c|}
\hline 1 & 310 & 1524 & 3.6 \\
\hline 2 & 307 & 847 & 3.11 \\
\hline 3 & 307 & 852 & 3.16 \\
\hline 4 & 311 & 1591 & 3.21 \\
\hline 5 & 271 & 665 & 3.26 \\
\hline 6 & 272 & 672 & 3.31 \\
\hline
\end{tabular}

The following conclusions can be drawn from the six cases run to determine the effects of injection rate and proppant type:

- The effects of a constant versus a variable injection rate on fracture propagation are unclear and are highly dependent upon the exact rates used and treatment parameters in combination with one another.

- The introduction of proppant into the slickwater fluid acts to decrease both fracture height and length.

- The size of the proppant used has a negligible effect on fracture height and a very slight effect on fracture length. Smaller proppant size appears to allow for slightly longer fracture lengths. 


\subsection{Influence of Fluid Volume}

To investigate the effects of fluid volume on fracture propagation, three cases were run with different injected fluid volumes. The first case, the base case (100 percent fluid volume and proppant mass), was simulated, and its results are shown in Figure 3.31. In the second case, used the same parameters as the base case were used, but with 50 percent of the fluid volume (and proppant mass) injected. The results of this case are shown in Figure 3.32. In the third case the same parameters as the base case were used, but with 150 percent of the fluid volume (and proppant mass) injected. The results of this case are shown in Figure 3.33. The results for each fracture dimension are shown numerically in Table 3.2.
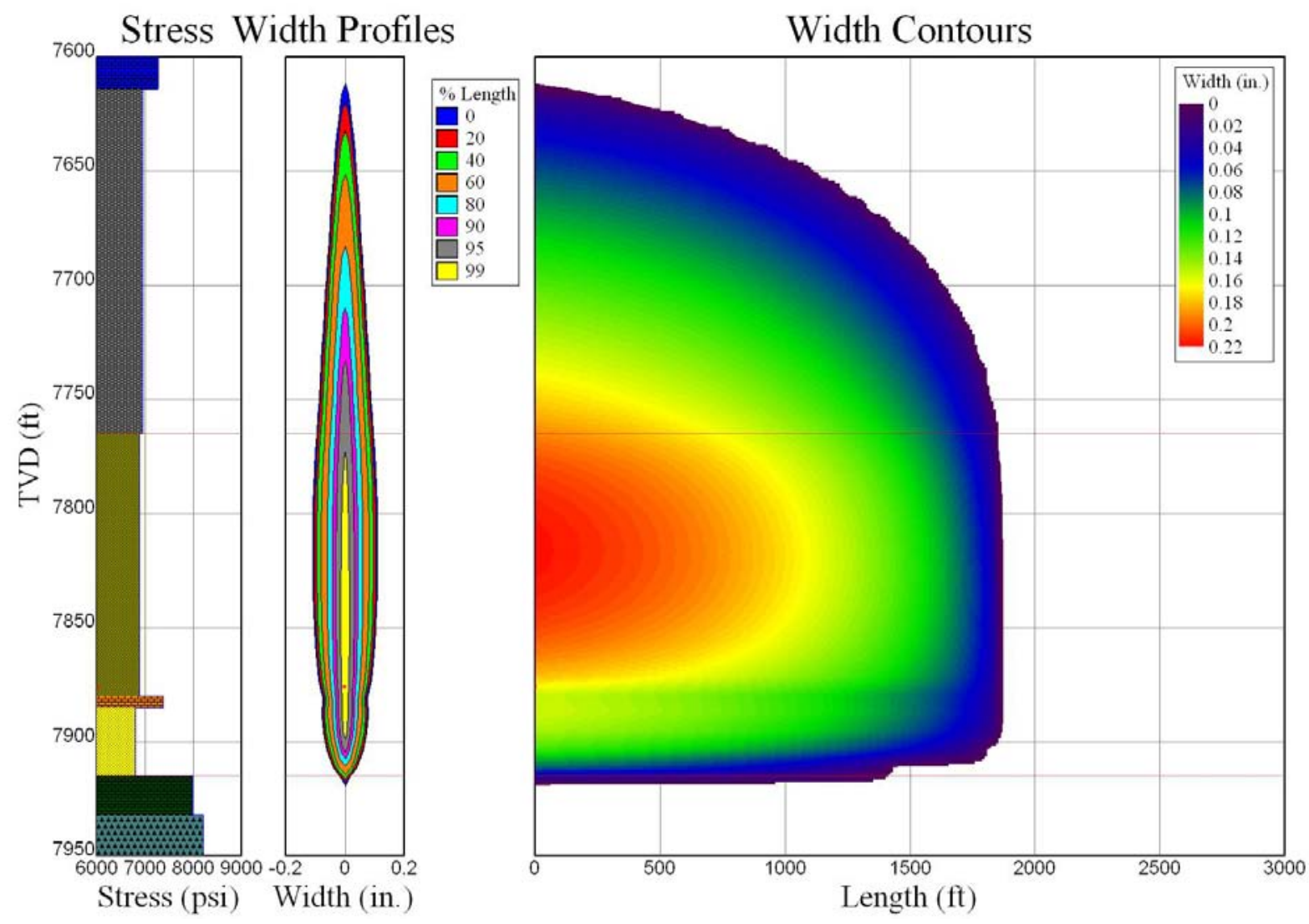

Figure 3.32: Fracture Dimensions for the Base Case Fluid Injection Volume 

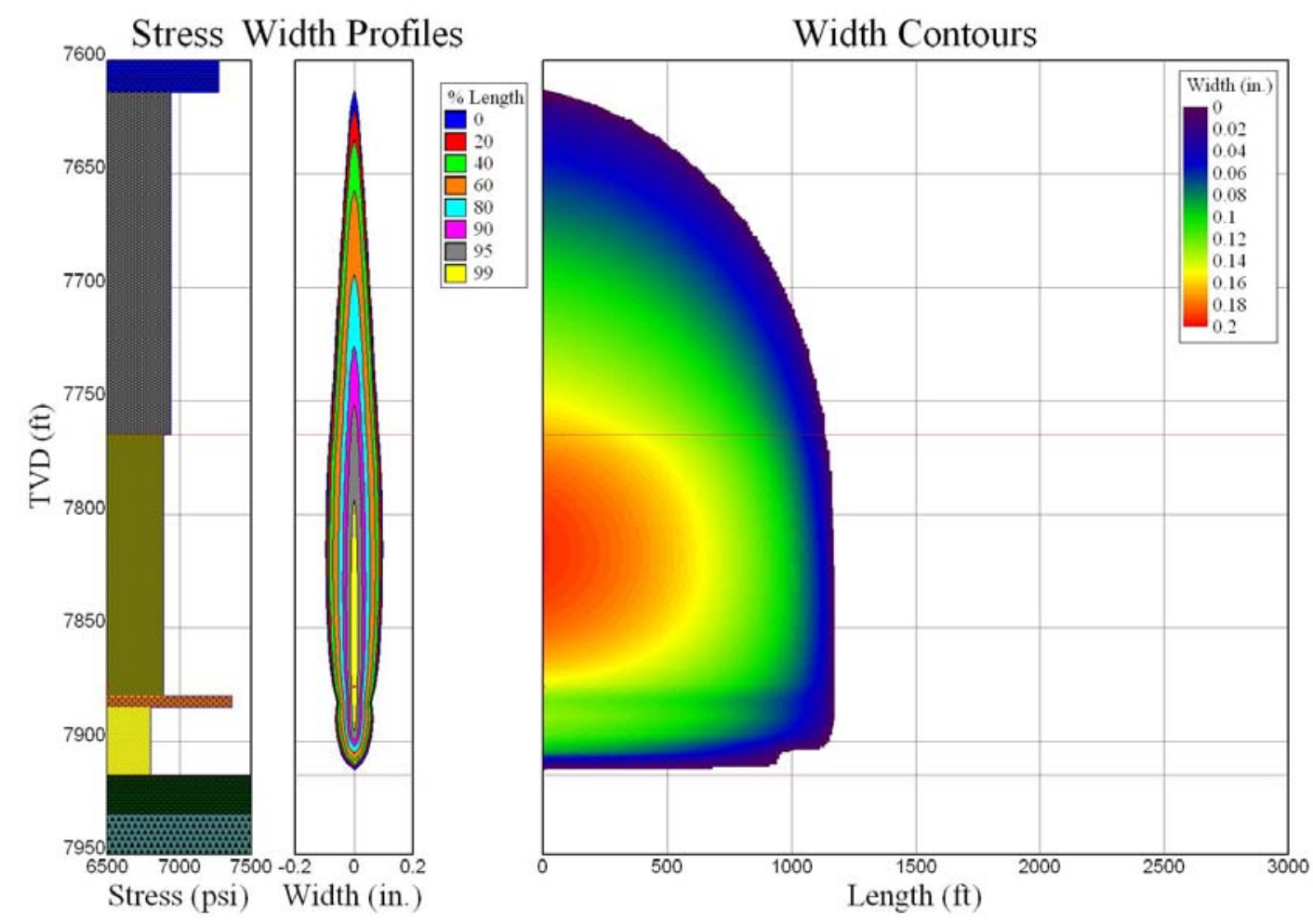

Figure 3.33: Fracture Dimensions for the 50 Percent Case Fluid Injection Volume
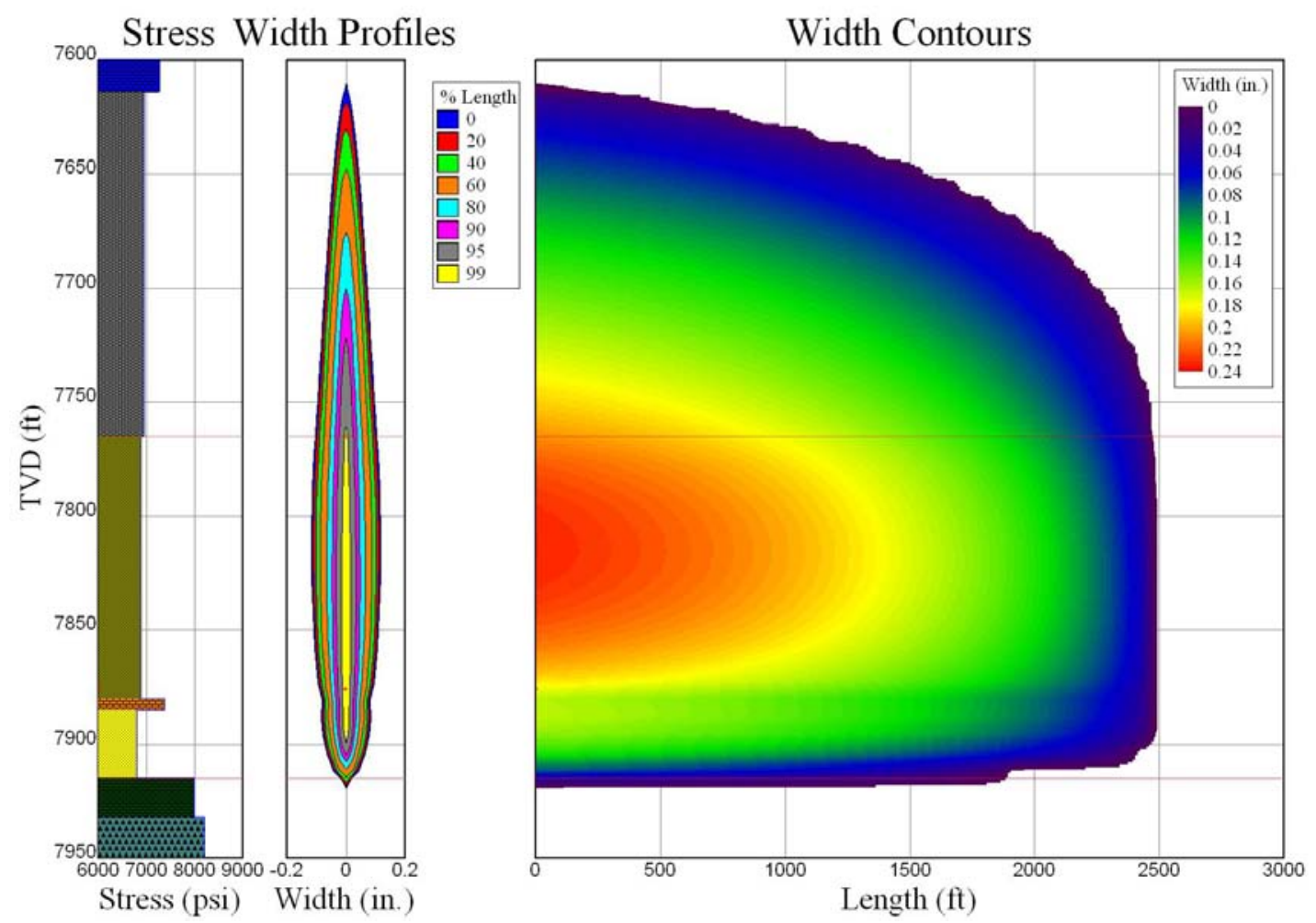

Figure 3.34: Fracture Dimensions for the 150 Percent Case Fluid Injection Volume 
Table 3.3: Influence of Fluid Injection Volume on Fracture Dimensions

\begin{tabular}{|c|c|c|c|c|}
\hline Case & $\begin{array}{c}\text { Fracture Length } \\
\text { (ft) }\end{array}$ & $\begin{array}{c}\text { Fracture Width } \\
\text { (in) }\end{array}$ & $\begin{array}{c}\text { Fracture Height } \\
\text { (ft) }\end{array}$ & Figure \\
\hline $\begin{array}{c}\text { Base Volume } \\
\text { Case }\end{array}$ & 1875 & 0.1708 & 307.8 & 3.32 \\
\hline $\begin{array}{c}\text { 50\% Volume } \\
\text { Case }\end{array}$ & 1174 & 0.1459 & 299.8 & 3.33 \\
\hline $\begin{array}{c}150 \% \text { Volume } \\
\text { Case }\end{array}$ & 2494 & 0.1819 & 309.6 & 3.34 \\
\hline
\end{tabular}

The results of these simulations are as expected. The larger the injected fluid volume, the larger the fracture dimensions. Each fracture dimension is larger with increased fluid injection. The fracture length shows a much higher increase than the height, as the height is restricted due to the bounding limestone layer. 


\subsection{Influence of Fluid (Apparent) Viscosity}

The (apparent) viscosity of the fracturing fluid can have a significant effect on the propagation of hydraulic fractures. This makes choosing the correct fracturing fluid essential in obtaining the desired fracture dimensions. The following equation (Meyer \& Associates, Inc., 2012) shows the relationship between apparent viscosity, the consistency index, the flow behavior index, and the shear rate of the fluid.

$$
\mu_{\text {app }}=k^{\prime} \gamma^{n^{\prime}-1}
$$

where $\mu_{\text {app }}$ is the apparent viscosity, $\mathrm{k}^{\prime}$ is the consistency index, $\gamma$ is the shear rate, and $\mathrm{n}^{\prime}$ is the flow behavior index of the fluid.

To determine the influence of fluid viscosity on fracture propagation, a number of cases were generated for simulation. In selecting a range of viscosities, the flow behavior index, n', and the shear rate, $\gamma$, were kept constant for simplicity. The consistency index, $\mathrm{k}^{\prime}$, of the fluid was varied and plotted against apparent viscosity. Three temperatures were selected for determining viscosity changes under different conditions. Figure 3.35 shows the relationship between $\mathrm{k}^{\prime}$ and apparent viscosity at 3 different temperatures for the defined conditions. It can be seen that temperatures of 80 degrees and 100 degrees Fahrenheit have the same viscosity values (the 80 and 100 degree curves are on top of one another in Figure 3.35). The range of viscosities shown was selected to encompass a wide range of situations for fracturing fluids, and to determine the critical viscosity values.

A series of 17 different cases were generated for the simulation of different viscosity values. All other treatment, geomechanical, and fluid flow properties were kept constant. See Table 3.4 for the base case stimulation parameters. These cases range in viscosity from $0.0001 \mathrm{cp}$ to $10,000 \mathrm{cp}$. Figure 3.36 shows the apparent viscosity versus the maximum fracture height. Figure 3.37 shows the apparent viscosity versus the maximum fracture width. Figure 3.38 shows the apparent viscosity versus the maximum fracture length. 
Table 3.4: Base Case Stimulation Parameters

\begin{tabular}{|c|c|c|}
\hline Parameter & Units & Value \\
\hline Maximum Slurry Rate & Barrels per minute & 120 \\
\hline Total Liquid Volume Injected & U.S. Gallons & $1,281,000$ \\
\hline Fluid Type & - & Slickwater \\
\hline Proppant Type & - & $40 / 70$ Mesh \\
\hline Max. Proppant Concentration & Ibm/U.S. Gallon & 1 \\
\hline Total Injection Time & Minutes & 293.794 \\
\hline
\end{tabular}

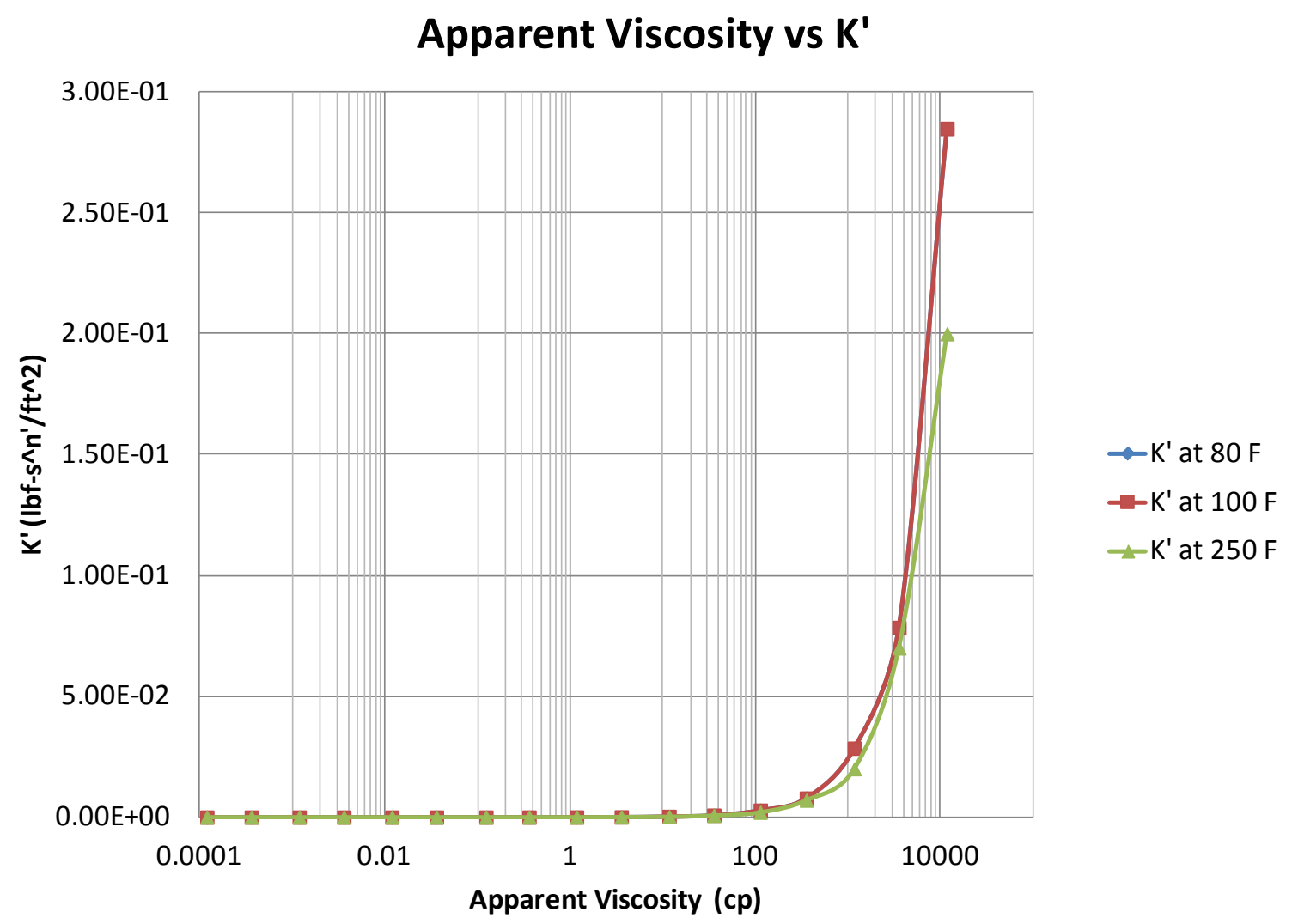

Figure 3.35: Apparent Viscosity vs. $k^{\prime}$ 


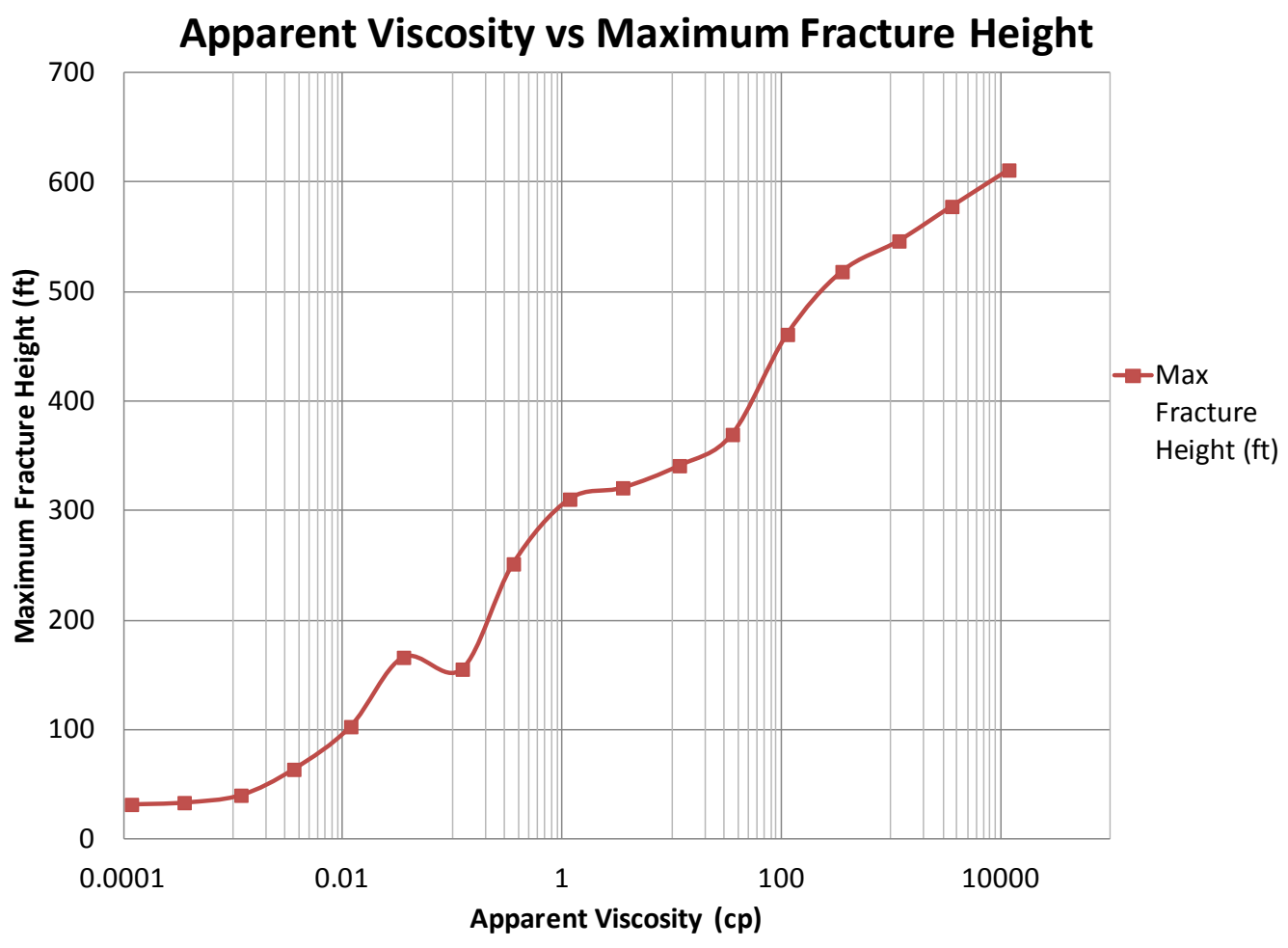

Figure 3.36: Apparent Viscosity vs. Maximum Fracture Height

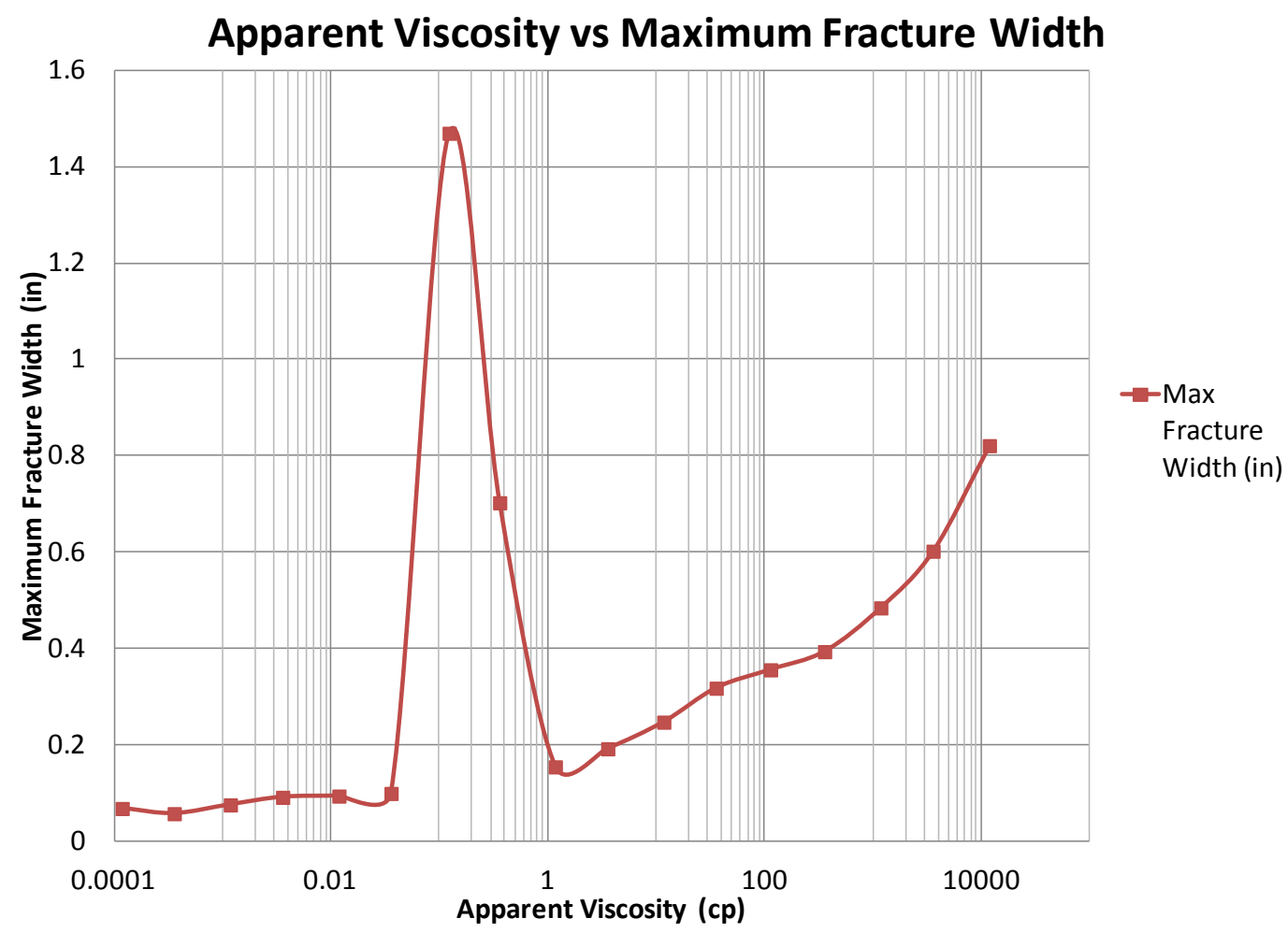

Figure 3.37: Apparent Viscosity vs. Maximum Fracture Width 


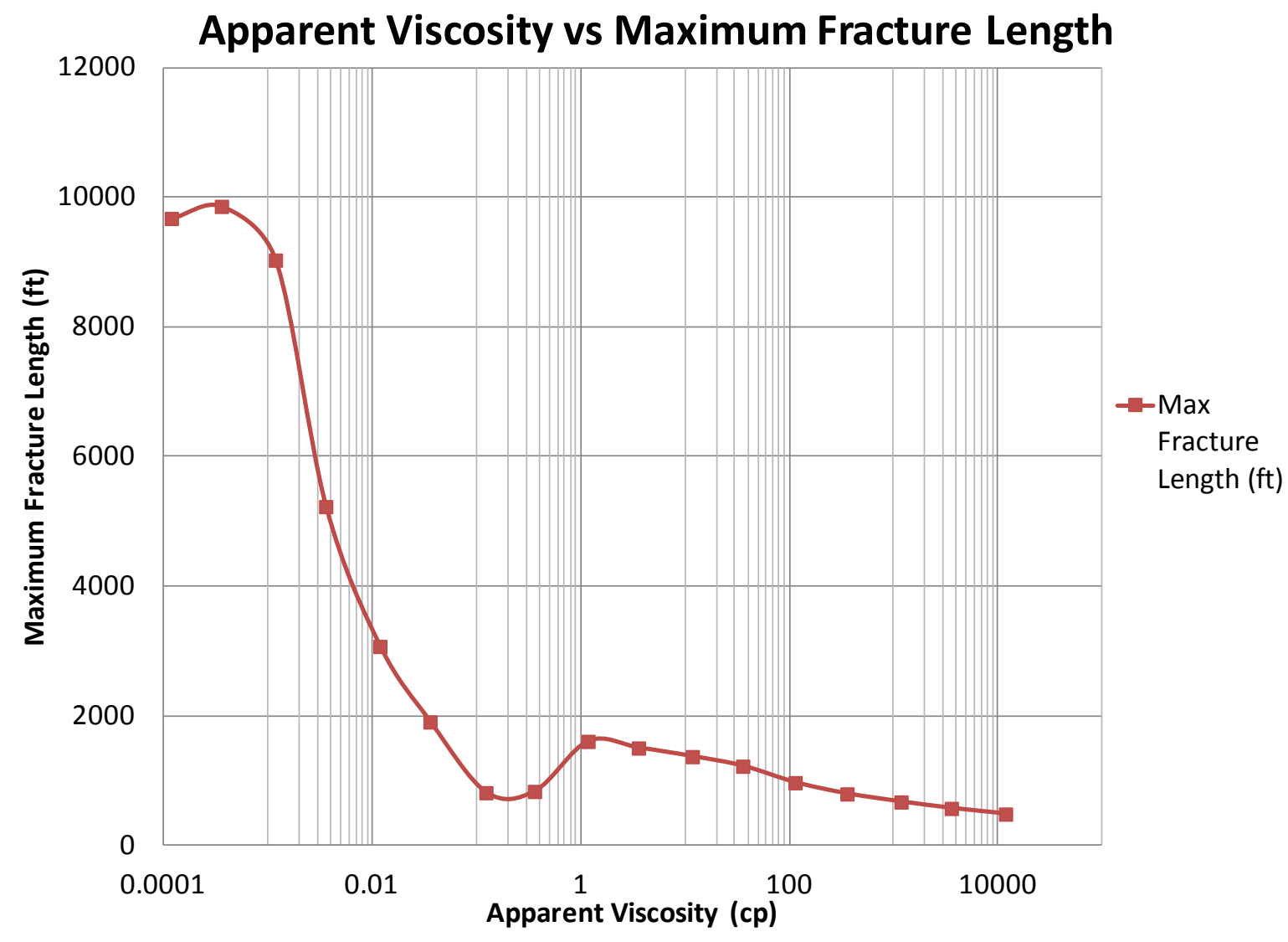

Figure 3.38: Apparent Viscosity vs. Maximum Fracture Length

The following conclusions can be made based on the results of this study on fluid viscosity's effect on fracture propagation:

- As fluid viscosity increases, fracture height and width tend to increase as well. This can be attributed to the increased friction on the walls of the fracture that allow the fluid to propagate further in the respective directions. Fracture length; however tends to decrease with increased fluid viscosity. This can be attributed to the increased friction on the walls of the fracture as well which help to slow the horizontal propagation of the fracture.

- Results for fluid viscosities in the range of $0.1 \mathrm{cp}$ to $1 \mathrm{cp}$ are shown in Figures 3.36 through 3.38. There are noticeable changes in the fracture propagation for these viscosities. This is an example of how fractures can exhibit a general increase or decrease in propagation in a given direction, but may, depending on the treatment and formation 
properties, change behavior. This change in behavior can be caused by proppant screenout or a change in geomechanical or fluid flow properties in a different layer in which the fracture has extended, among other possibilities.

- Fluid viscosity is an important treatment parameter which must be studied on a case by case basis to determine its influence on fracture propagation. 


\section{CHAPTER 4: INFLUENCE OF GEOMECHANICAL AND FLUID LOSS PROPERTIES ON HYDRAULIC FRACTURE PROPAGATION}

\subsection{Influence of Layer Homogeneity}

To study the effects of layer homogeneity on hydraulic fracture propagation, three cases were developed and simulated. The three cases which were simulated are detailed in Table 4.1, and schematic diagrams of each are shown in Figures 4.1 through 4.3. The geologic setting is the same as previously described in chapter 3 . Table 4.2 shows the base case injection parameters for all cases presented in this chapter.

Table 4.1: Layer Homogeneity Influence Case Details

\begin{tabular}{|c|c|c|}
\hline Case & Details & Figure \\
\hline Fully Heterogeneous & Original Layers & 4.1 \\
\hline $\begin{array}{c}\text { Three Homogenized } \\
\text { Layers }\end{array}$ & $\begin{array}{c}\text { Overburden, Payzone, } \\
\text { and Underburden }\end{array}$ & 4.2 \\
\hline $\begin{array}{c}\text { One Homogeneous } \\
\text { Layer }\end{array}$ & $\begin{array}{c}\text { No distinction } \\
\text { between layers }\end{array}$ & 4.3 \\
\hline
\end{tabular}


Table 4.2: Base Case Injection Parameters

\begin{tabular}{|c|c|c|}
\hline Parameter & Units & Value \\
\hline Maximum Slurry Rate & Barrels per minute & 95 \\
\hline Total Liquid Volume Injected & U.S. Gallons & 430,900 \\
\hline Fluid Type & - & Slickwater \\
\hline Proppant Type & - & $70 / 140$ \\
\hline Max. Proppant Concentration & Ibm/U.S. Gallon & Mesh and \\
\hline Total Injection Time & Minutes & $40 / 70$ Mesh \\
\hline
\end{tabular}

Layer heterogeneity was found to have a significant effect on fracture dimensions. The changes can be seen in Table 4.3. Fracture width profiles and contours can be seen for Cases 1 , 2, and 3 in Figures 4.4, 4.5, and 4.6, respectively.

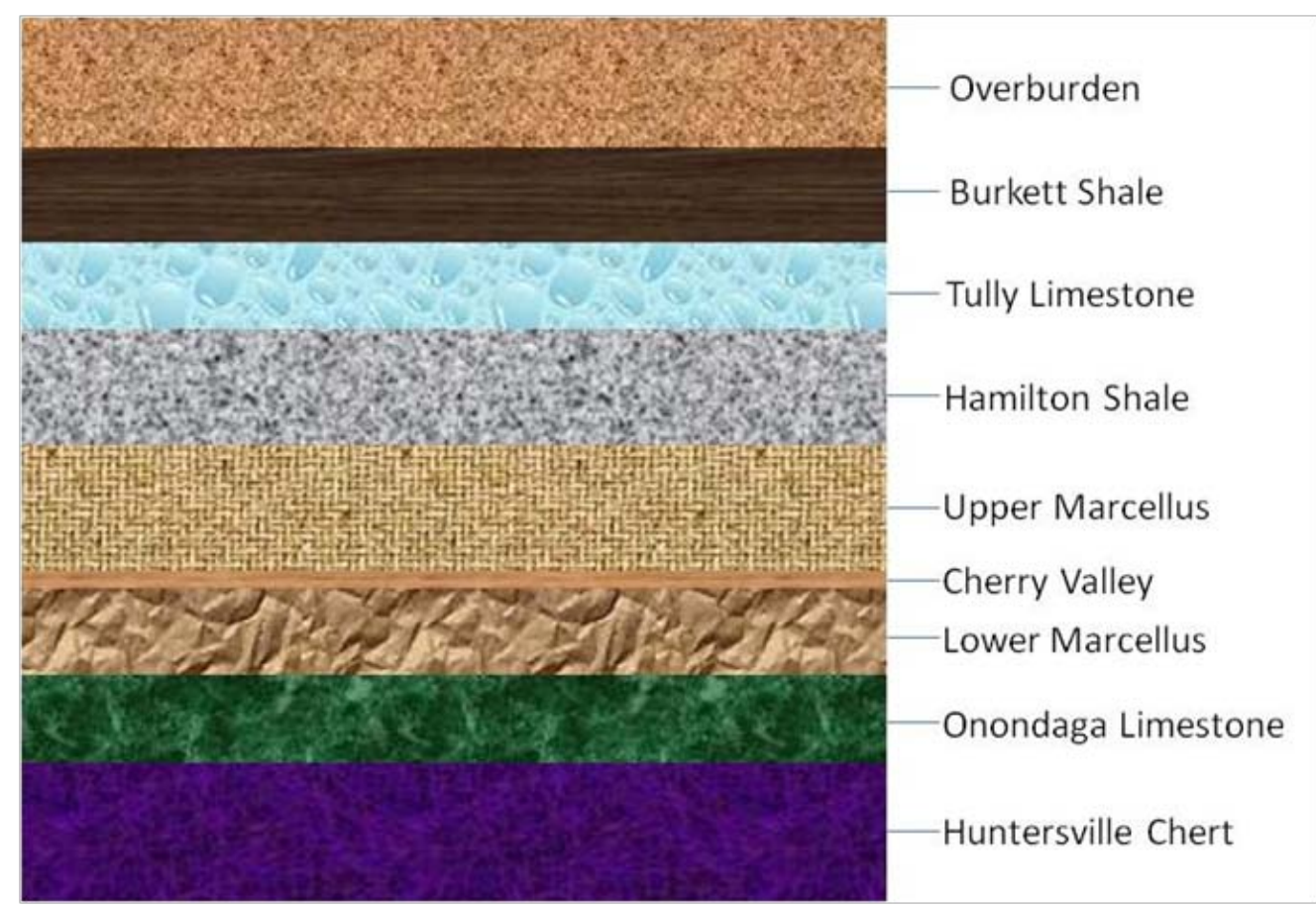

Figure 4.1: Case 1 - Heterogeneous Layers with Original Properties 


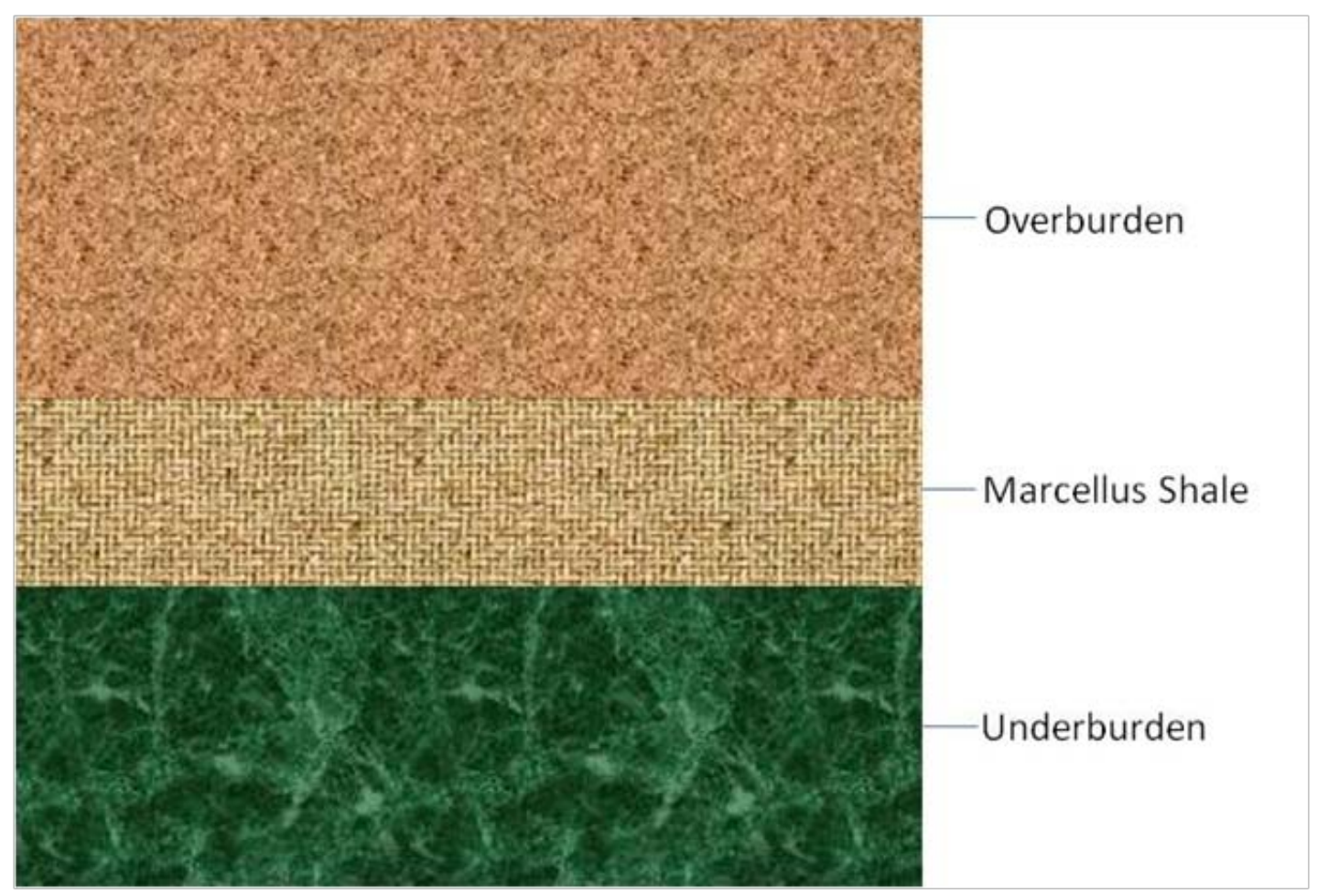

Figure 4.2: Case 2 - Three Homogenized Layers with Averaged Properties

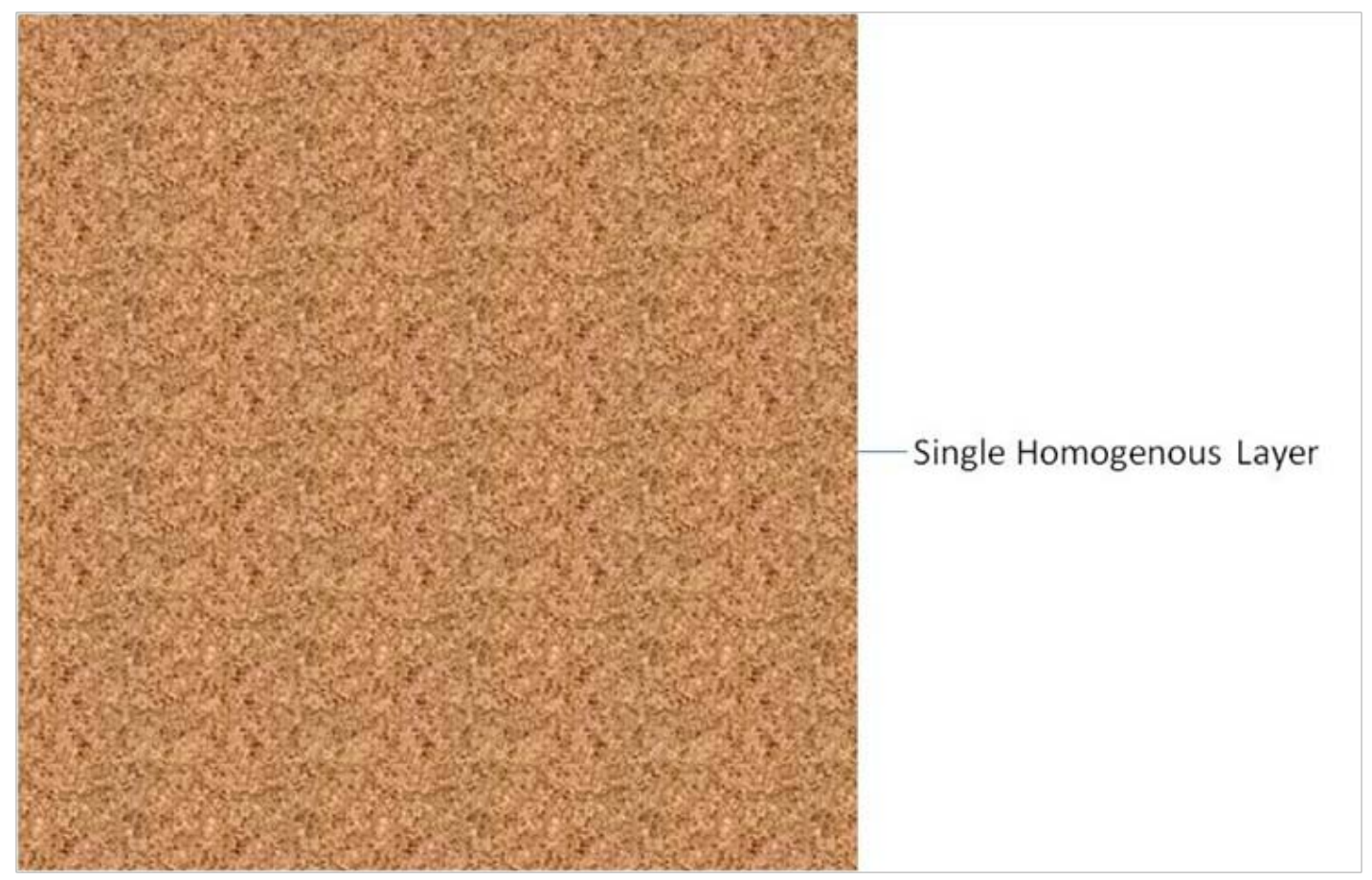

Figure 4.3: Case 3 - Single Homogenized Layer with Average Properties 


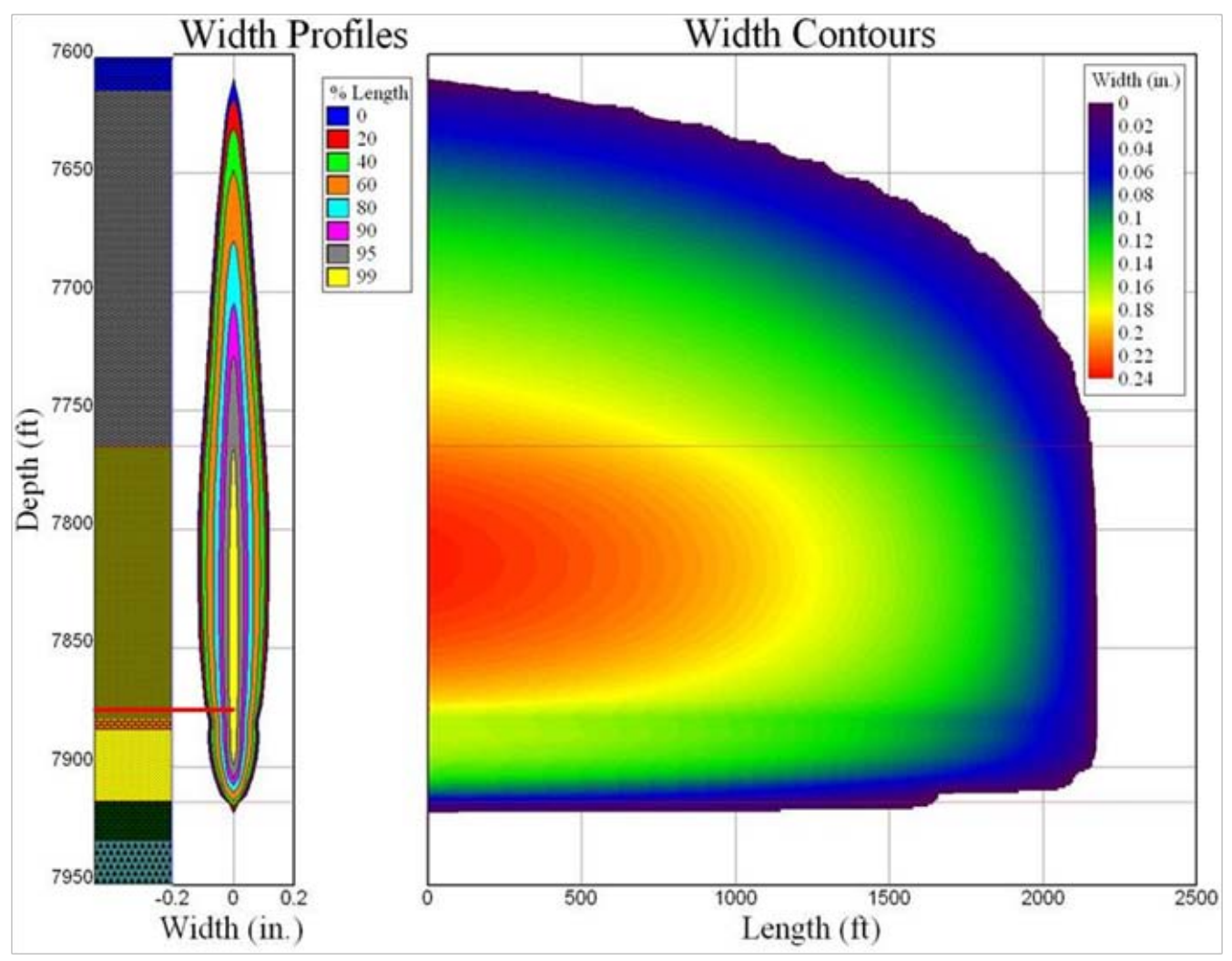

Figure 4.4: Width Profiles and Contours for Case 1

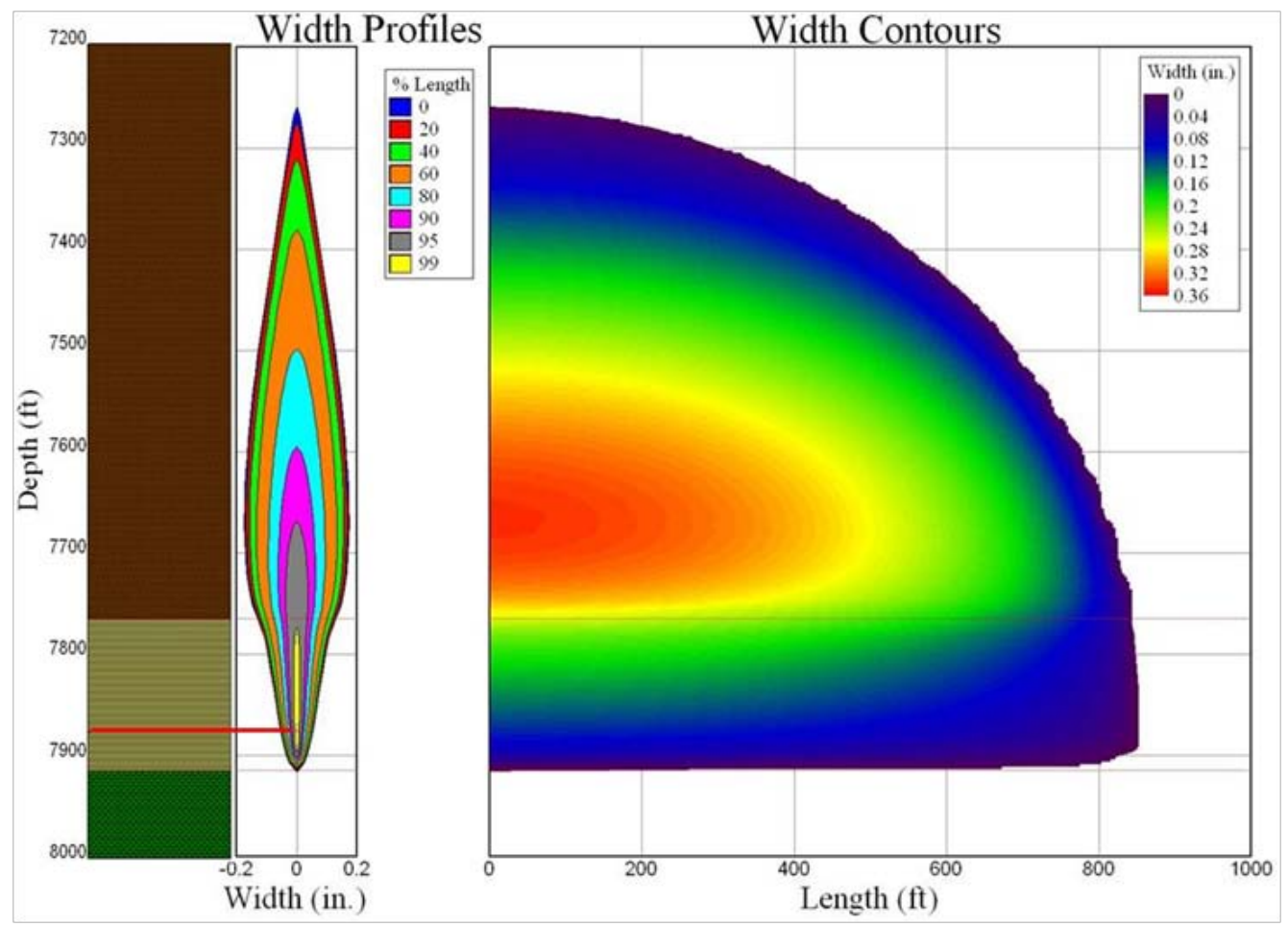

Figure 4.5: Width Profiles and Contours for Case 2 


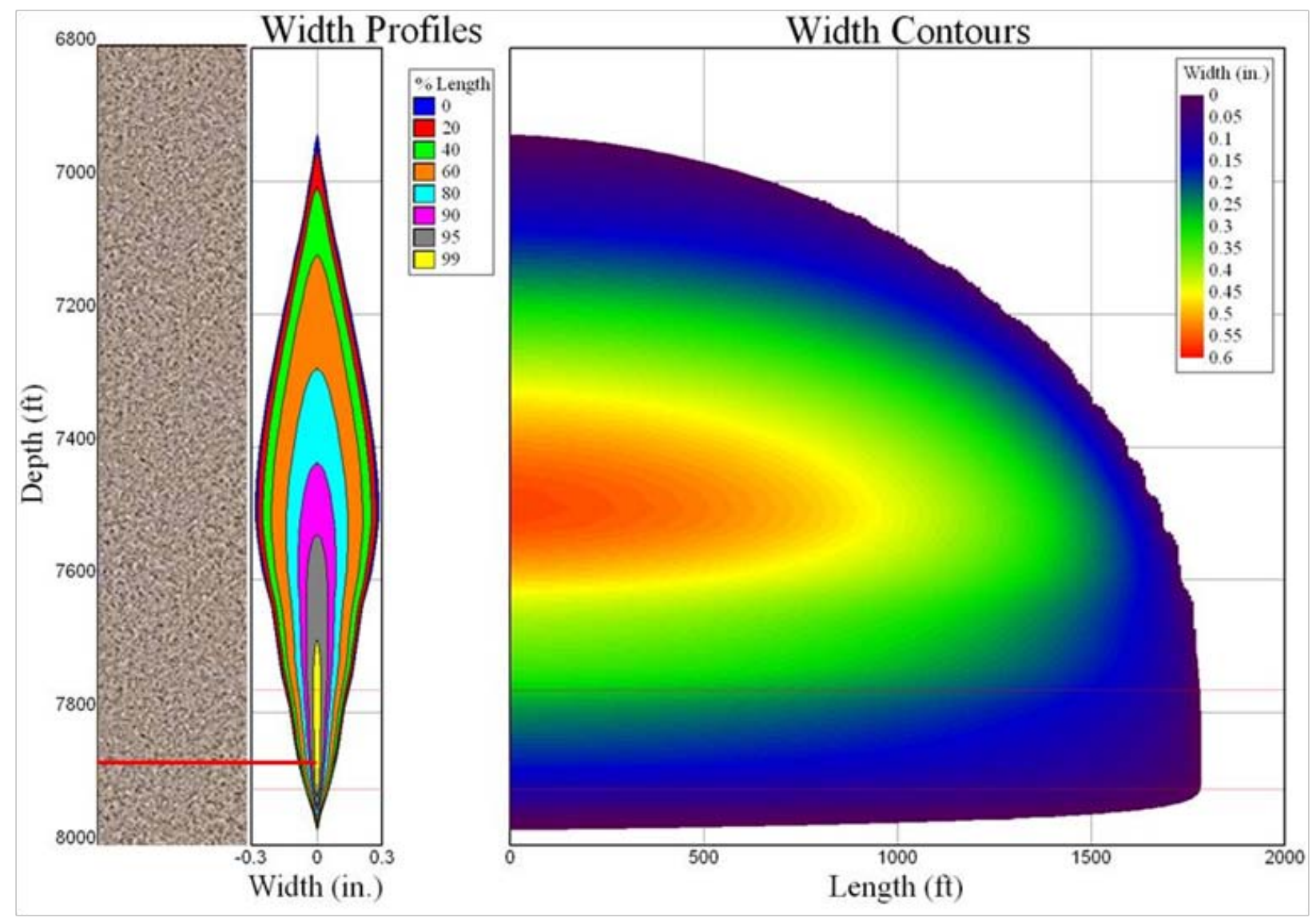

Figure 4.6: Width Profiles and Contours for Case 3

Table 4.3: Numerical Values of Fracture Dimensions for the Three Cases

\section{Case $\quad$ Fracture Half-Length (ft) $\quad$ Fracture Width (in) $\quad$ Fracture Height (ft)}

\begin{tabular}{|c|c|c|c|}
\hline 1 & 2177 & 0.1833 & 309.4 \\
\hline 2 & 853.2 & 0.1079 & 657 \\
\hline 3 & 637.5 & 0.0809 & 949.7 \\
\hline
\end{tabular}

As can be noted from the figures and the numerical values in the above table, as the homogeneity of the layers are increases, the fracture length and width are reduced, while the fracture height increases. In the natural strata of the Marcellus shale and other shale formations (and geologic strata in general), the formations are extremely heterogeneous. This implies that fractures should be relatively well contained by the heterogeneous nature of geologic strata. 


\subsection{Influence of Poisson's Ratio and Horizontal Stress (Gradient)}

In the numerical model (MFrac) used for simulation, Poisson's ratio may be independently changed, but its affects on fracture propagation are negligible. In reality, Poisson's ratio is linked closely with the stresses in rock. The following equation can be used to relate Poisson's ratio to vertical and horizontal stresses (Jaeger \& Cook, 1979):

$$
\sigma_{H}=\frac{v}{1-v} \sigma_{V}
$$

where $\sigma_{H}$ is the horizontal stress, $v$ is Poisson's ratio, and $\sigma_{V}$ is the vertical stress. The vertical stress can then be calculated using the following equation:

$$
\sigma_{V}=\gamma_{D} h
$$

where $\gamma_{D}$ is the density unit weight, and $\mathrm{h}$ is the depth at the midpoint of the layer in question.

In this section and the rest of this chapter, the base case defined in Table 4.2 is used as a starting point for comparisons. Figure 4.7 shows the base case with its dimensions of 1875 feet in length, 0.1708 inches in width, and 307.8 feet in height.

For the determination of the effects of Poisson's ratio on fracture propagation, Equations 4.1 and 4.2 were used to calculate the corresponding stresses based on the given geologic strata. Table 4.4 shows the calculations used to find the horizontal stresses. The density unit weight values were found based on Zhu (2013). These density unit weights were multiplied by the midpoint of each layer to find the vertical stress as shown in Equation 4.2. The vertical stress was then input into Equation 4.1 to find the horizontal stress. 


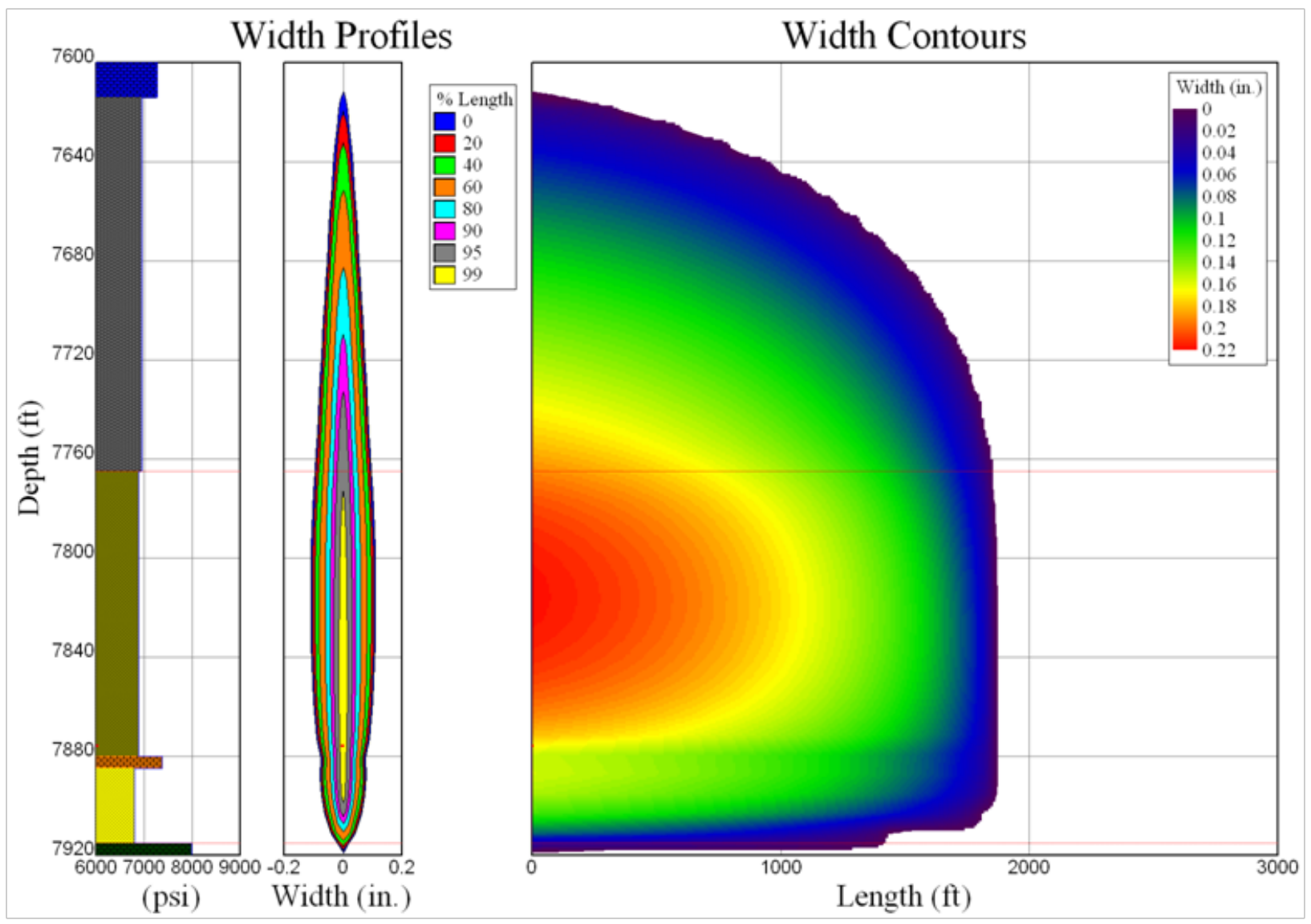

Figure 4.7: Fracture Profile and Contours for the Base Case 
Table 4.4: Horizontal Stress Calculations for Each Layer

\begin{tabular}{|c|c|c|c|c|c|}
\hline Layer & $\begin{array}{c}\text { Midpoint } \\
\text { Depth (ft) }\end{array}$ & $\begin{array}{c}\text { Density } \\
\text { Unit } \\
\text { Weight } \\
(\text { lbf/ft })\end{array}$ & $\begin{array}{c}\text { Vertical } \\
\text { Stress } \\
\text { (psi) }\end{array}$ & $\begin{array}{c}\text { Poisson's } \\
\text { Ratio (-) }\end{array}$ & $\begin{array}{c}\text { Horizontal } \\
\text { Stress (psi) }\end{array}$ \\
\hline Overburden & 3764.0 & 124.9 & 3263.6 & 0.250 & $\mathbf{1 0 8 7 . 9}$ \\
\hline Burkett Shale & 7541.5 & 156.1 & 8173.6 & 0.213 & $\mathbf{2 2 1 2 . 2}$ \\
\hline Tully Limestone & 7584.5 & 168.6 & 8877.8 & 0.248 & $\mathbf{2 9 2 7 . 8}$ \\
\hline Hamilton Shale & 7689.5 & 156.1 & 8334.0 & 0.209 & $\mathbf{2 2 0 2 . 0}$ \\
\hline Upper Marcellus & 7822.5 & 156.1 & 8478.2 & 0.201 & $\mathbf{2 1 3 2 . 8}$ \\
\hline Cherry Valley Limestone & 7882.5 & 168.6 & 9226.7 & 0.260 & $\mathbf{3 2 4 1 . 8}$ \\
\hline Lower Marcellus Shale & 7900.0 & 156.1 & 8562.2 & 0.187 & $\mathbf{1 9 6 9 . 4}$ \\
\hline Onondaga Limestone & 7923.5 & 168.6 & 9274.7 & 0.249 & $\mathbf{3 0 7 5 . 1}$ \\
\hline Huntersville Chert & 8020.0 & 168.6 & 9387.6 & 0.250 & $\mathbf{3 1 2 9 . 2}$ \\
\hline
\end{tabular}

Since the numerical model (MFrac) does not automatically calculate the horizontal stress based on new Poisson's ratio values, the values for horizontal stress were input into the model (MFrac) to reevaluate the fracture propagation. Figure 4.8 shows the results of the simulation with the modified stresses based on the Poisson's ratio values. 


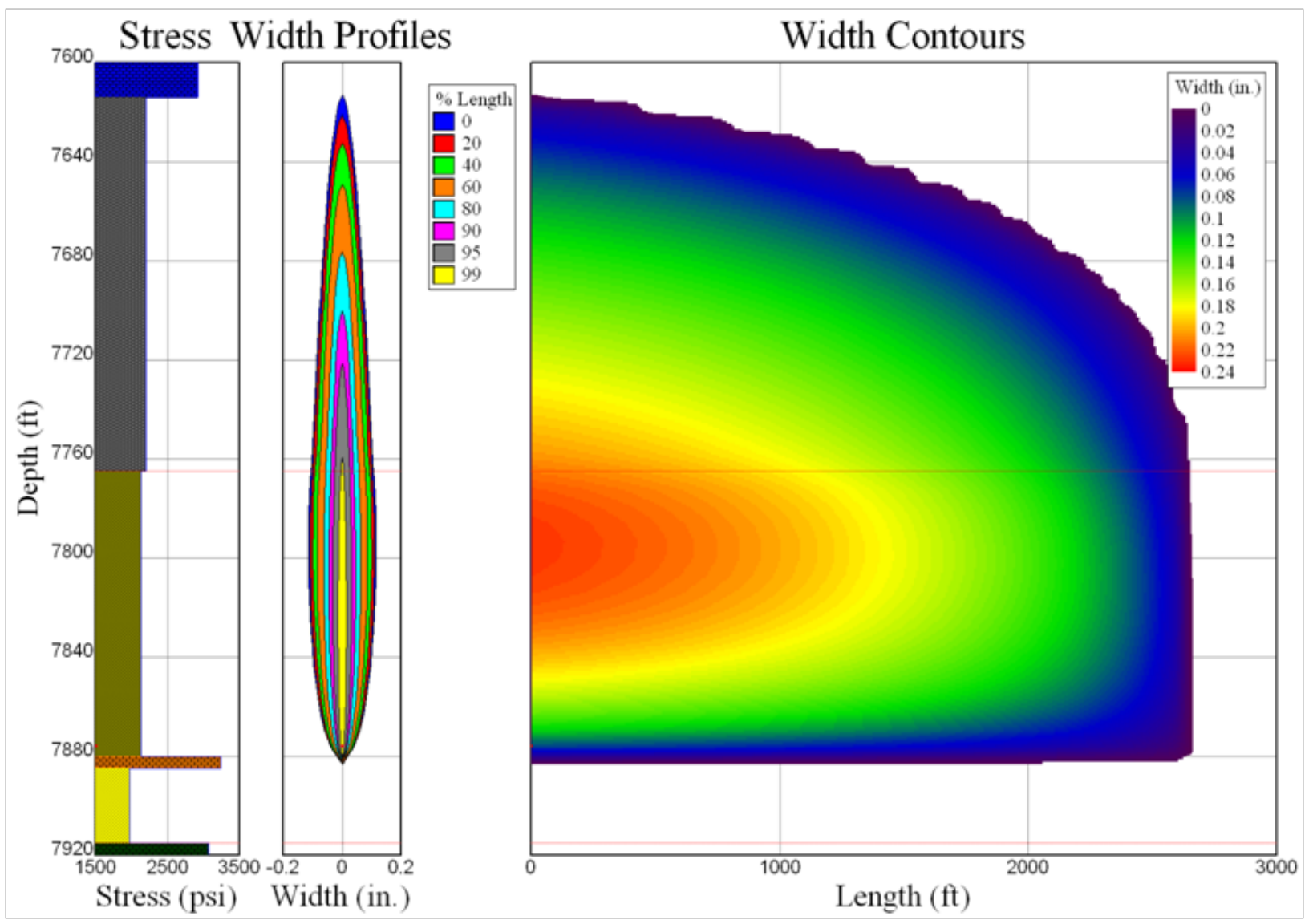

Figure 4.8: Width Profiles and Contours for the Modified Stress Case

The results from the modified stress and base cases, in numerical form, are presented in Table 4.5.

Table 4.5: Numerical Fracture Dimensions for the Base and Modified Stress Cases

\begin{tabular}{|c|c|c|}
\hline Fracture Dimension & Original Case & Modified Stress Case \\
\hline Length $(\mathrm{ft})$ & 1875 & 2662 \\
\hline Width $(\mathrm{in})$ & 0.1708 & 0.0821 \\
\hline Height $(\mathrm{ft})$ & 307.8 & 270.5 \\
\hline
\end{tabular}

As can be seen from the results presented in Table 4.5, there is a significant difference between the two cases. In the first case, Poisson's ratio and horizontal stress values taken from 
well logs were used. In the second case, the same Poisson's ratio values from the logs and used independently calculated stress values were used. The primary difference between the cases, which affects all fracture dimensions, is the stress difference between the Upper Marcellus and Cherry Valley layers. This stress difference acts to limit fracture propagation in the vertical direction. This decreases the fracture height, and increases the fracture length significantly. The horizontal stresses calculated from the Poisson's Ratio equation (Equation 4.1) are quite different, and much smaller than those which would be expected at such depths. This means that the calculations done here do not account for the complexity of the geology (tectonic stress, pore/reservoir pressure). Even though the stresses may be low, they are still proportional to one another based on the values of Poisson's ratio. Results shown in Table 4.3 give some insight into the effects of Poisson's ratio on and horizontal stresses and, hence, the fracture propagation.

Now that the link between Poisson's ratio and horizontal stresses has been established, the focus can be shifted to the impacts of horizontal stress (gradient) on fracture propagation. First, it is necessary to know the difference between horizontal stress and horizontal stress gradient. Horizontal stress is simply the maximum stress in the horizontal plane at a given depth. Horizontal stress gradient is the rate at which horizontal stress increases per vertical foot of depth. The horizontal stress gradient will be discussed for its effects on fracture propagation in this section.

The horizontal stress gradient was varied using the base case (defined in Table 4.2) as a starting point as previously discussed. The gradient was varied in the Tully Limestone layer, because it is assumed to be the bounding layer for vertical fracture propagation for the base case. Figures 4.9 through 4.15 show the results of fracture modeling for various notable horizontal fracture gradients investigated. The following stress gradients were used in the Tully Limestone to determine the effects of horizontal stress gradient on fracture propagation: 0.955 (base case), $0.94,0.93,0.92,0.91,0.9,0.75,0.5,0.25$, and 0.00013134 (lowest gradient possible in the program) psi/ft. 


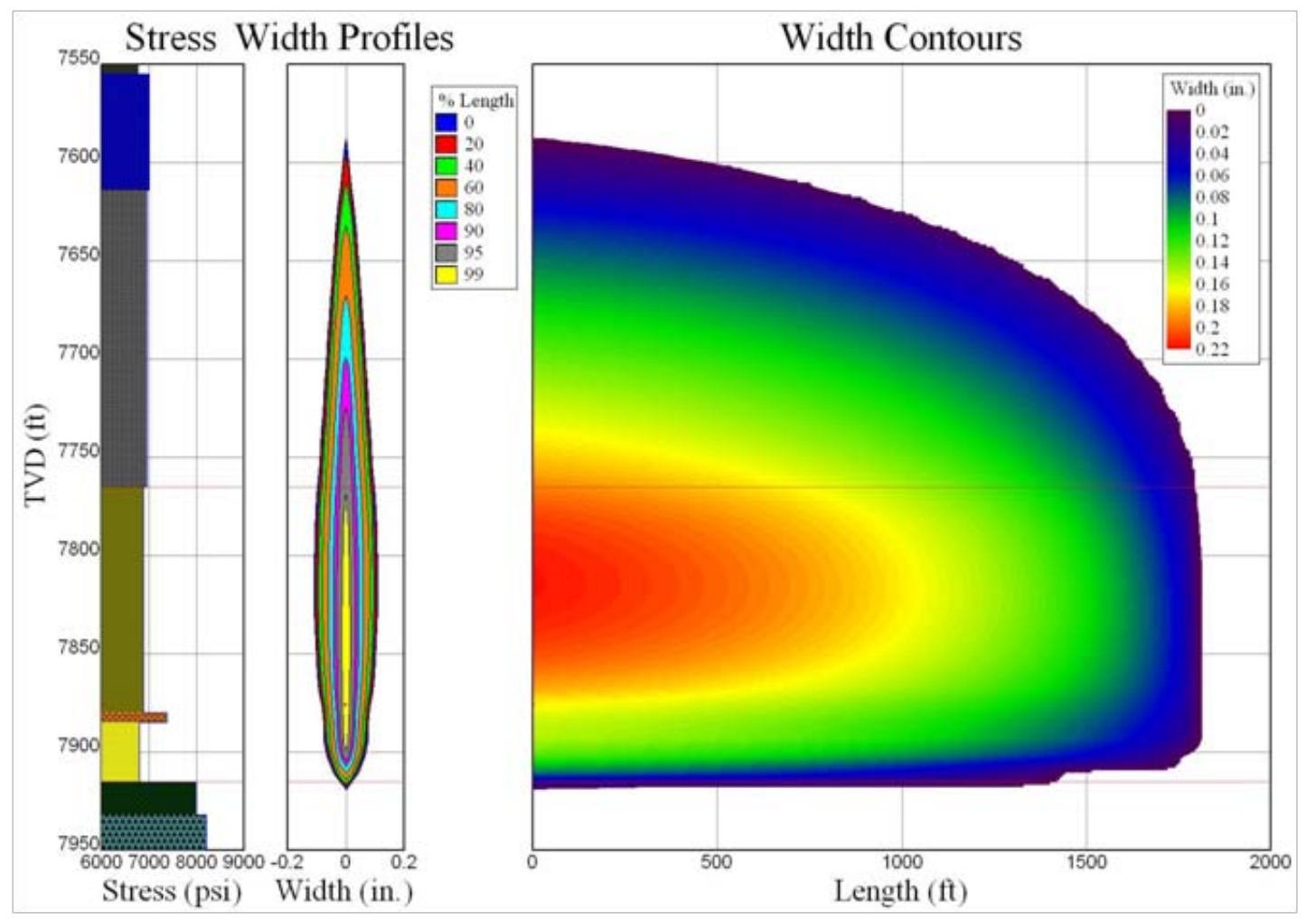

Figure 4.9: Width Profiles and Contours for Horizontal Stress Gradient $=0.92 \mathrm{psi} / \mathrm{ft}$

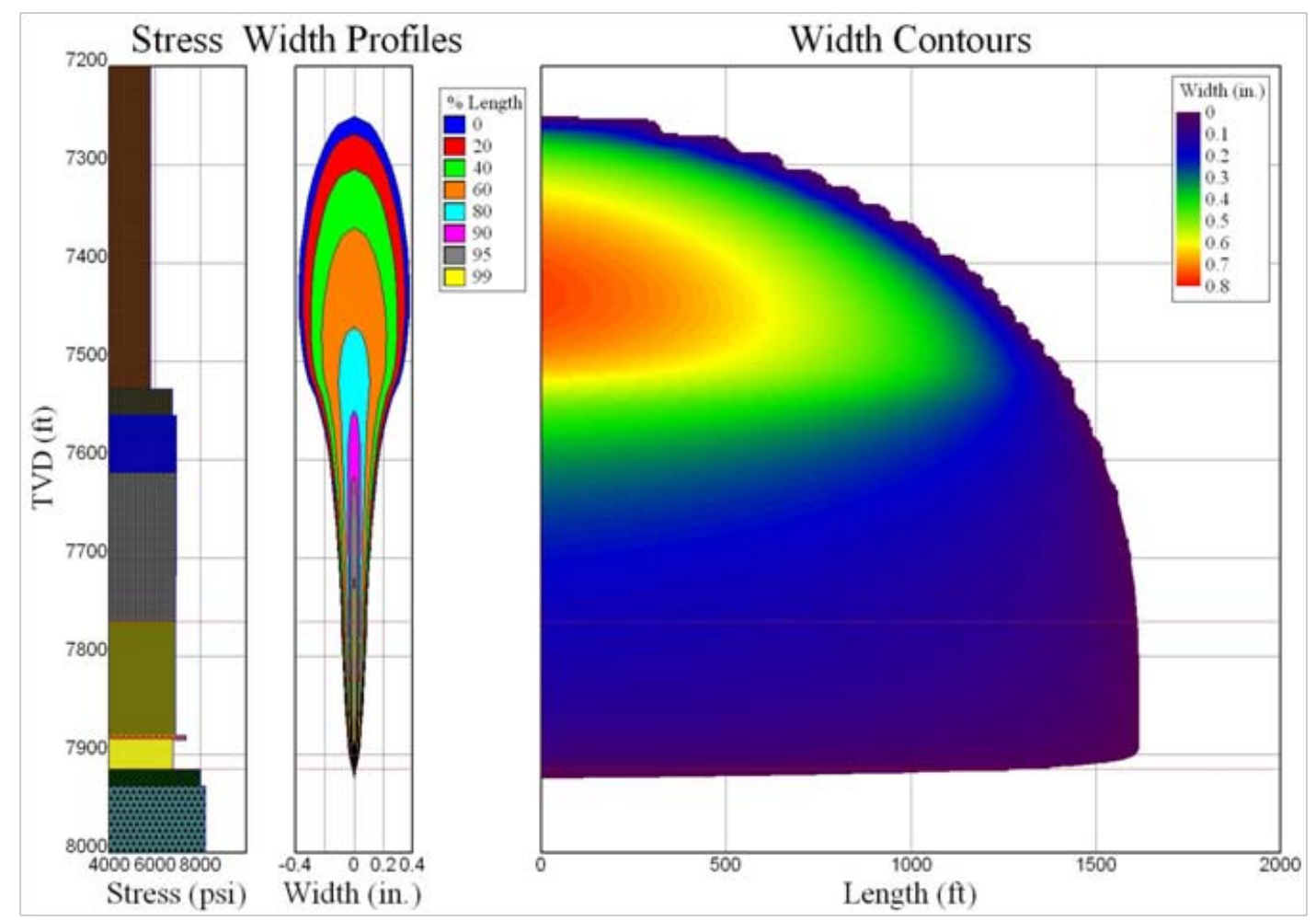

Figure 4.10: Width Profiles and Contours for Horizontal Stress Gradient $=0.91 \mathrm{psi} / \mathbf{f t}$ 


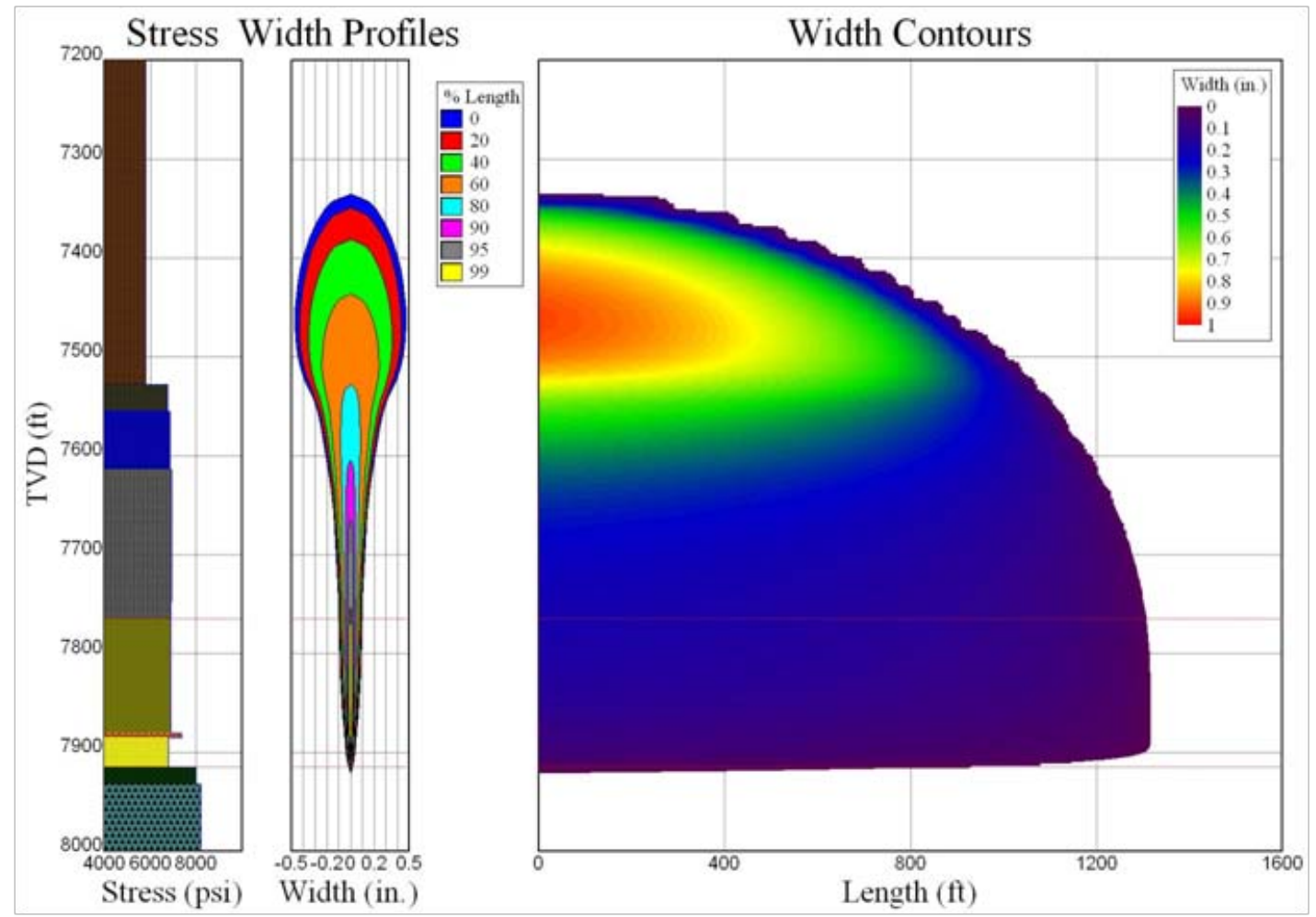

Figure 4.11: Width Profiles and Contours for Horizontal Stress Gradient $=0.9 \mathrm{psi} / \mathrm{ft}$

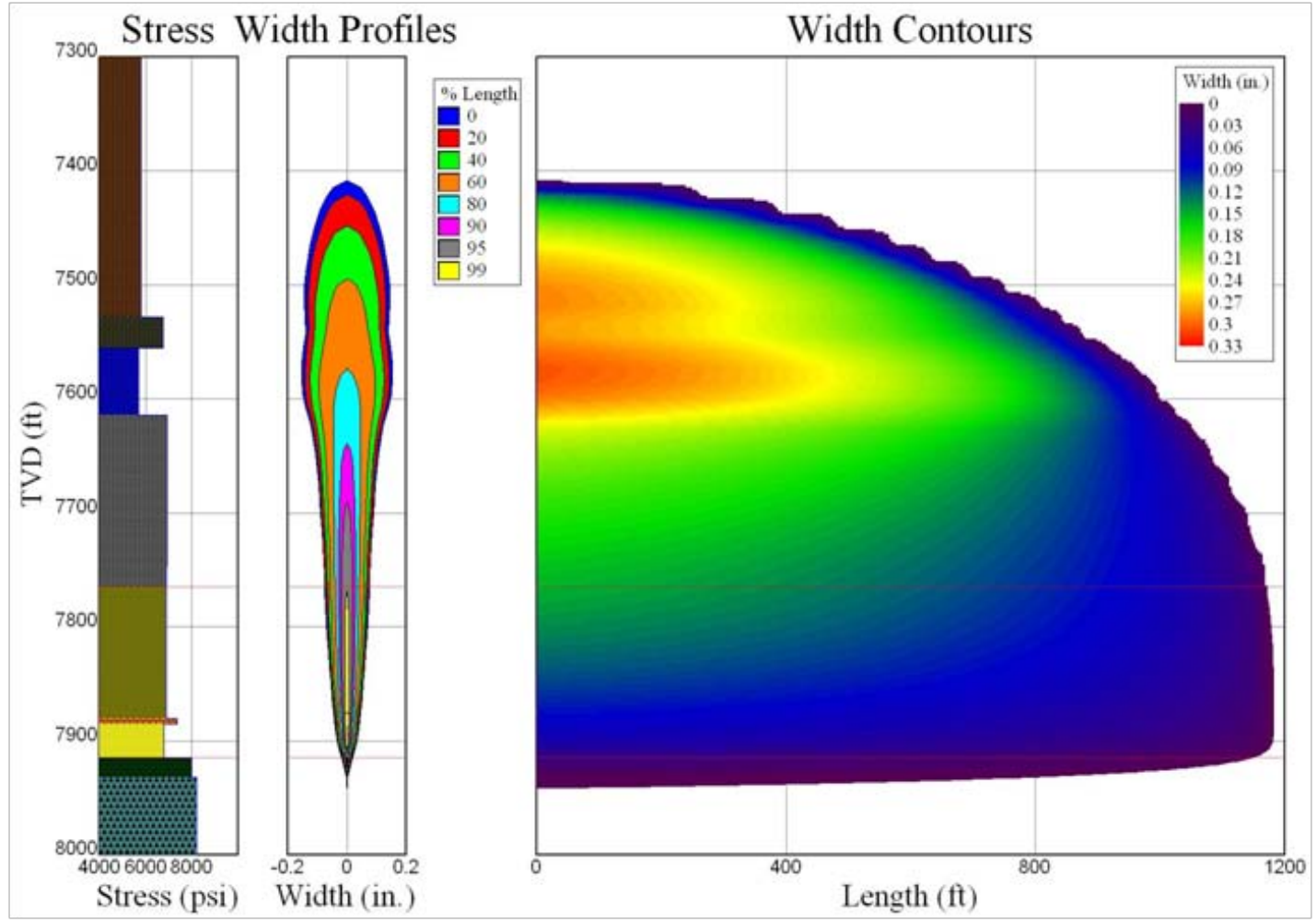

Figure 4.12: Width Profiles and Contours for Horizontal Stress Gradient $=0.75 \mathrm{psi} / \mathrm{ft}$ 


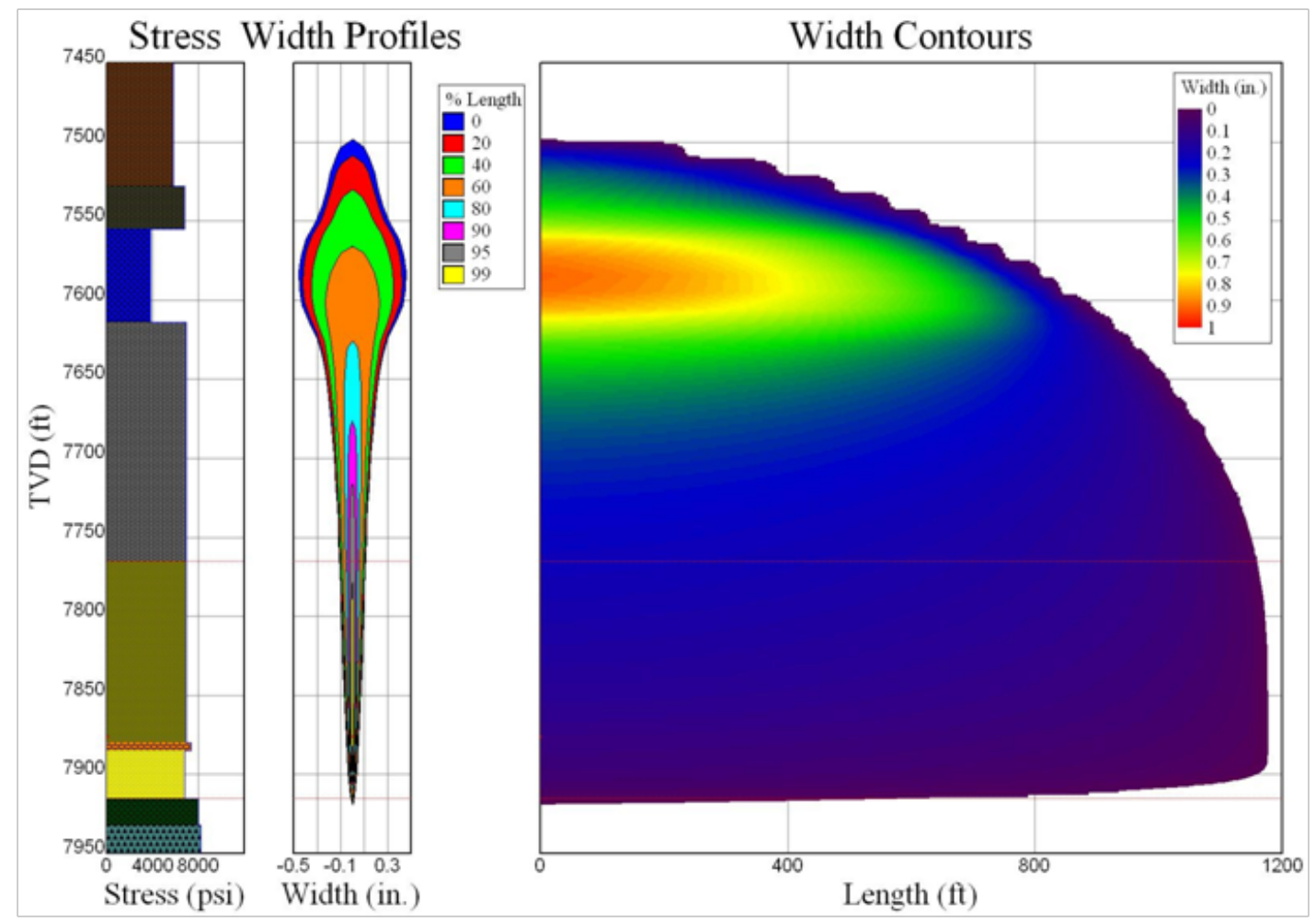

Figure 4.13: Width Profiles and Contours for Horizontal Stress Gradient $=0.50 \mathrm{psi} / \mathrm{ft}$

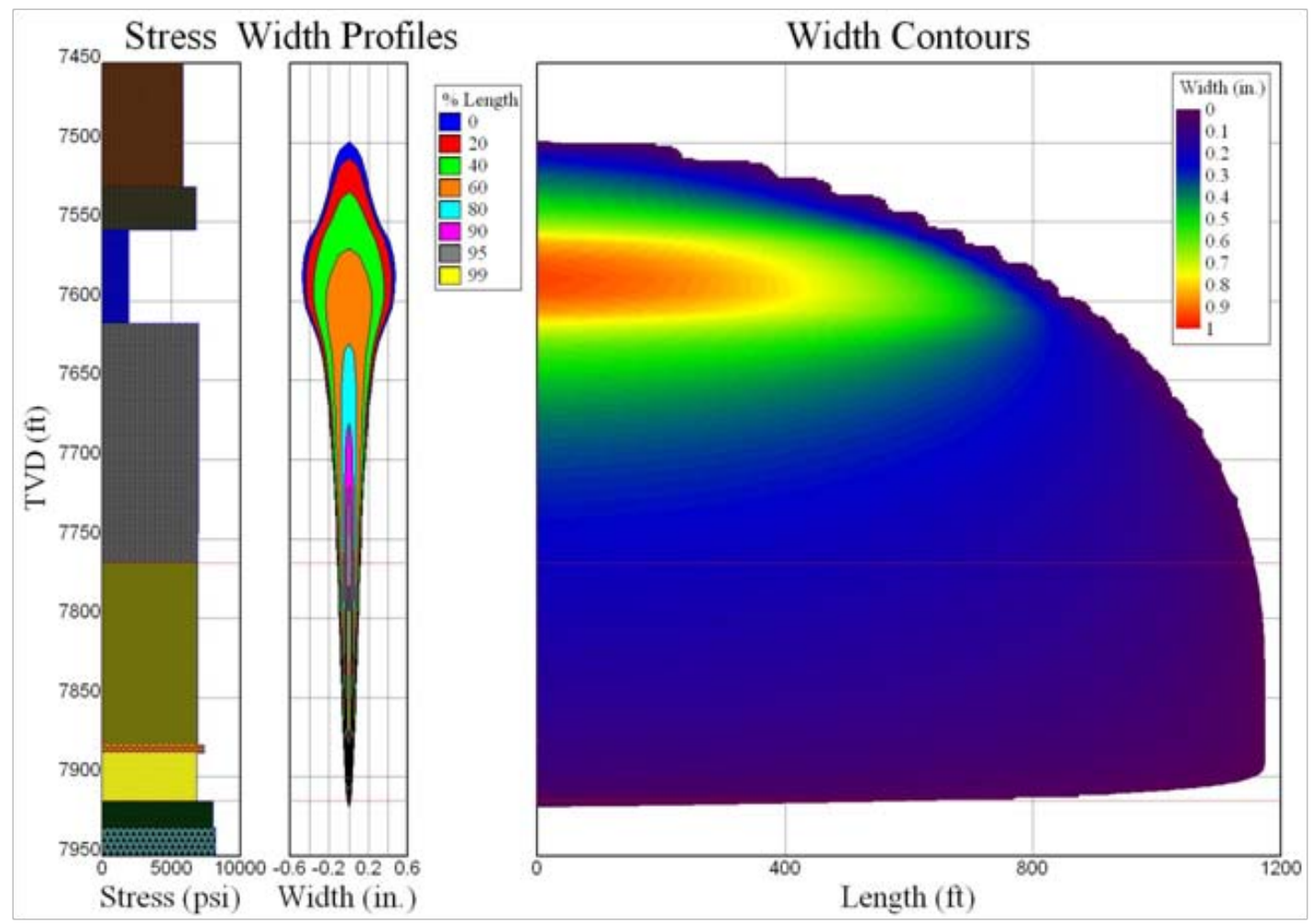

Figure 4.14: Width Profiles and Contours for Horizontal Stress Gradient $=0.25$ psi/ft 


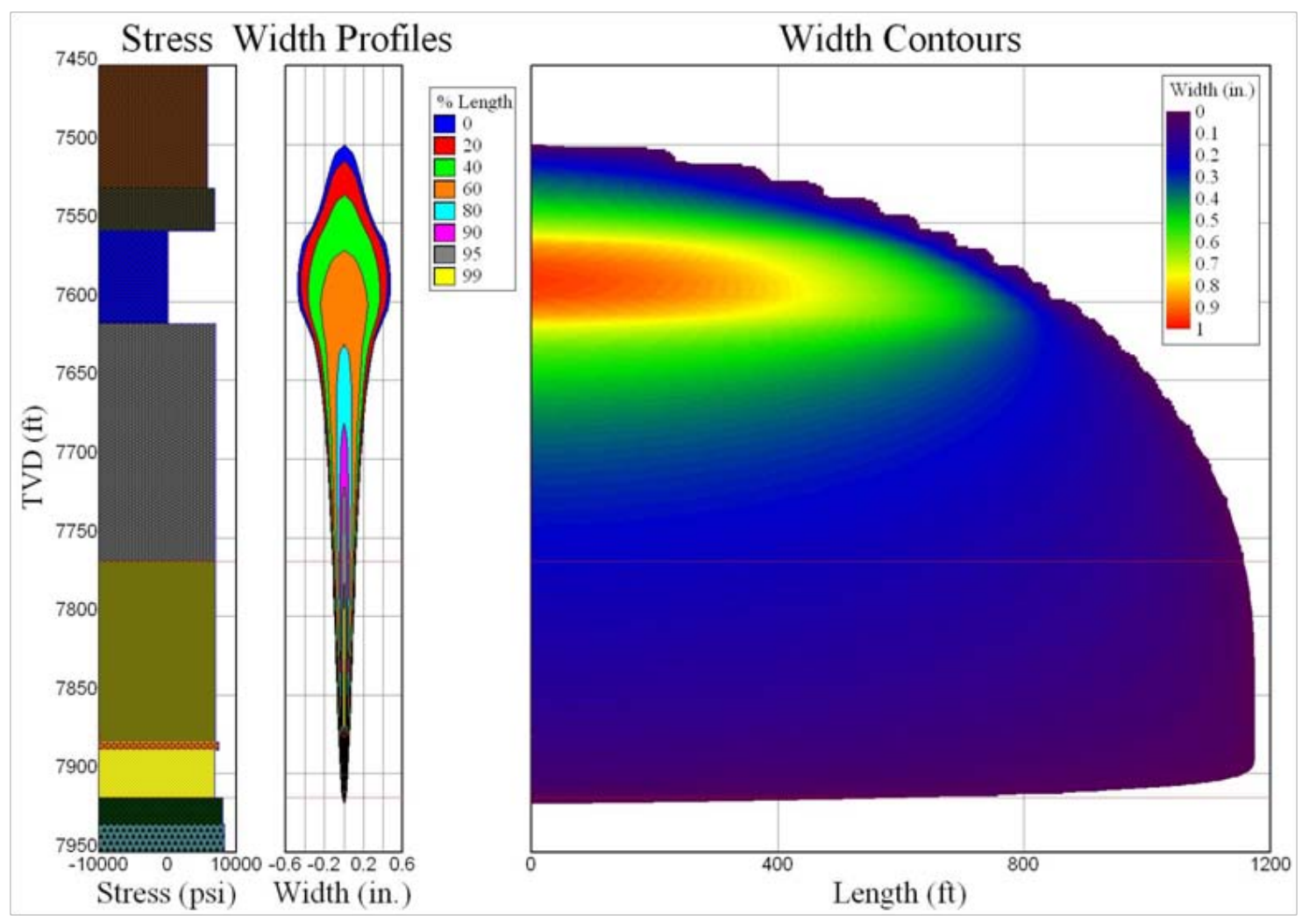

Figure 4.15: Width Profiles and Contours for Horizontal Stress Gradient $=\mathbf{0 . 0 0 0 1 3 1 3 4}$ psi/ft

Figure 4.16 and Table 4.6 show the graph and table, respectively, which compare the fracture height with the horizontal stress gradient. 


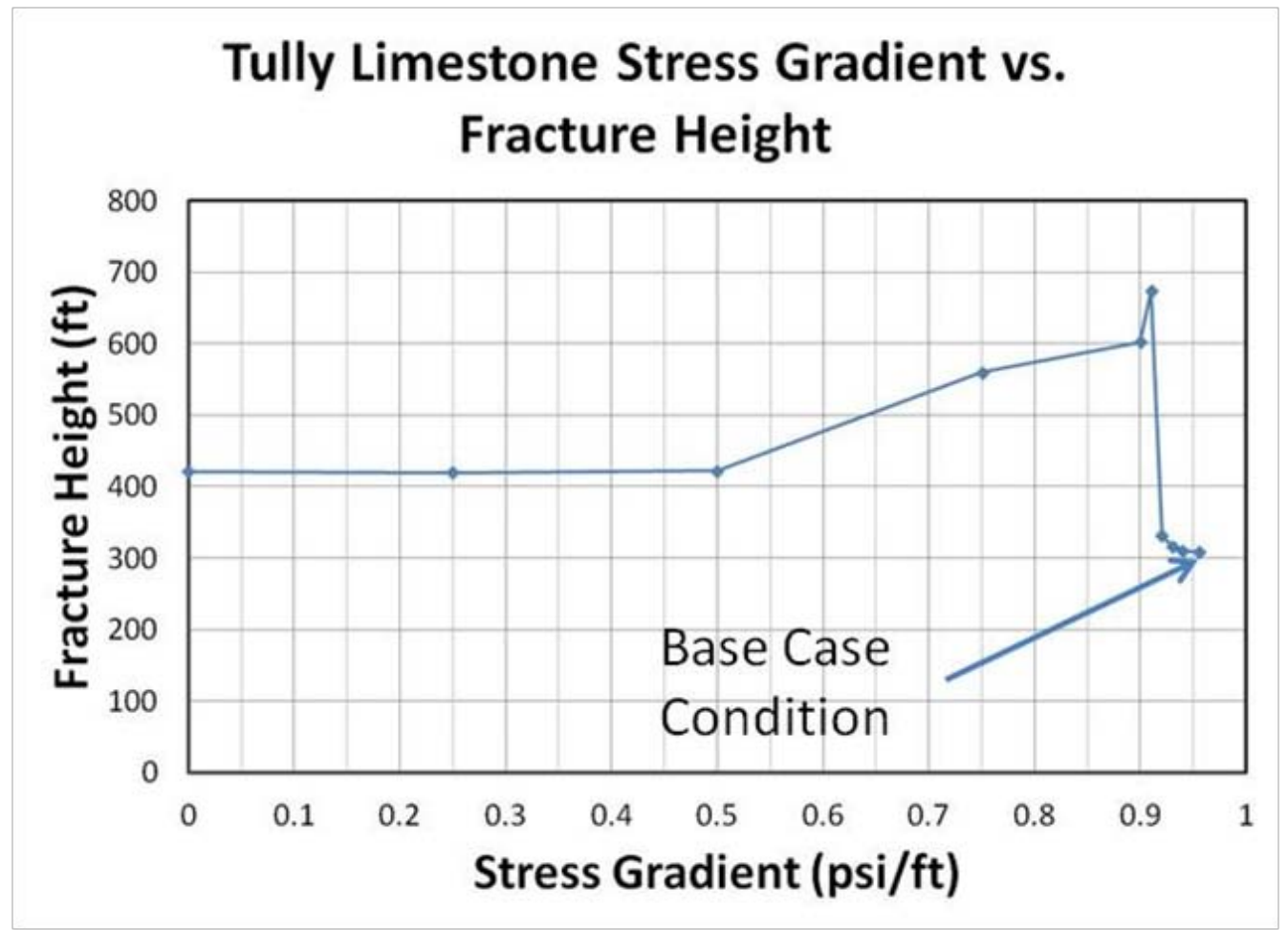

Figure 4.16: Horizontal Stress Gradient in Tully Limestone vs. Fracture Height

Table 4.6: Horizontal Stress Gradient in Tully Limestone and Computed Fracture Height

\begin{tabular}{|c|c|}
\hline Stress Gradient (psi/ft) & Fracture Height (ft) \\
\hline 0.955 & 307.8 \\
\hline 0.940 & 310.7 \\
\hline 0.930 & 316.0 \\
\hline 0.920 & 332.0 \\
\hline 0.910 & 673.6 \\
\hline 0.900 & 602.6 \\
\hline 0.750 & 559.9 \\
\hline 0.500 & 421.7 \\
\hline 0.250 & 420.1 \\
\hline 0.00013134 & 421.4 \\
\hline
\end{tabular}


The following statements can be concluded based on the simulations performed with the horizontal stress gradient:

- Decreases in the horizontal stress gradient will allow for a fracture in a given layer to extend further into that layer.

- Once a fracture has fully extended through a layer, further deceases in the horizontal stress gradient will allow the fracture to extend to a certain point above that layer.

- If the horizontal stress gradient in a given layer becomes too low, the fracture will begin to propagate further in the horizontal direction, and will not extend as high in the vertical direction.

- The horizontal stress gradient difference between layers has a great impact on fracture propagation. The closer two adjacent layers are to one another in terms of their horizontal stress gradient, the more easily a fracture will be able to propagate through that layer.

- A lower horizontal stress gradient layer above a higher one will allow the fracture to propagate into it and then propagate horizontally within the layer.

- A higher horizontal stress gradient layer above a lower one will only allow fracture propagation into that layer marginally (if the gradient difference is large enough).

- Fractures were able to propagate above the Tully Limestone for a decrease in horizontal stress gradient of about $0.04 \mathrm{psi} / \mathrm{ft}$ from the base value of $0.955 \mathrm{psi} / \mathrm{ft}$. This is realistic for the stress gradient to decrease this much due to potential layer non-homogeneity or natural fractures. 


\subsection{Influence of Young's Modulus and Fracture Toughness}

The Young's Modulus was varied using the base case (as defined in Table 4.2) as a starting point as previously discussed. The modulus was varied in the Tully Limestone layer, because it is assumed to be the bounding layer for vertical fracture propagation for the base case. Figure 4.17 shows the results of the fracture modeling for the lowest modulus case investigated. Table 4.7 shows the Elastic Modulii cases used for the Tully Limestone to determine the influence of Young's Modulus on fracture propagation.

Table 4.7: Elastic Modulii Cases

\begin{tabular}{|c|c|}
\hline Case & Elastic Modulus $\left(\mathrm{x} 10^{5} \mathrm{psi}\right)$ \\
\hline $\mathrm{Y}_{1}$ & 0.993 \\
\hline $\mathrm{Y}_{2}$ & 4.93 \\
\hline $\mathrm{Y}_{3}$ & 9.93 \\
\hline $\mathrm{Y}_{4}$ & 49.3 \\
\hline
\end{tabular}




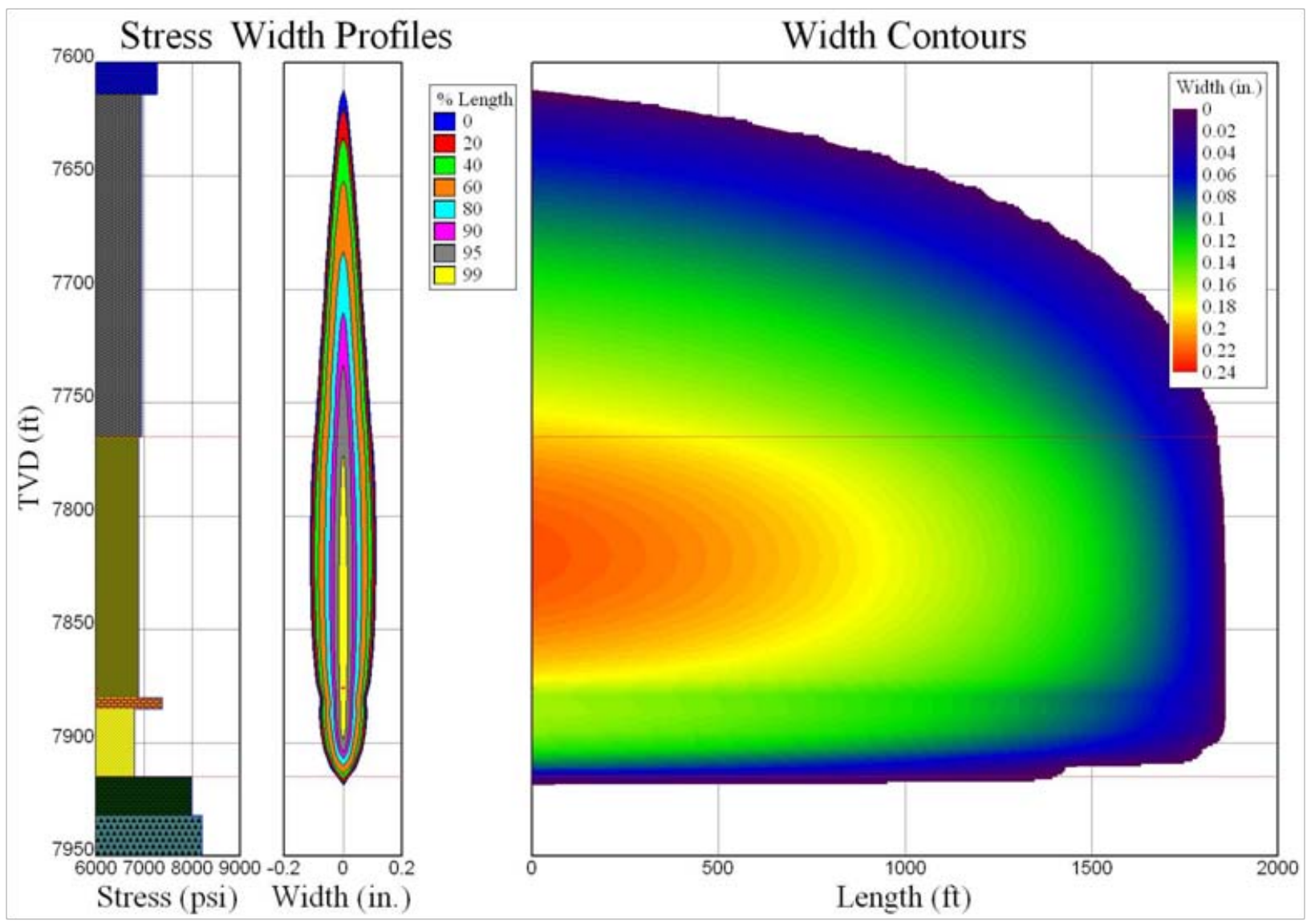

Figure 4.17: Width Profiles and Contours for Young's Modulus - Case $Y_{1}$

Figure 4.18 and Table 4.8 show the graph and table, respectively, which compare the variation of fracture height with the Young's Modulus value. 


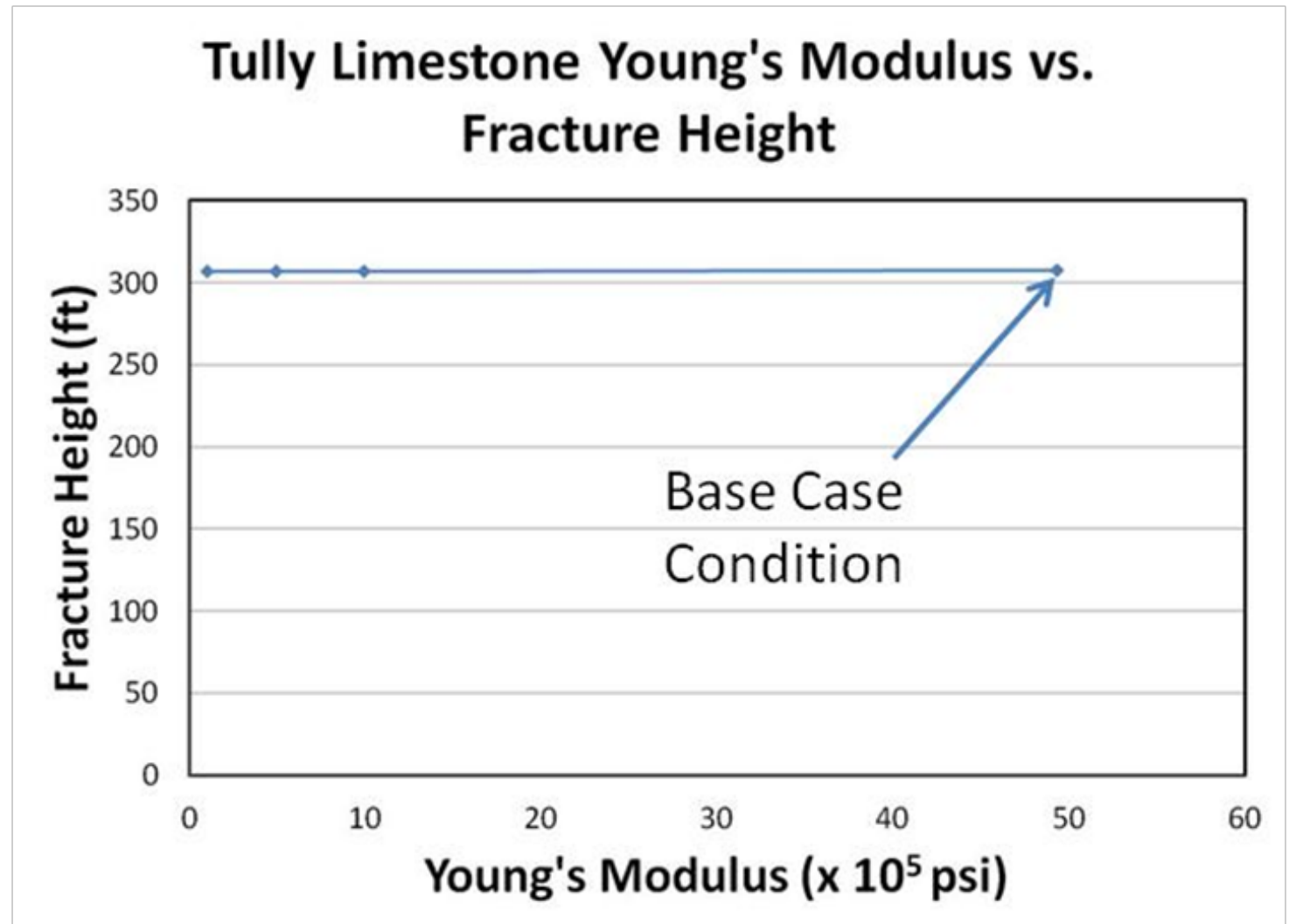

Figure 4.18: Young's Modulus of the Tully Limestone vs. Fracture Height

Table 4.8: Young's Modulus of the Tully Limestone vs. Computed Fracture Height

\begin{tabular}{|c|c|}
\hline Young's Modulus (E+05 psi) & Fracture Height (ft) \\
\hline 0.993 & 306.9 \\
\hline 4.93 & 306.9 \\
\hline 9.93 & 307.0 \\
\hline 49.3 & 307.8 \\
\hline
\end{tabular}


The fracture toughness was also varied using the base case as a starting point as previously discussed. Fracture toughness is defined as the measure of a material's resistance to the propagation of a fracture (Meyer \& Associates, Inc., 2012). Fracture toughness may be found using the following equation:

$$
K_{I C}=T \sqrt{\pi a_{c}}
$$

where $K_{I C}$ is the fracture toughness, $\mathrm{T}$ is the tensile strength of the material, and $a_{c}$ is the area of the largest defect in the material. The units of fracture toughness are usually psi-in ${ }^{0.5}$ or kPa-m ${ }^{0.5}$.

The fracture toughness was varied in the Tully Limestone layer, because it is assumed to be the bounding layer for vertical fracture propagation for the base case (as defined in Table 4.2; the same geologic setting as shown in Figure 3.1). Figure 4.19 shows the width profile for a fracture toughness value of zero. The following fracture toughnesses were used in the Tully Limestone to determine the effects of fracture toughness on fracture propagation: 1120 (base case), 920, 720, 520, 320, and 120 psi-in $^{0.5}$. 


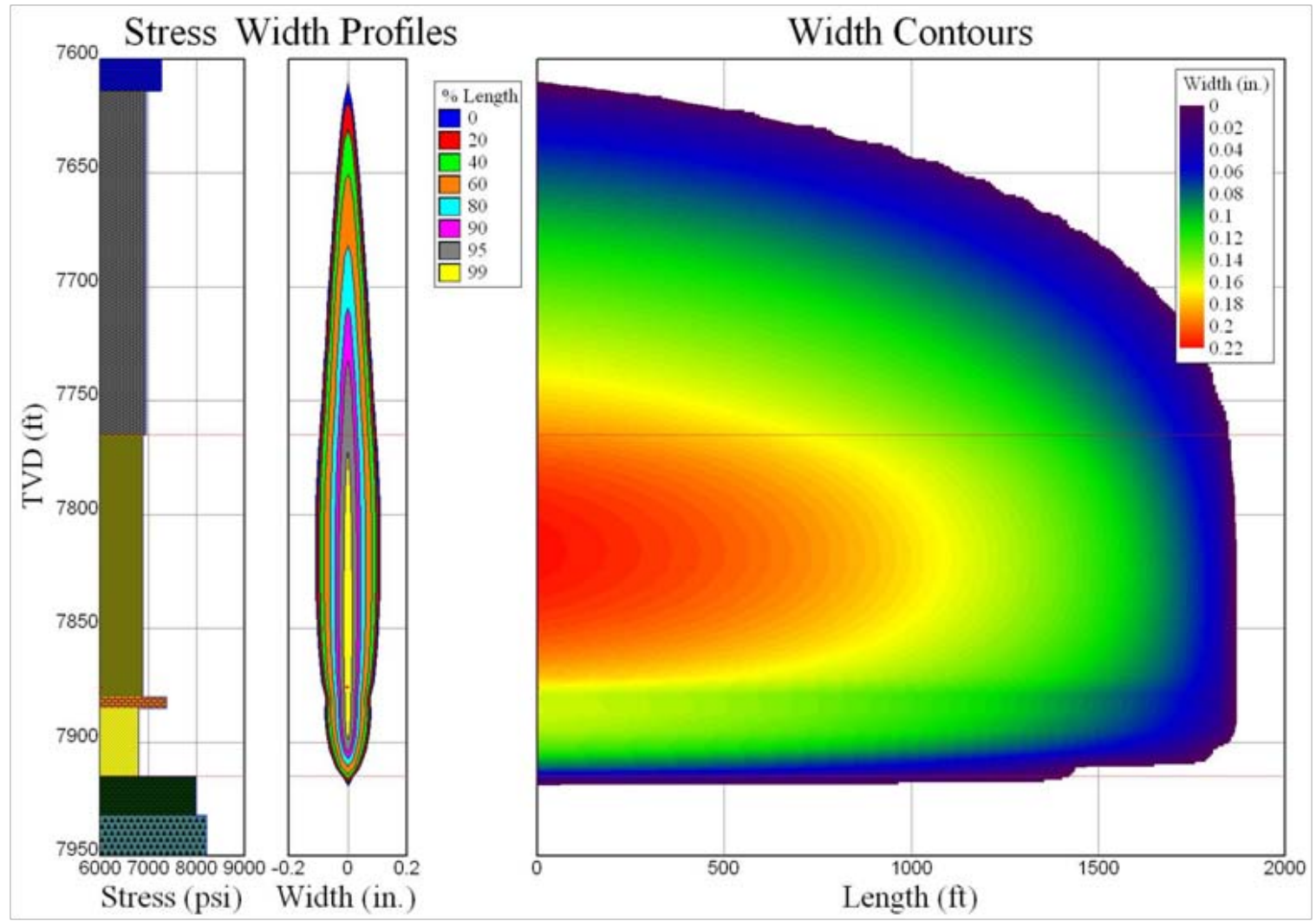

Figure 4.19: Width Profiles and Contours for Fracture Toughness $=0$ psi-in ${ }^{0.5}$

Figure 4.20 and Table 4.9 show the graph and table, respectively, which compare the fracture height with the fracture toughness. 


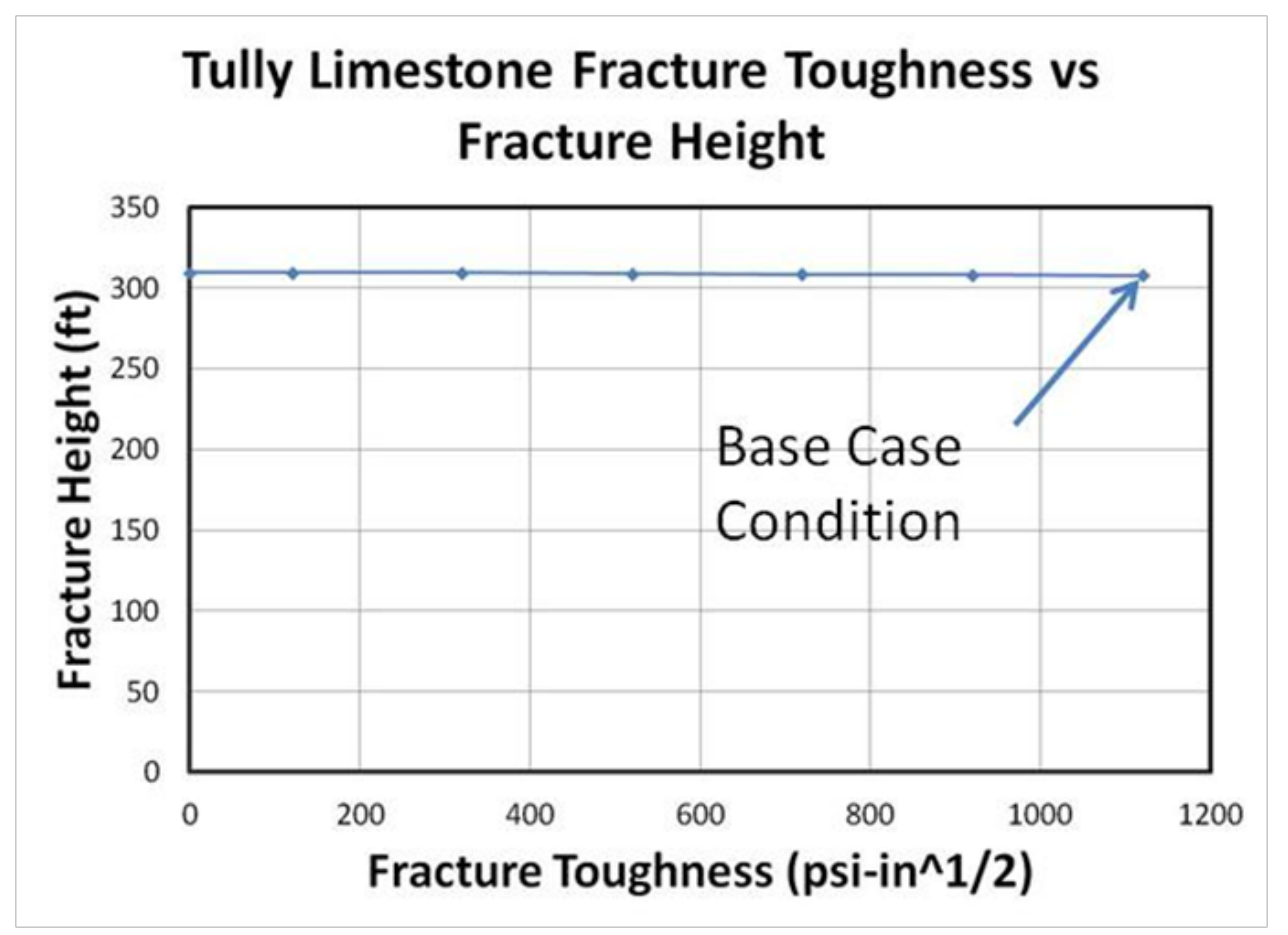

Figure 4.20: Fracture Toughness of the Tully Limestone vs. Fracture Height

Table 4.9: Fracture Toughness of the Tully Limestone vs. Computed Fracture Height

\begin{tabular}{|c|c|}
\hline Fracture Toughness $\left(\right.$ psi-in $\left.^{0.5}\right)$ & Fracture Height (ft) \\
\hline 1120 & 307.8 \\
\hline 920 & 308.1 \\
\hline 720 & 308.5 \\
\hline 520 & 308.9 \\
320 & 309.3 \\
\hline 120 & 309.3 \\
\hline 0 & 309.3 \\
\hline
\end{tabular}


The following statements can be concluded based on the simulations performed with the Young's Modulus and fracture toughness:

- As the Young's Modulus increases, the fracture height increases as well. This makes sense, as it is easier to fracture something stiffer with tensile stress than it is to fracture something softer with a tensile stress.

- As the fracture toughness decreases, the fracture height increases slightly. If the definition of fracture toughness is examined again, it can be noted that fracture toughness is a measure of a material's resistance to the propagation of a fracture. So, it makes sense that materials with a lower fracture toughness will allow fractures to propagate further through them.

- Both of these geomechanical parameters show only a small difference in fracture height due to the fracture only extending partially into the layer.

- None of the simulated fractures were able to propagate above the Tully Limestone for any Young's Modulus or fracture toughness values. Low Young's Modulus and fracture toughness values may signify a naturally fractured layer. These simulations show that neither the Young's Modulus nor the fracture toughness values significantly affect the vertical propagation of a fracture through the Tully Limestone layer. 


\subsection{Influence of Fluid Leakoff Coefficient}

The fluid leakoff coefficient was varied using the base case (as defined in Table 4.2) as a starting point as previously discussed. The leakoff coefficient was varied in the Tully Limestone layer, because it is assumed to be the bounding layer for vertical fracture propagation for the base case. Figure 4.21 shows the results of the fracture modeling for the case with the highest fluid leakoff coefficient. The following leakoff coefficients were used in the Tully Limestone to determine the effects of fluid leakoff coefficient on fracture propagation: $0,0.001,0.01$, and 0.1 $\mathrm{ft} / \min ^{0.5}$.

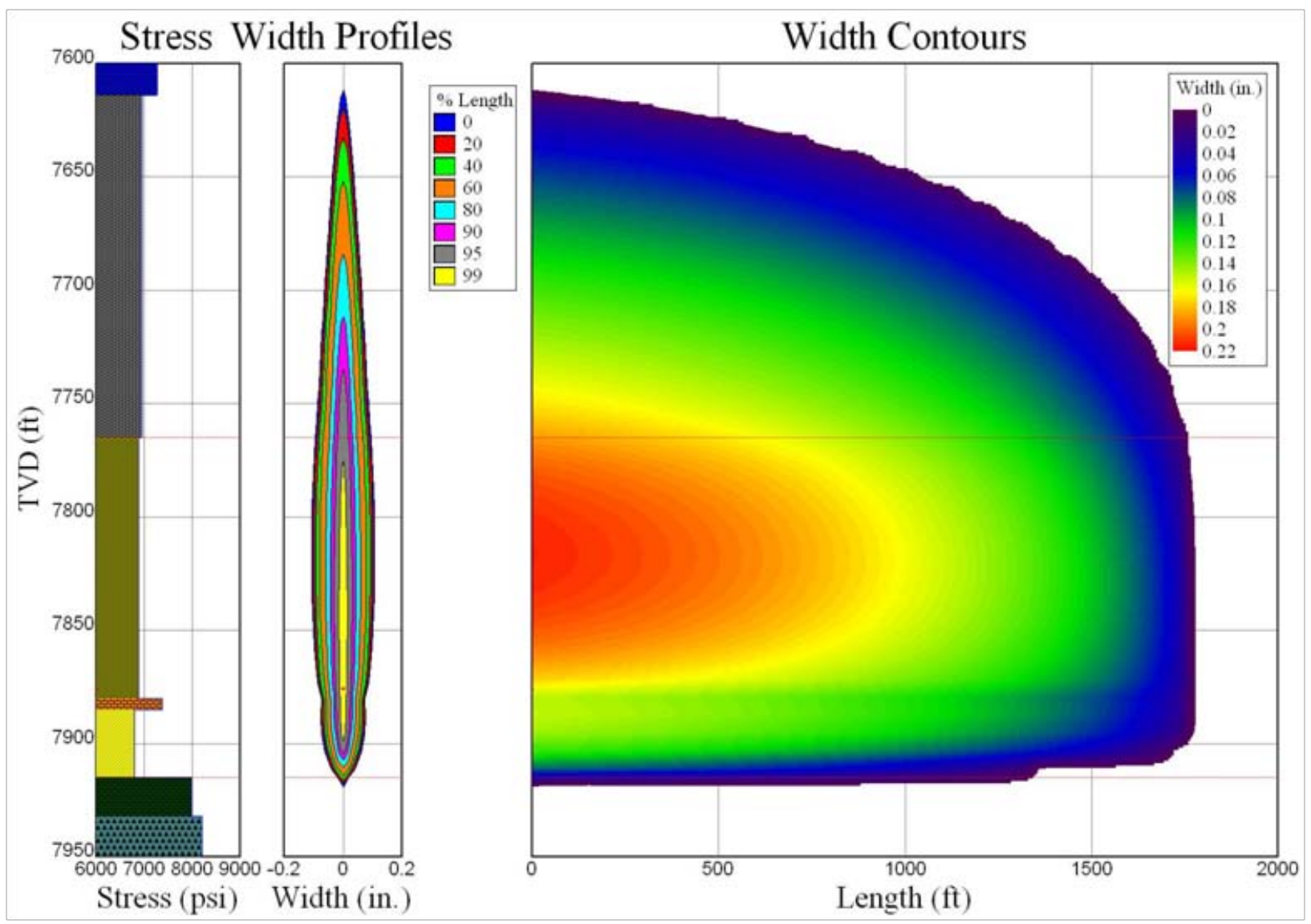

Figure 4.21: Width Profiles and Contours for Fluid Leakoff Coefficient $=0.1 \mathrm{ft} / \mathrm{min}^{0.5}$

Figure 4.22 and Table 4.10 show the graph and table, respectively, which compare the fracture height with the fluid leakoff coefficient. 


\section{Tully Limestone Leakoff Coefficient vs. Fracture Height}

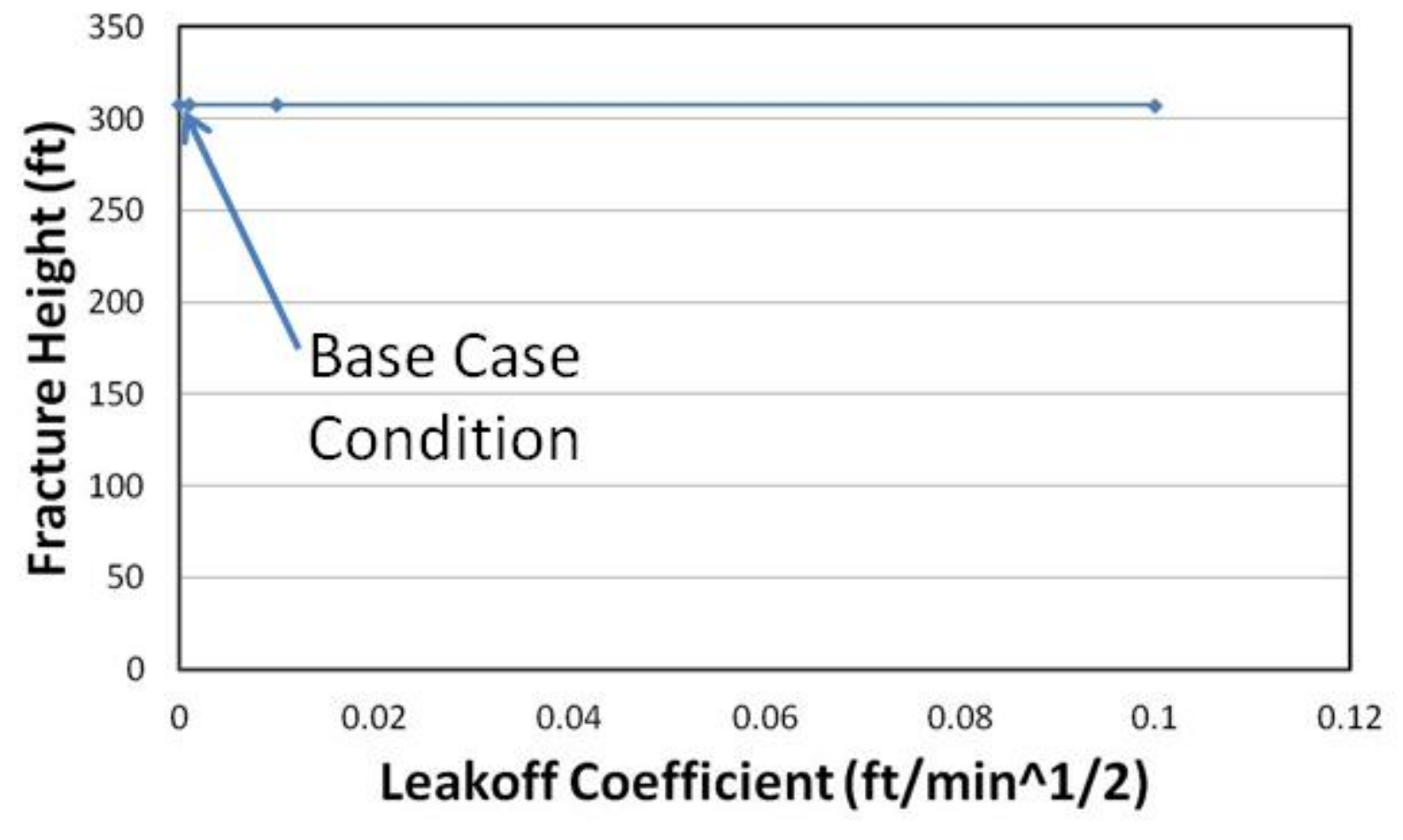

Figure 4.22: Leakoff Coefficient of the Tully Limestone vs. Fracture Height

Table 4.10: Leakoff Coefficient of the Tully Limestone vs. Computed Fracture Height

\section{Leakoff Coefficient (ft/min ${ }^{0.5}$ ) Fracture Height (ft)}

\begin{tabular}{c|c|}
\hline 0 & 307.8 \\
\hline 0.001 & 307.8 \\
\hline 0.01 & 307.7 \\
\hline 0.1 & 307.5 \\
\hline
\end{tabular}


The following statements can be concluded based on the simulations performed with the fluid leakoff coefficient:

- Increased fluid leakoff coefficient in a layer will decrease hydraulic fracture propagation. More fluid will be lost into the formation with a higher leakoff coefficient, and the fluid volume available for fracture growth will be lower and, hence, limit the fracture propagation in vertical direction.

- As with the previous two properties tested, the vertical fracture propagation is only marginally changed, because the fracture extends only partially into the layer. However, the effects of fluid leakoff coefficient are able to be adequately understood.

- A higher leakoff coefficient signifies the presence of natural fractures in the Tully Limestone. This acts to limit vertical fracture growth slightly in the Tully, and shows that a natural fracture would increase fluid leakoff and limit fracture propagation from the hydraulic fracture. 


\section{CHAPTER 5: FRACTURE PROPAGATION IN THE MARCELLUS SHALE USING LATIN HYPERCUBE SAMPLING}

\subsection{Latin Hypercube Sampling}

In order to address the range of geomechanical, geometric, and fluid flow data present across the Marcellus shale in Pennsylvania, New York, and West Virginia, a sampling method was needed to create a set of cases for analysis. Latin Hypercube Sampling was developed to address a need for uncertainty analysis for a specific type of problem. This sampling method was originally developed by McKay, Conover, and Beckman (1979). Latin Hypercube sampling selects "n" different values from each of "k" variables $X_{1}, X_{2}, \ldots, X_{k}$. Each variable's range is divided into " $\mathrm{n}$ " non-overlapping intervals on the basis of equal probability. Then, one value from each interval is selected at random with respect to the probability density in each interval. The "n" values obtained for $X_{1}$ are paired randomly with the "n" values of $X_{2}$. This process continues until "n" k-tuplets are formed. Once all "n" k-tuplets are formed, the Latin Hypercube Sampling is complete (Wyss \& Jorgensen, 1998). This sample forms an "n" by "k" size matrix, which can be used for data input into a computer program, or wherever needed. More information on Latin Hypercube Sampling and its applications can be found elsewhere: (Steck et. al., 1976; Iman et. al., 1981a; Iman et. al., 1981b; Iman and Conover, 1982; and Iman and Helton, 1985). 


\subsection{Sampling Cases and Results}

The cases which are mentioned in this chapter use a geologic column formed closely mimic the geology of the Marcellus regions previously described. Figure 5.1 shows the complete geologic column from the ground surface to the Huntersville Chert, which was considered for modeling purposes in this chapter.

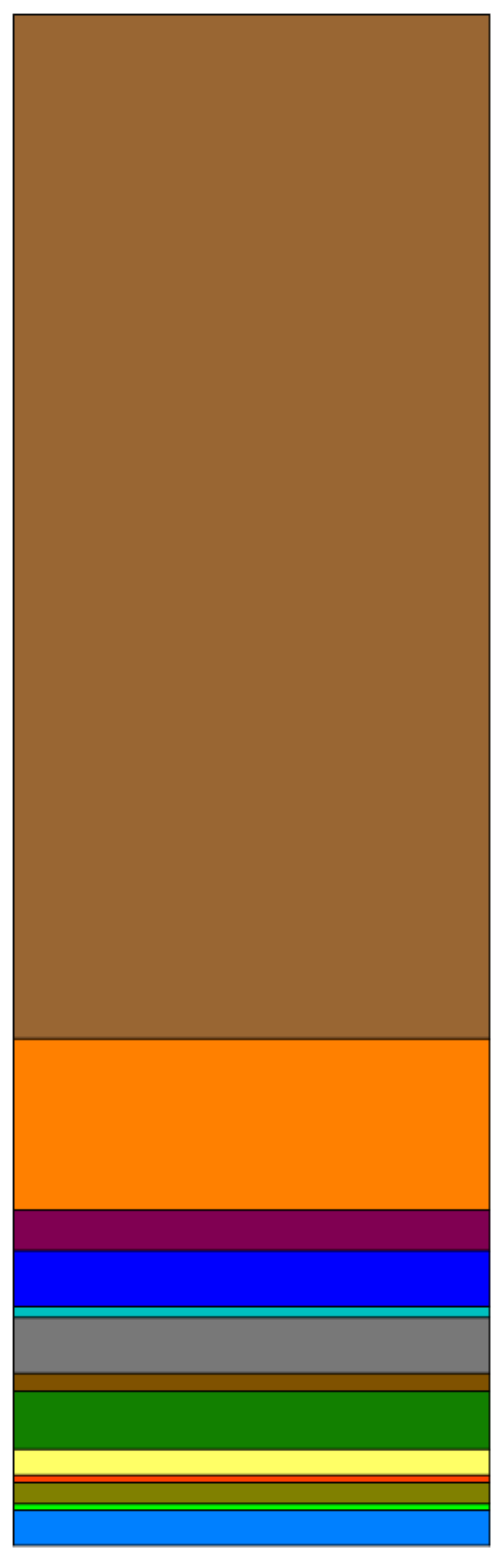

Legend

$\square$ Overburden
Lower Brallier Formation
Rhinestreet Formation
Cashaqua Formation
Middlesex Formation
Burkett Shale
Tully Limestone
Hamilton Shale
$\square$ Upper Marcellus
Cherry Valley Limestone
Lower Marcellus Shale
$\square$ Onondaga Limestone
Huntersville Chert

Figure 5.1: Assumed Geologic Column 
A literature study was performed to compare and evaluate geometric, geomechanical, and fluid flow parameters. A range of probable values for each of the geometric, geomechanical, and fluid flow properties was identified for simulation based on available and unpublished data. Realistic values were assumed based on available literature for injection parameters and kept constant for all injection scenarios. It was assumed that the injection was carried out in the center of the Lower Marcellus layer. After all ranges were identified, the Latin Hypercube Sampling method was used to determine 300 realizations for simulation in the commercial available hydraulic fracturing model, MFrac (Meyer \& Associates, Inc., 2012). The depths of the Marcellus shale formation for each case are shown in Figure 5.3. The thicknesses for the Marcellus shale formation in each case are shown in Figure 5.4. Figure 5.5 shows the Young's (elastic) modulus, stress gradient, and fracture toughness values of the Lower Marcellus layer for each case. Figure 5.6 shows the Poisson's ratio, leakoff coefficient, and thickness of the Lower Marcellus layer for each case.

The depths of the Marcellus layer correspond to those found in the southwest, central, and northeast regions of Pennsylvania, and partially in surrounding states (Marcellus Center for Outreach and Research, 2010). The Marcellus shale reaches shallower depths in northwestern Pennsylvania and in Ohio, but these areas were not the focus of this study. All properties selected were assumed to represent those of the formations found in these regions of the Marcellus shale. 


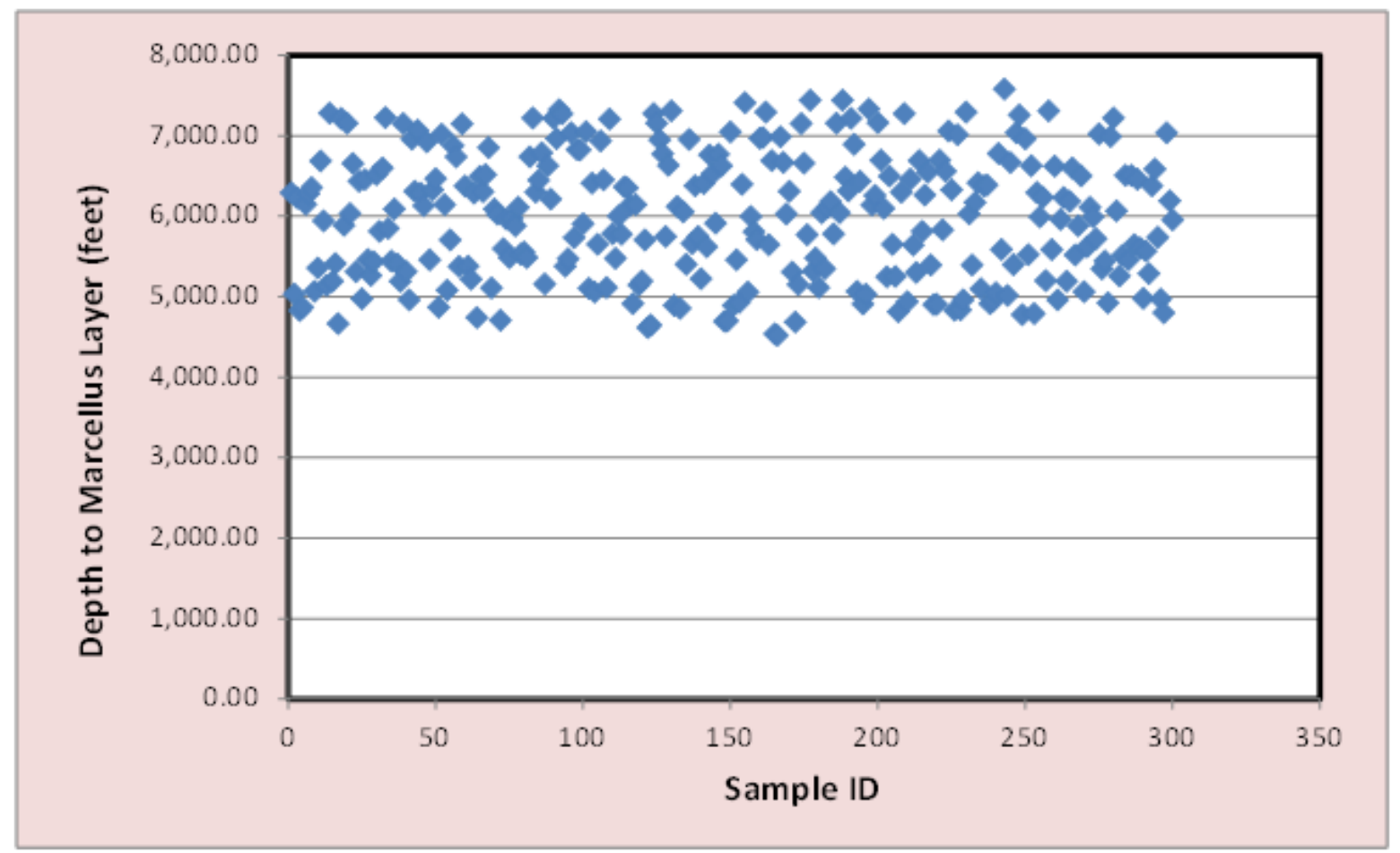

Figure 5.2: Depth to the (Upper) Marcellus shale layer

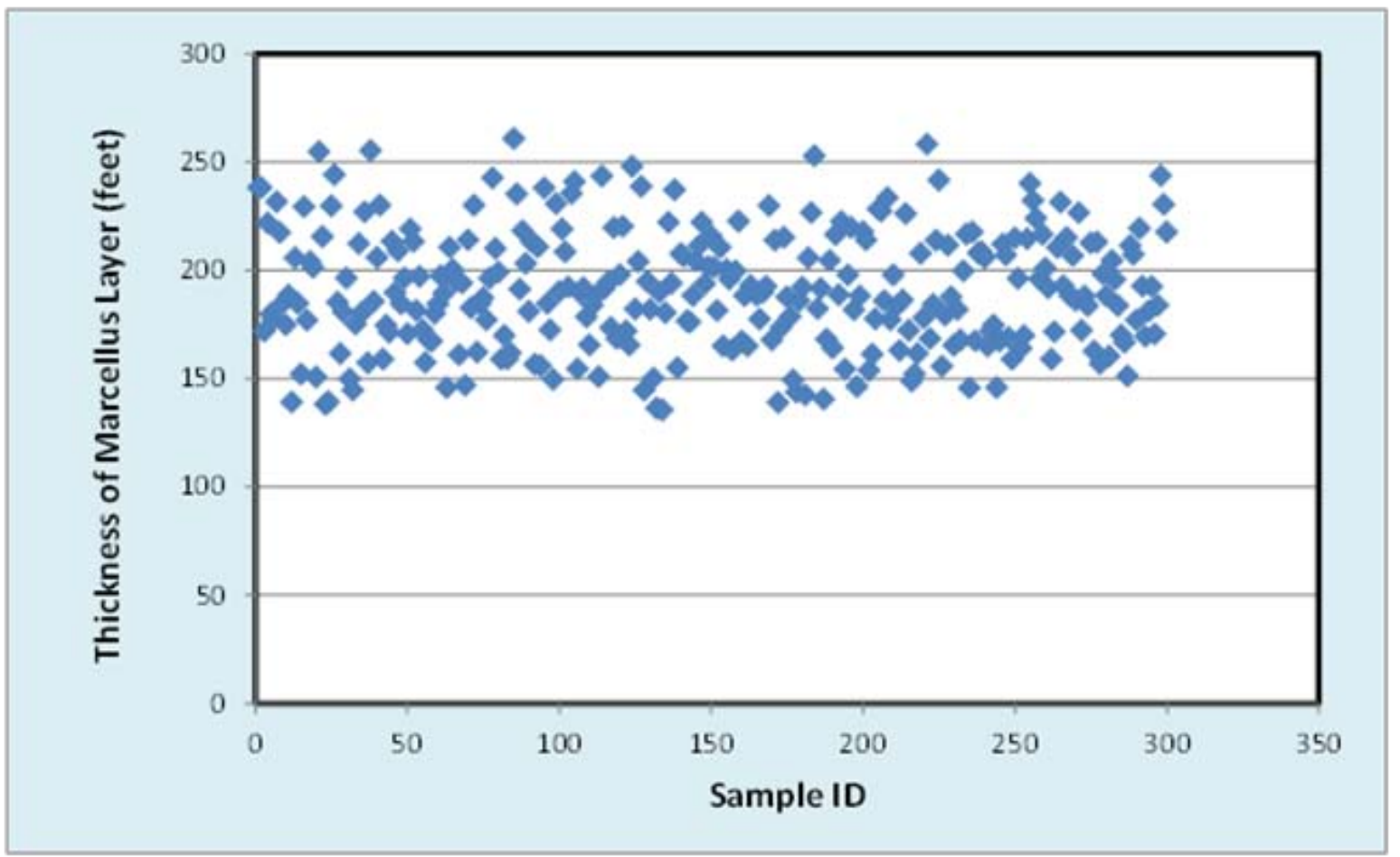

Figure 5.3: Thickness of the Marcellus layer (Upper, Lower, and Cherry Valley) 

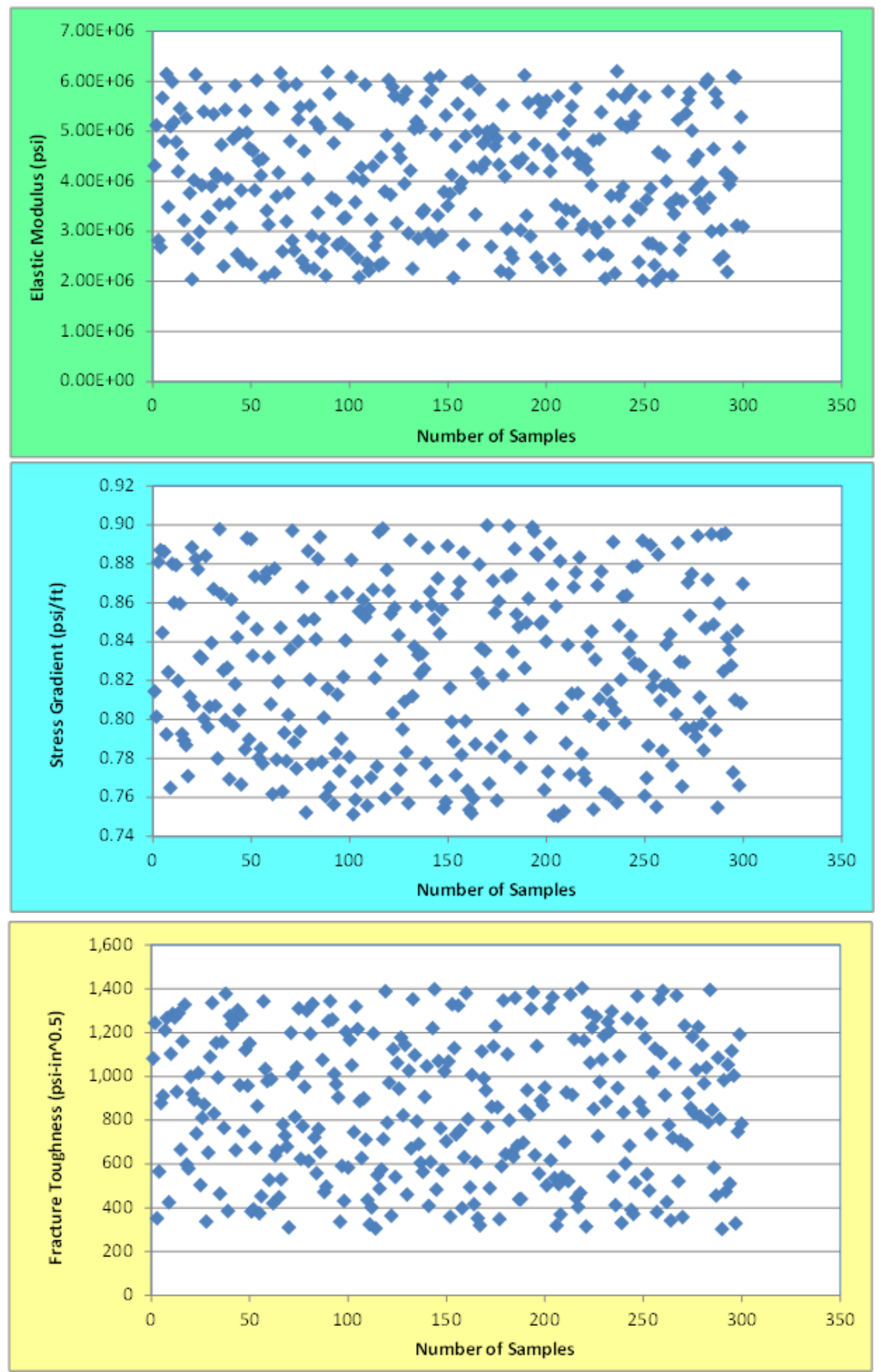

Figure 5.4: Elastic (Young's) Modulii, Stress Gradients, and Fracture Toughnesses of the Lower Marcellus Layer 

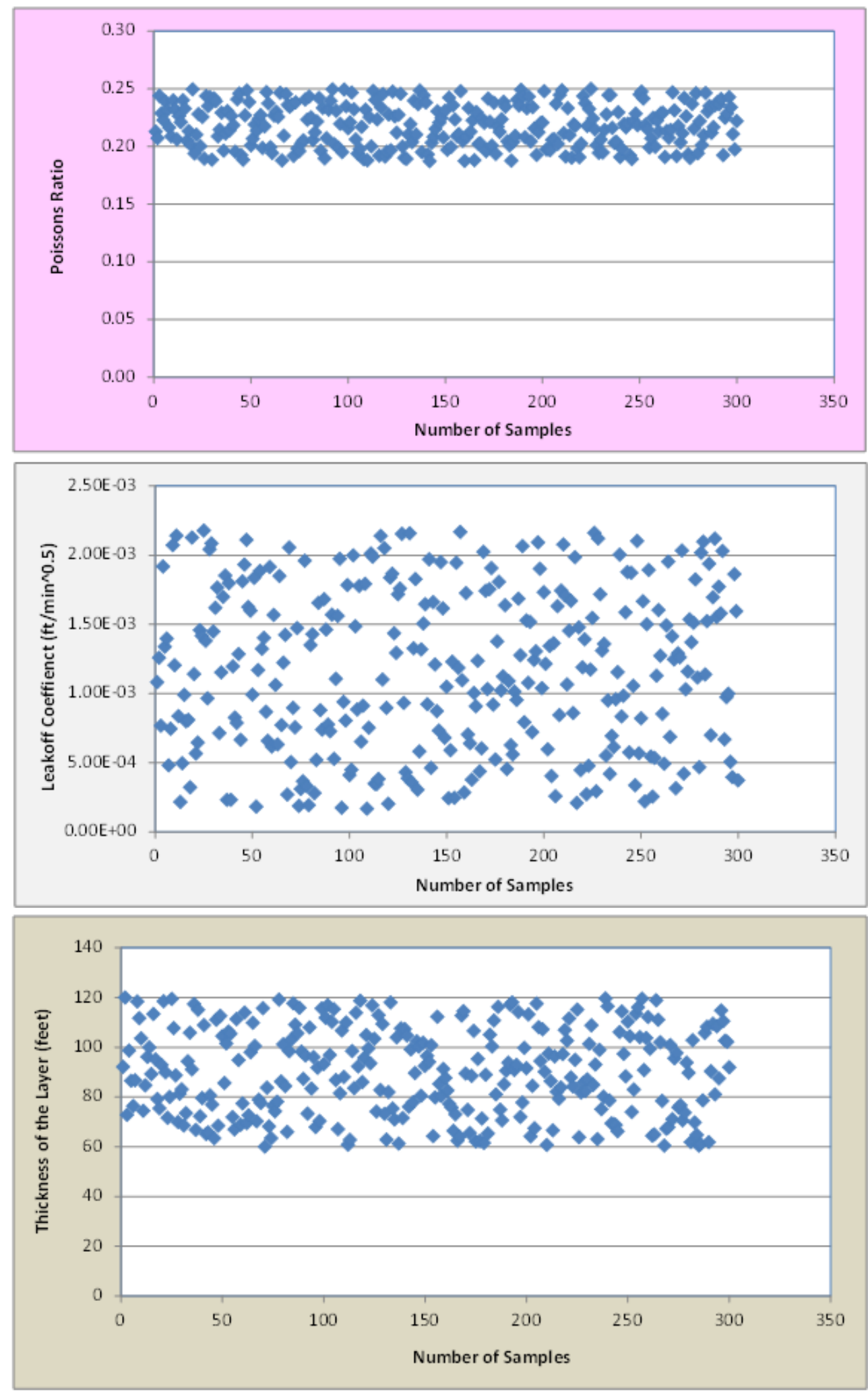

Figure 5.5: Poisson's Ratios, Leakoff Coefficients, and Thicknesses of the Lower Marcellus Layer 
After using the Latin Hypercube Sampling method to find the ranges of data for all geometric, geomechanical, and fluid flow properties, the data was input into the fracture model, MFrac. The results of the simulation of 300 cases were recorded and plotted to show the important results. Figure 5.7 shows the maximum fracture heights plotted with the depth of each Marcellus shale layer. The depth of the Marcellus shale layer is plotted against the clearance depth, which is the distance between the top of the hydraulic fracture and the ground surface, in Figure 5.8. Figure 5.9 shows the maximum fracture half-length for each case. Figure 5.10 shows the maximum fracture width at perforations for each case. Figure 5.11 shows the maximum fracture height for each case. Figure 5.12 shows the average fracture width for each case. Figure 5.13 shows the clearance depth for each case. Figure 5.14 shows the height of each maximum fracture above the top of the (Upper) Marcellus shale (if it does not rise above the top of the Marcellus shale, it is recorded as zero instead of a negative number). Figures 5.15 and 5.16 show the fracture height termination frequency and percentage, respectively, for each case.

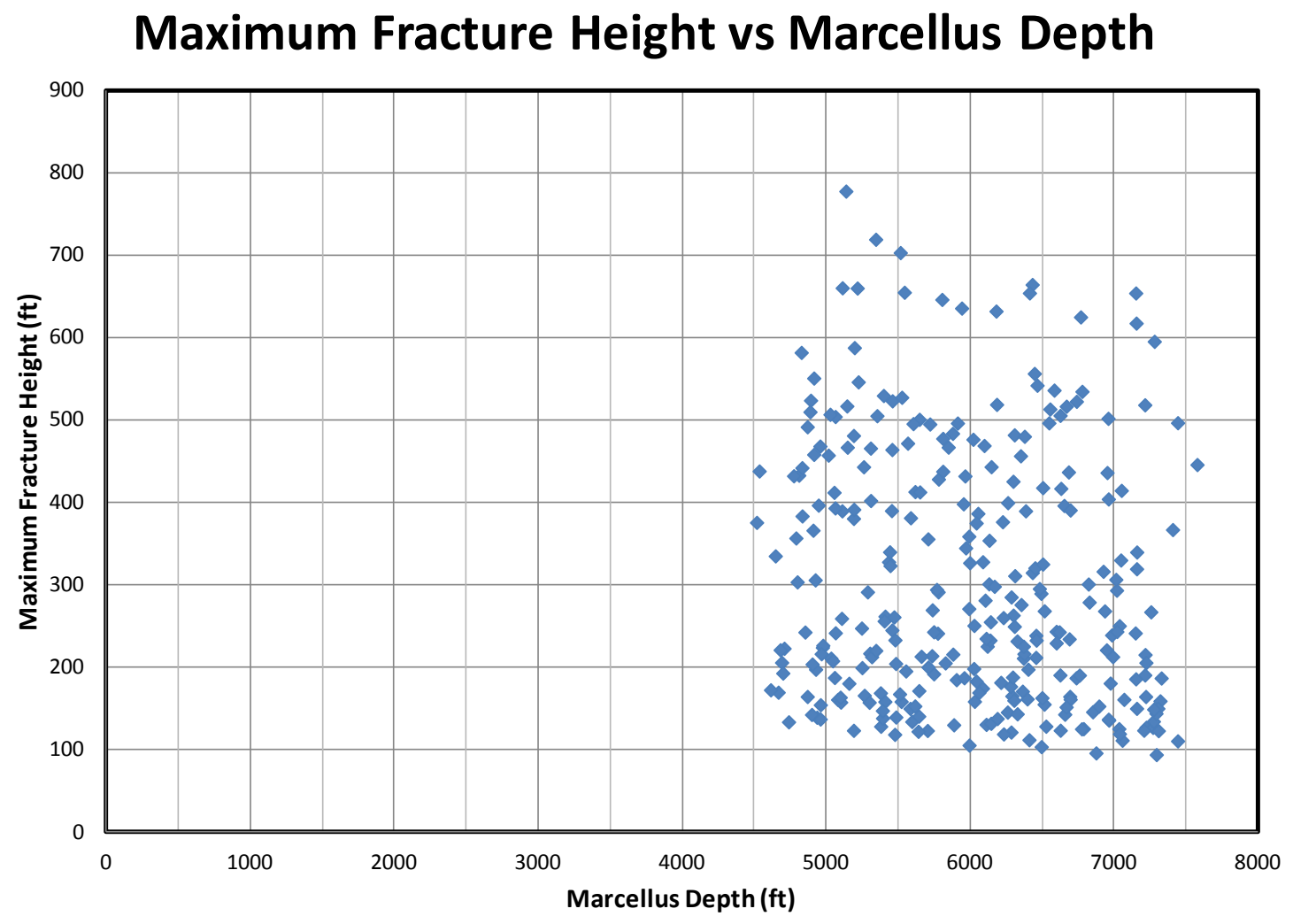

Figure 5.6: Maximum Fracture Height vs. Marcellus Depth 


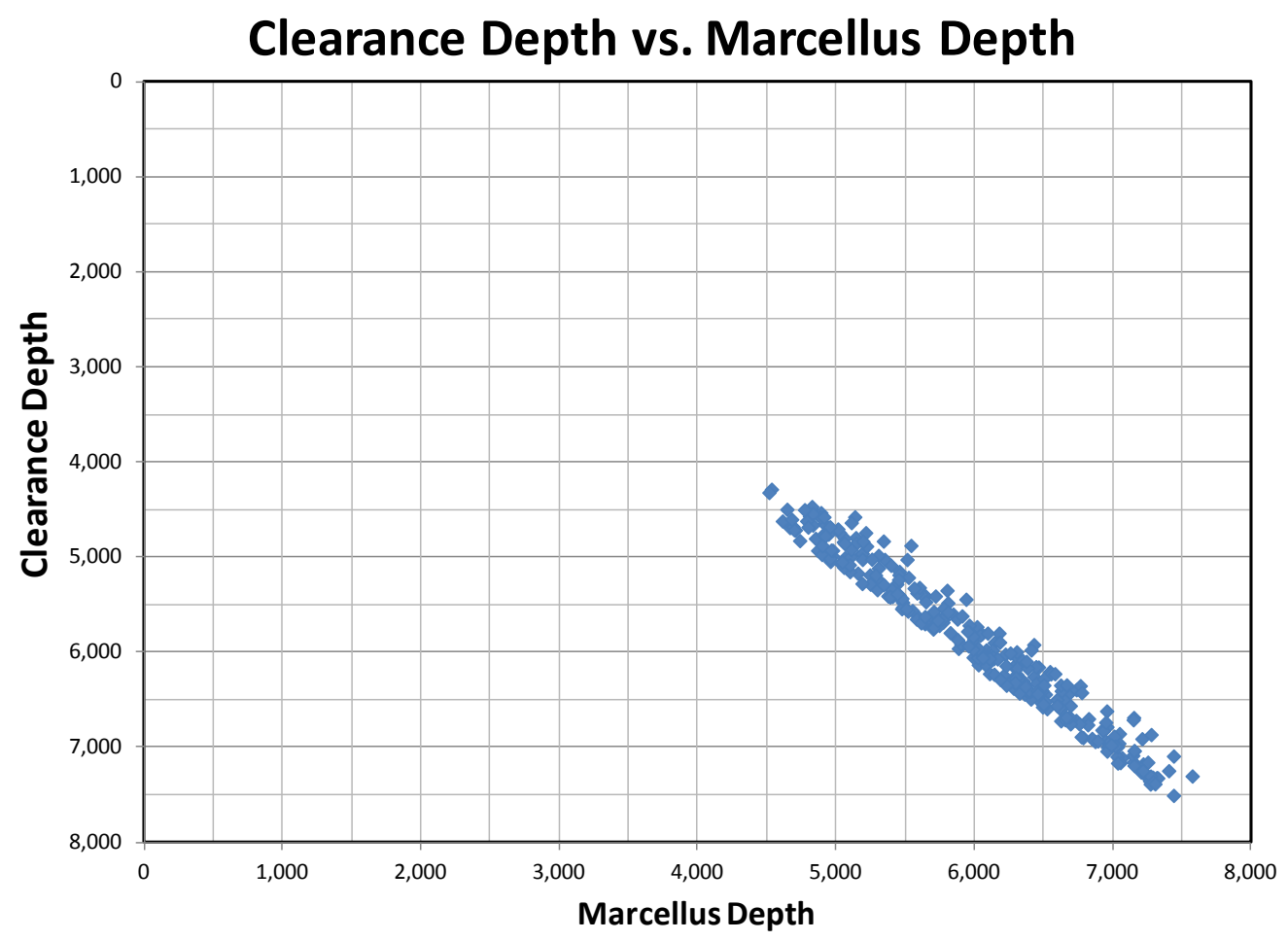

Figure 5.7: Clearance Depth vs. Marcellus Depth

\section{Maximum Fracture Half-Length}

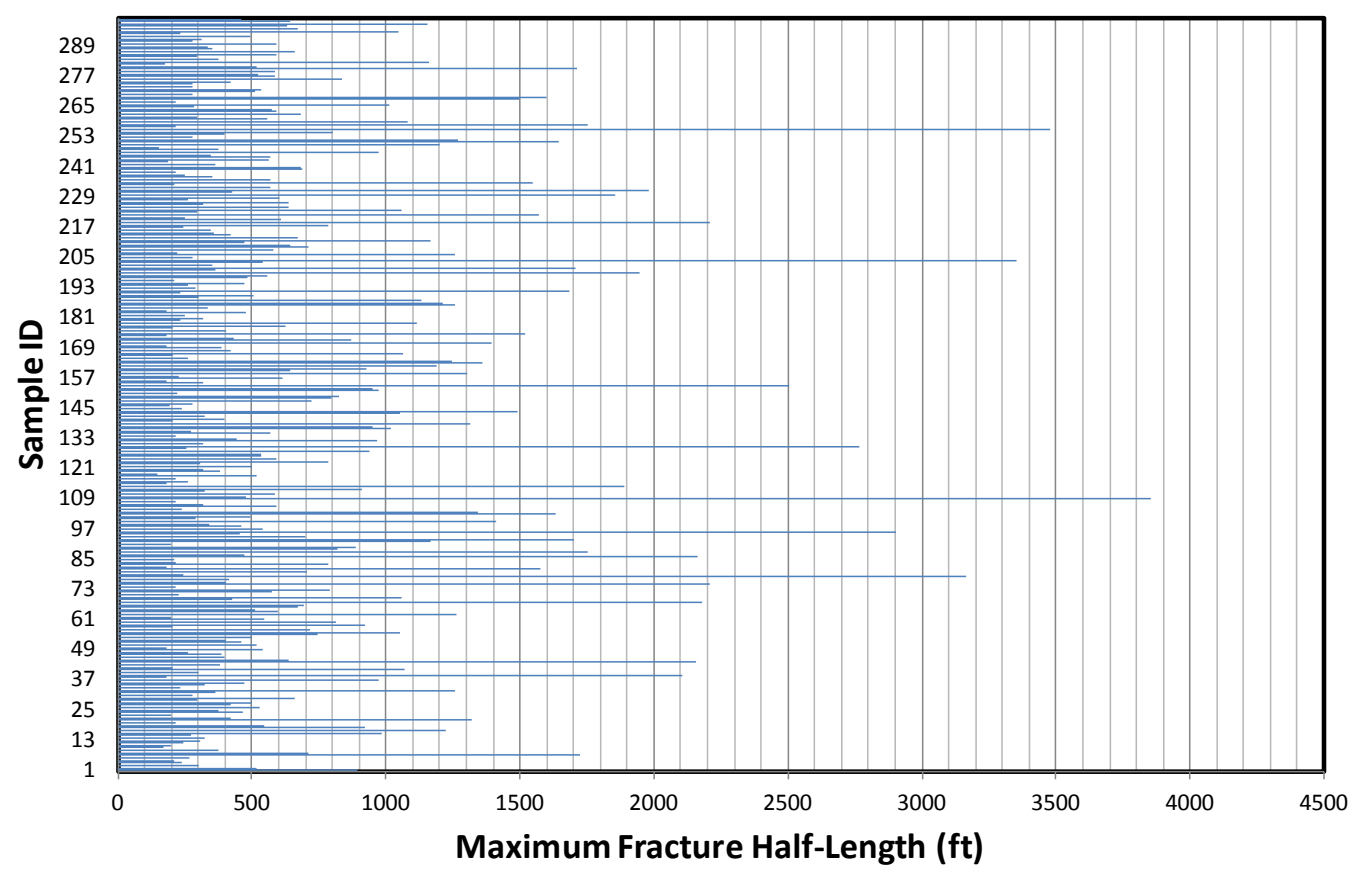

Figure 5.8: Maximum Fracture Half-Length for Each Case 


\section{Maximum Fracture Width at Perforations}

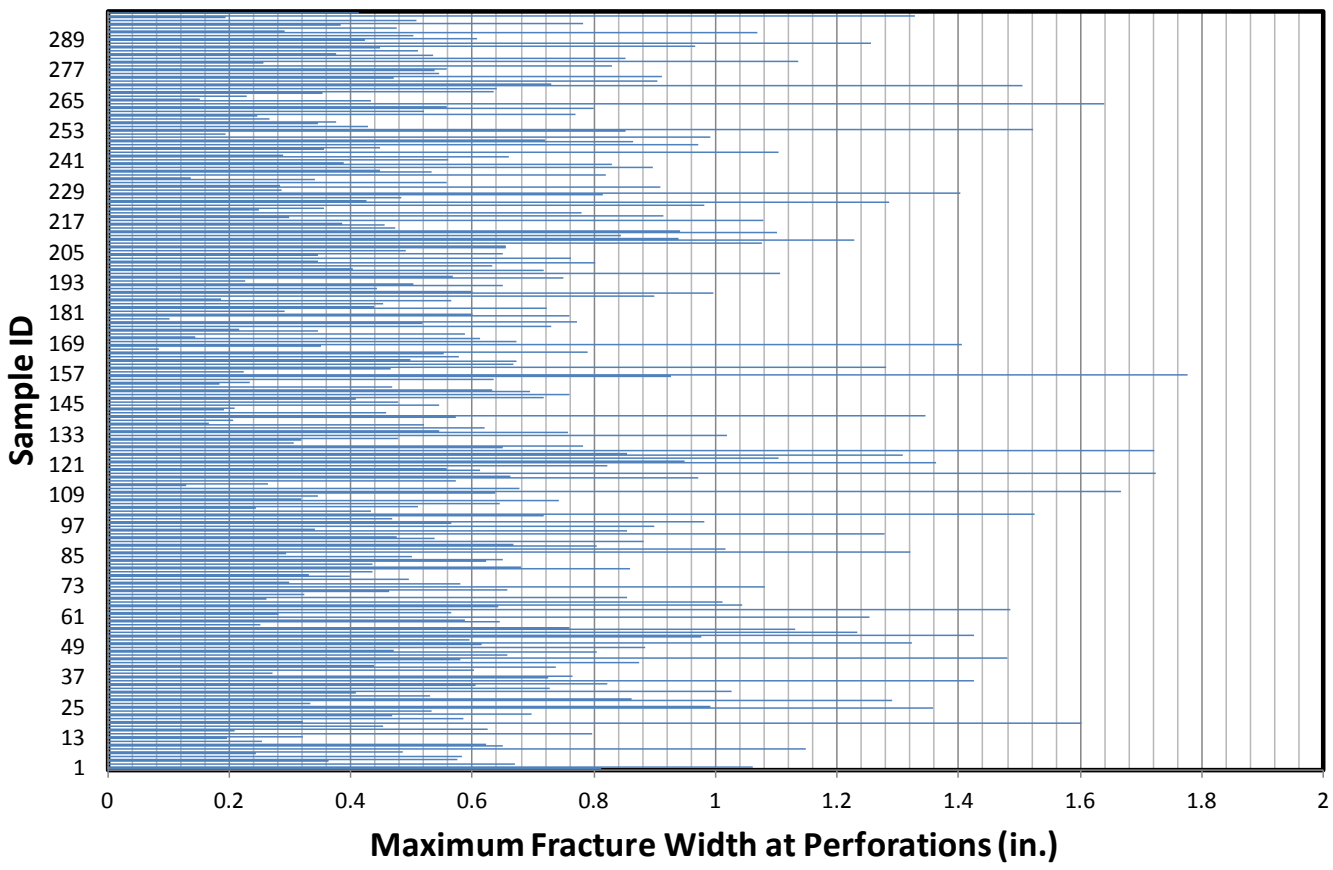

Figure 5.9: Maximum Fracture Width at Perforations for Each Case

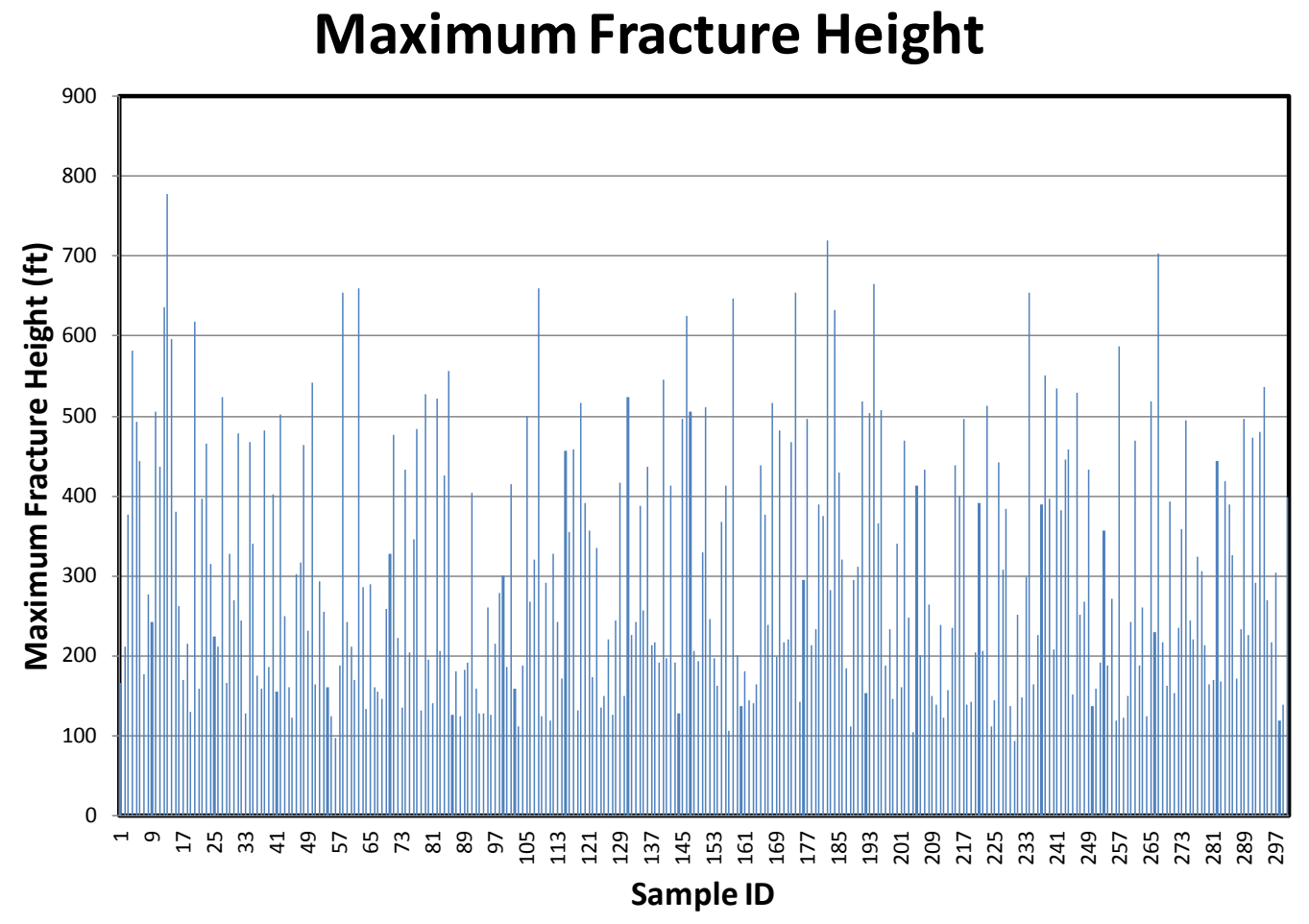

Figure 5.10: Maximum Fracture Height for Each Case 


\section{Average Fracture Width}

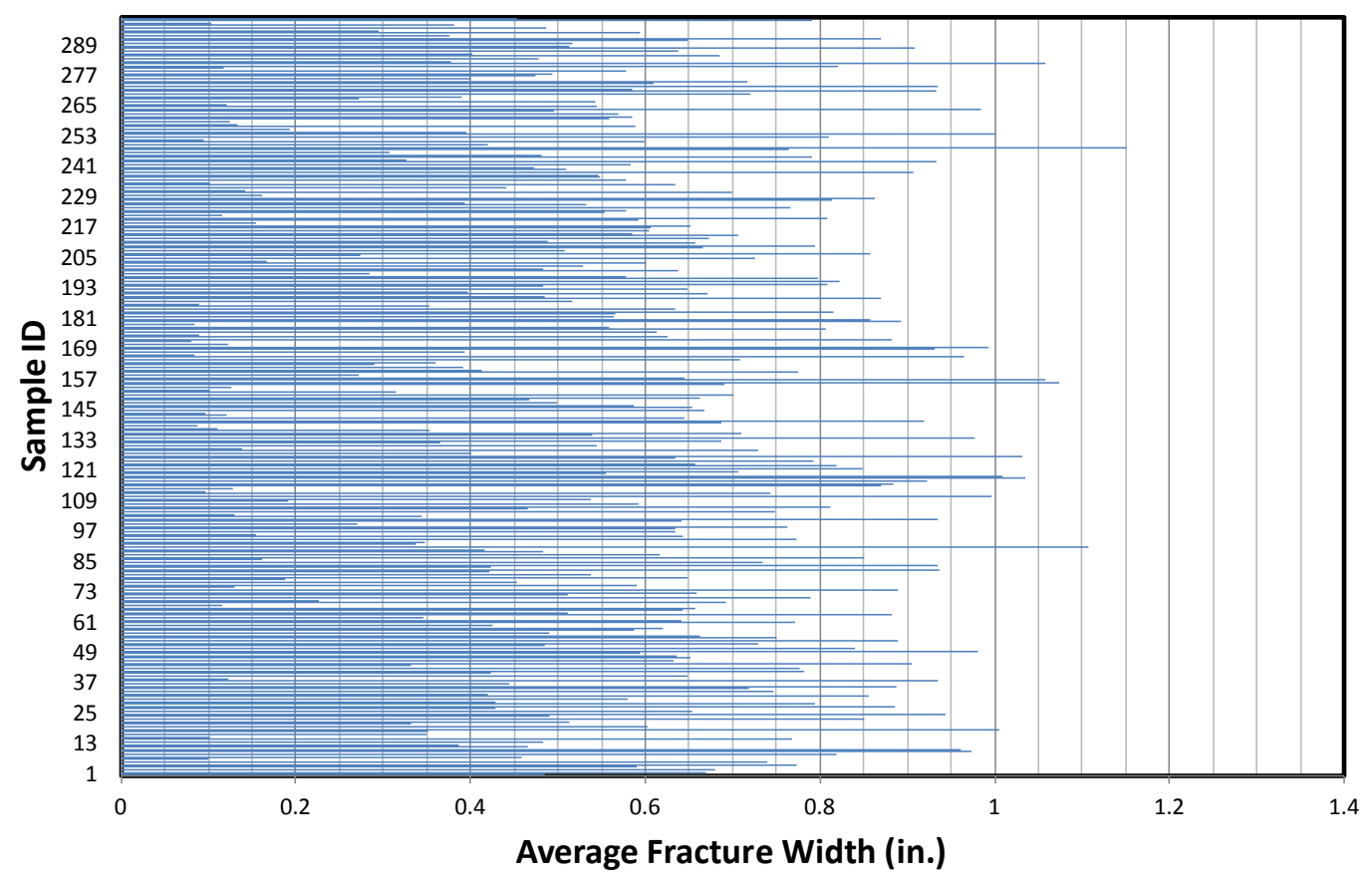

Figure 5.11: Average Fracture Width for Each Case

\section{Clearance Depth}

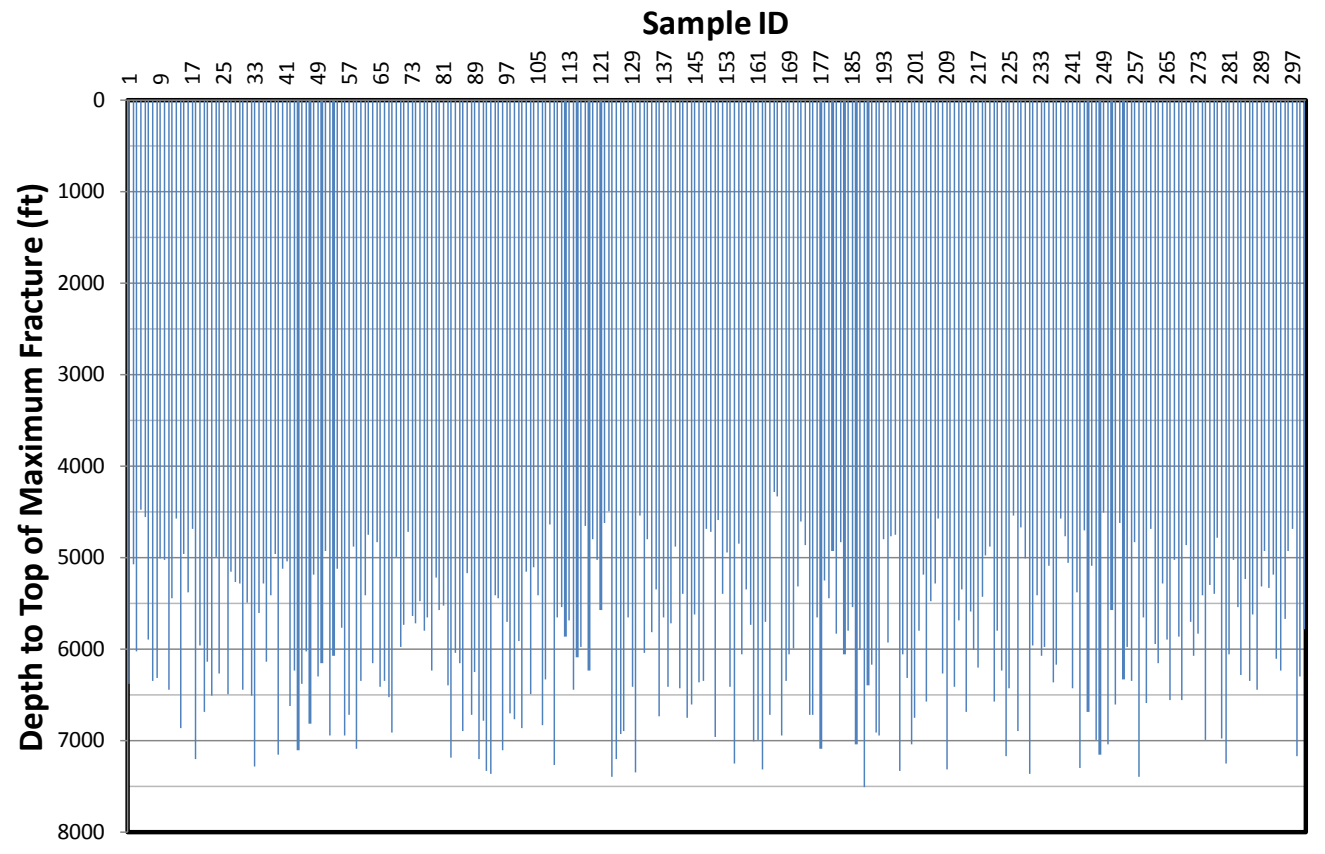

Figure 5.12: Clearance Depth for Each Case 


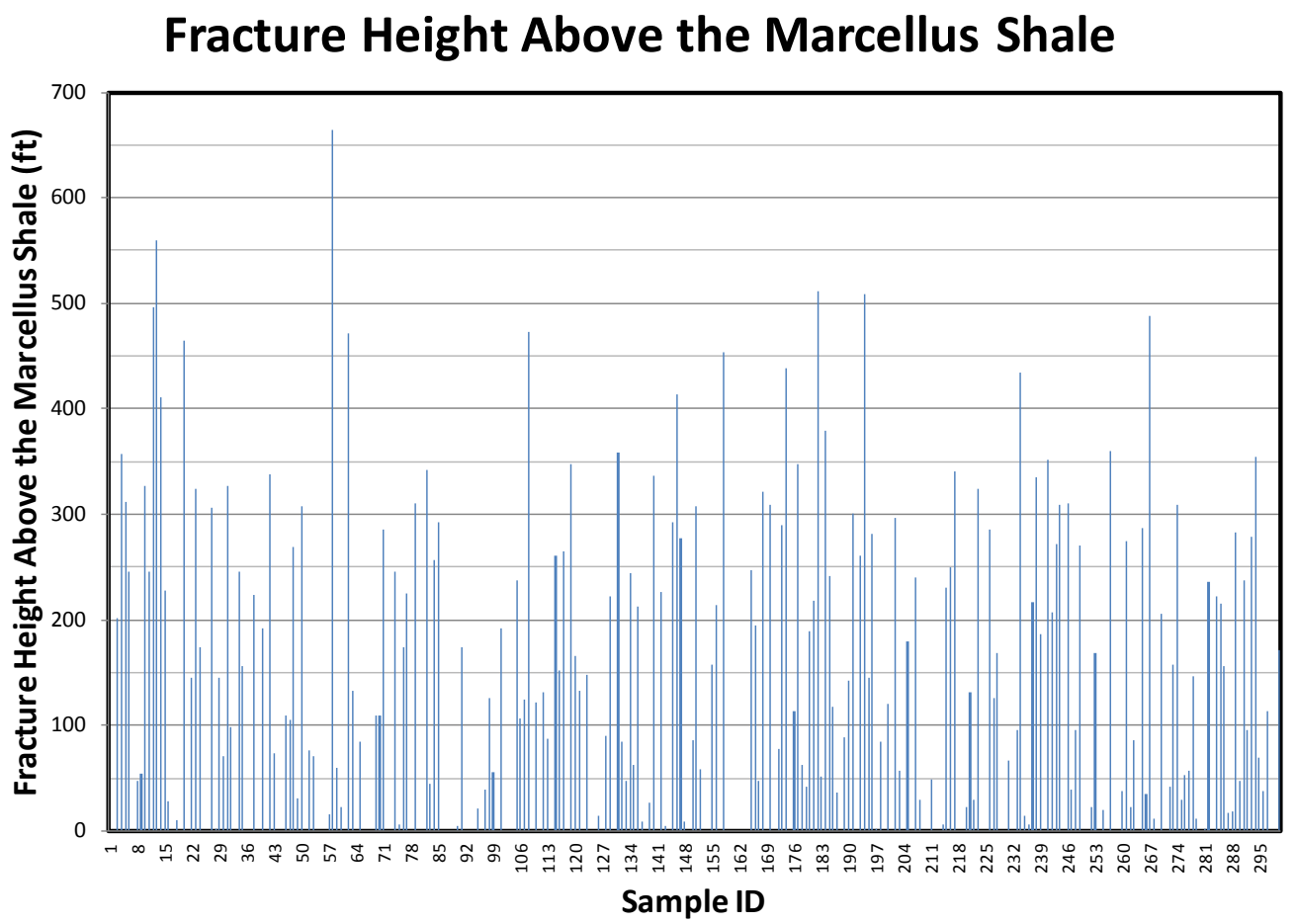

Figure 5.13: Fracture Height Propagation above the Marcellus Shale Layer

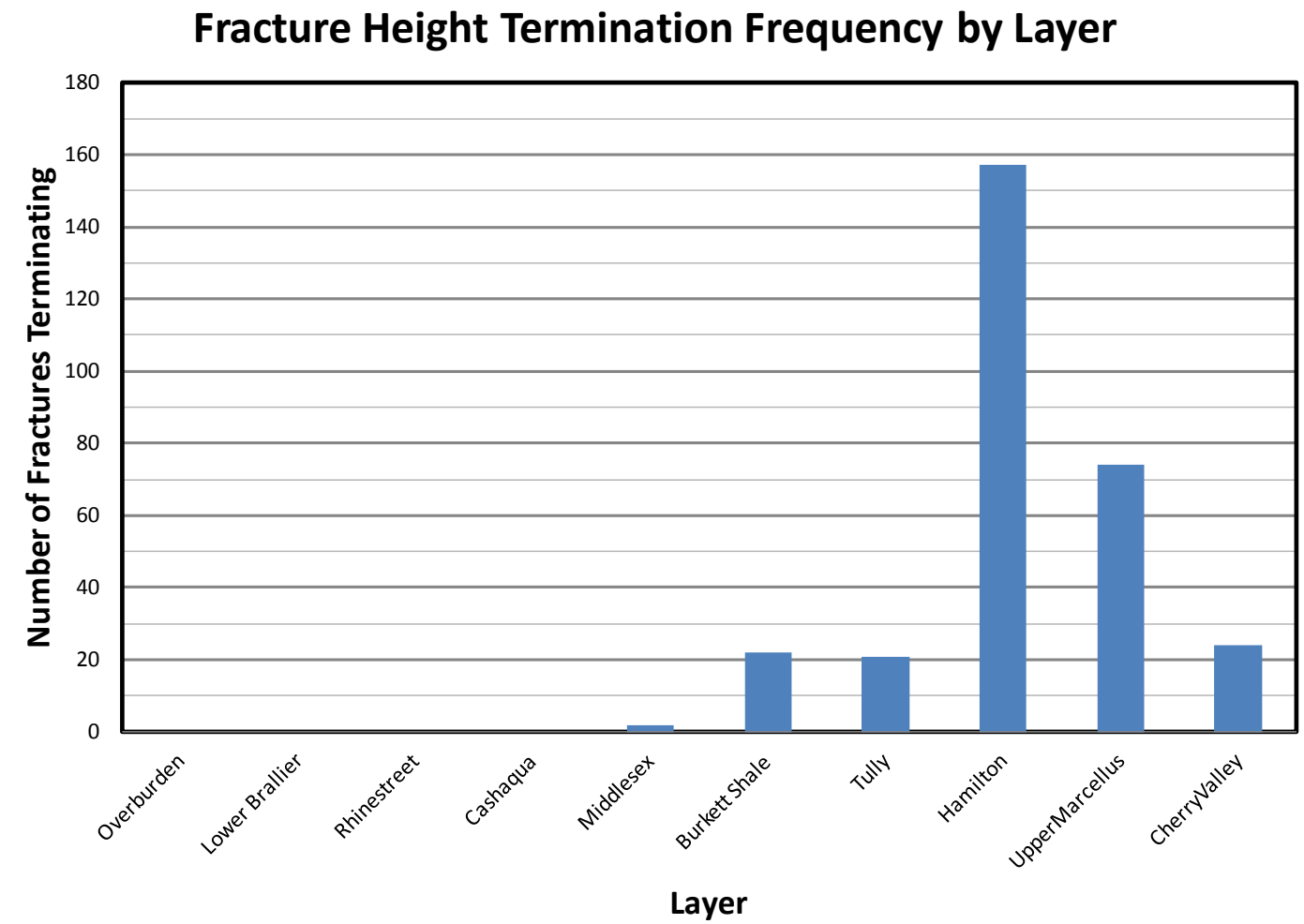

Figure 5.14: Fracture Height Termination Frequency by Layer 


\section{Fracture Height Termination Percentage by Layer}

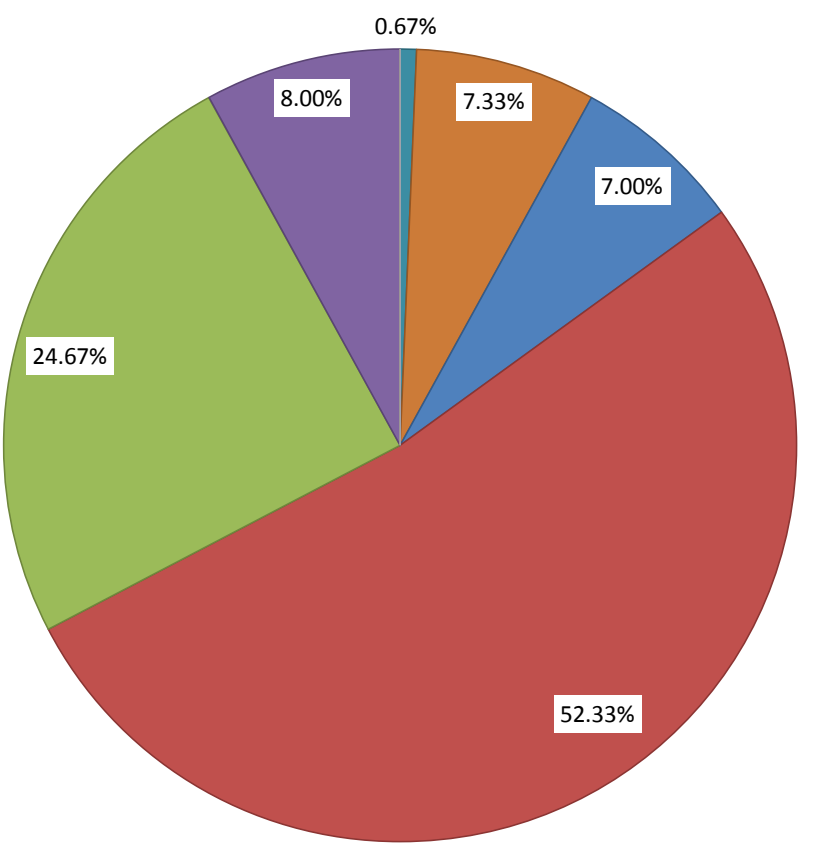

- Overburden

- Lower Brallier

$\square$ Rhinestreet

Cashaqua

$\square$ Middlesex

$\square$ Burkett Shale

- Tully

$\square$ Hamilton

$\square$ UpperMarcellus

$\square$ CherryValley

$\square$ LowerMarcellus

$\square$ Onondaga

Huntersville

Figure 5.15: Fracture Height Termination Percentage by Layer

The following conclusions can be made based on the results of the 300 Latin Hypercube Sampling simulations:

- Fracture heights range from just under 100 feet to nearly 800 feet. Fracture widths at perforations range greatly, from about 0.1 inches to about 1.8 inches. Fracture halflengths range greatly from about 150 feet to nearly 3900 feet. Average fracture widths range from less than 0.1 inches to about 1.15 inches.

- Clearance depths (the distance from the top of a hydraulic fracture to the ground surface) range greatly, depending on the injection depth, from 4287 feet to about 7500 feet.

- Fractures are able to propagate up to 664 feet above the top of the Marcellus shale layer.

- Most fractures (52.33\%) extend into the Hamilton shale layer, located directly above the Upper Marcellus shale layer.

- About eight percent of the fractures are able to propagate beyond the bounding layer of the Tully Limestone under certain conditions. 
- Fracture height growth found in our simulation models is within the range of heights and clearance depths reported in Fisher and Warpinski (Fisher \& Warpinski, 2011) (Page 4, Figure 4). 


\section{CHAPTER 6: SUMMARY AND CONCLUSIONS}

\subsection{Summary}

Hydraulic fracturing has been an important method for extracting oil and natural gas from underground reservoirs over the past 60 years. Determining the extent of vertical propagation of hydraulic fractures is of the utmost importance to the safe production of Marcellus shale gas.

Hydraulic fracturing is used in tight formations with very low permabilities. Without the hydraulic fracturing technology, the energy resources within the rock would not be economically obtainable. Another technology which makes the extraction of energy from these tight formations economical is that of horizontal wellbores. Horizontal wells expose more of the wellbore to the formation, allowing for more energy to be extracted from a single well compared to a vertical well. The Marcellus shale is one of the primary sources of hydraulic fracturing operations in the United States. It is this formation which was focused on in this paper. The Marcellus in West Virginia, southwestern, central, and northeastern Pennsylvania were investigated for their geomechanical, geometric, and fluid flow properties specifically.

Three different fracture models, PKN (Perkins, Kern \& Nordgren, 1961), GDK (Geertsma and deKlerk, 1969), and 3D Ellipsoidal (Meyer, 1986), were discussed for their mathematical backgrounds and applications. Linear elasticity, formations stresses, and stress measurement techniques were also covered.

Simulations were run to determine the effects of various treatment, geomechanical, geometric, and fluid flow properties on the propagation of hydraulic fractures. The treatment parameters of injection rate, proppant type, fluid volume, and fluid viscosity were investigated for their influence on fracture propagation. The geomechanical and fluid flow properties of Poisson's ratio, horizontal stress gradient, Young's modulus, fracture toughness, and fluid leakoff coefficient were also investigated to determine their impacts on hydraulic fracture propagation. Finally, Latin Hypercube Sampling was performed on a range of data to determine an adequate sampling of the data for use in modeling. 300 cases were prepared for hydraulic fracture simulation, and the subsequent results were analyzed for fracture propagation. 


\subsection{Conclusions}

The following conclusions have been drawn based on the results presented in this research work:

- The effects of a constant versus a variable injection rate on fracture propagation are unclear and are highly dependent upon the exact rates used and treatment parameters in combination with one another.

- The introduction of proppant into a slickwater fluid acts to decrease both fracture height and length. The size of the proppant used has a negligible effect on fracture height and a very slight effect on fracture length. Smaller proppant size appears to allow for slightly longer fracture lengths.

- As the homogeneity of geologic layers increases, the fracture length and width are reduced, while the fracture height increases. In the natural strata of the Marcellus shale and other shale formations (and geologic strata in general), the formations are extremely heterogeneous. This is good for limiting vertical fracture propagation.

- If the horizontal stress gradient in a given layer becomes too low, the fracture will begin to propagate further in the horizontal direction, and will not extend as high in the vertical direction. The horizontal stress gradient difference between layers has a great impact on fracture propagation. The closer two adjacent layers are to one another in terms of their horizontal stress gradient, the more easily a fracture will be able to propagate through that layer.

- Variations in Poisson's ratio, elastic modulus, fracture toughness, and leakoff coefficient were found to not have a significant impact on vertical fracture growth. Horizontal stress gradient is the primary factor in determining the vertical growth of fractures.

- For the Latin Hypercube Sampling cases, fracture heights range from just under 100 feet to nearly 800 feet. Fracture widths at perforations range greatly from about 0.1 inches to about 1.8 inches. Fracture half-lengths range greatly from about 150 feet to nearly 3900 feet. Average fracture widths range from less than 0.1 inches to about 1.15 inches. 
- Out of the 300 cases, only a couple fractures are able to propagate up to almost 664 feet above the top of the Marcellus shale layer; however, clearance depths are still well over 4200 feet.

- Most fractures (52.33\%) extend into the Hamilton shale layer, located directly above the Upper Marcellus shale layer.

- Eight percent of the fractures are able to propagate beyond the bounding layer of the Tully Limestone under certain conditions.

- Fracture height growth appears to be within the range found in published literature from field data. 


\subsection{Recommendations for Future Work}

- Based on the findings of this paper, it is recommended that all geomechanical and fluid flow properties are collected from the field with extreme precision and accuracy.

- Determine geomechanical, geometric, and fluid flow properties for shallower depth Marcellus shale areas, and determine the extent of fracture propagation.

- Investigate the specific causes of why in certain cases fractures are able to propagate further into overburden formations than others. 


\section{REFERENCES}

1. Arthur, J., Bohm, B., \& Layne, M. (2008). Hydraulic Fracturing Considerations for Natural Gas Wells of the Marcellus Shale. The Ground Water Protection Council. Cincinatti, $\mathrm{OH}$.

2. Arthur, J., Bohm, B., Coughlin, B., \& Layne, M. (2009). Evaluating Implications of Hydraulic Fracturing in Shale Gas Reservoirs. SPE Americas E\&P Environmental \& Safety Conference. San Antonio, TX.

3. Bilgesu, H., \& Yusuf, A. (2011). The Impact of Stress and Formation Properties on the Outcome of Fracture Operations in Horizontal Shale Wells. SPE Eastern Regional Meeting. Columbus, $\mathrm{OH}$.

4. Billington, E., \& Tate, A. (1981). The Physics of Deformation and Flow. New York: McGraw Hill.

5. Biot, M. (1956). General Solution of the Equations of Elasticity and Considerations for a Porous Material. Journal of Applied Mechanics 23 , 91-96.

6. Daneshy, A. (1973). On the Design of Vertical Hydraulic Fractures. Journal of Petroleum Technology, 83-97.

7. Das, B. (2002). Principles of Geotechnical Engineering. Pacific Grove: Brooks/Cole.

8. England, A., \& Green, A. (1963). Some Two-Dimensional Punch and Crack Problems in Classical Elasticity. Proceedings of the Cambridge Philosophical Society London 59 , 489-500.

9. Fisher, K., \& Warpinski, N. (2011). Hydraulic Fracture-Height Growth: Real Data. SPE Annual Technical Conference and Exhibition. Denver, CO, USA.

10. Fontaine, J., Johnson, N., \& Schoen, D. (2008). Design, Execution, and Evaluation of a "Typical" Marcellus Shale Slickwater Stimulation: A Case History. SPE Eastern Regional/AAPG Eastern Section Joint Meeting. Pittsburgh, PA, USA. 
11. Friedman, M. (1972). Residual Elastic Strains in Rocks. Tectonophysics 15 , 297-330.

12. Geertsma, J., \& de Klerk, F. (1969). A Rapid Method of Predicting Width and Extent of Hydraulically Induced Fractures. Journal of Petroleum Technology, 1571-1581.

13. Geertsma, J., \& Haafkens, R. (1979). A Comparison of the Theories for Predicting Width and Extent of Vertical Hydraulically Induced Fractures. Journal of Energy Resources Technology, 8-19.

14. Geology.com. (n.d.). Marcellus Shale - Appalachian Basin Natural Gas Play . Retrieved March 28, 2014, from Geology.com: http://geology.com/articles/marcellus-shale.shtml

15. Green, A., \& Zerna, W. (1968). Theoretical Elasticity. London: Oxford University Press.

16. Griffith, A. (1920). The Phenomenon of of Rupture and Flow in Solids. Philosophical Transactions of the Royal Society A: 221, 163-198.

17. Haimson, B. (1978). The Hydrofracturing Stress Measuring Method and Recent Field Results. International Journal of Rock Mechanics and Mining Sciences 25 , 167-178.

18. Haimson, B. (1981). Confirmation of Hydrofracturing Results Through Comparisons with Other Stress Measurements. Proceedings of the 22nd U.S. Rock Mechanics Symposium (pp. 379-385). Boston: MIT.

19. Haimson, B., \& Fairhurst, C. (1967). Initiation and Extension of Hydraulic Fractures in Rocks. SPE Journal (Sept.) , 310-318.

20. Haimson, B., \& Fairhurst, C. (1969). Hydraulic Fracturing in Porous Permeable Materials. Journal of Petroleum Technology (July) , 811-817.

21. Howard, G., \& Fast, C. (1970). Hydraulic Fracturing. SPE Monograph 2 .

22. Hubbert, M., \& Willis, D. (1957). Mechanics of Hydraulic Fracturing. Transactions of the American Institute of Mining, Metallurgical, and Petroleum Engineers 210, 153-166.

23. Iman, R., \& Conover, W. (1982). Sensitivity Analysis Techniques: Self-Teaching Curriculum. Albaquerque, NM: Sandia National Laboratories SAND81-1978. 
24. Iman, R., \& Helton, J. (1985). A Comparison of Uncertainty and Sensitivity Analysis Techniques for Computer Models. Albaquerque, NM: Sandia National Laboratories SAND84-1461.

25. Iman, R., Helton, J., \& Campbell, J. (1981a). An Approach to Sensitivity Analysis of Computer Models, Part 1. Introduction, Input Variable Selection and Preliminary Variable Assessment. Journal of Quality Technology 13(3), 174-183.

26. Iman, R., Helton, J., \& Campbell, J. (1981b). An Approach to Sensitivity Analysis of Computer Models, Part 2. Ranking of Input Variables, Response Surface Validation, Distribution Effect and Technique Synopsis. Journal of Quality Technology 13(4) , 232240.

27. Jackson, R., Vengosh, A., Darrah, T., Warner, T., Down, A., Poreda, R., et al. (2013). Increased stray gas abundance in a subset of drinking water wells near Marcellus shale gas extraction. Proceedings of the National Academy of Sciences of the United States of America .

28. Jacot, R., Bazan, L., \& Meyer, B. (2010). Technology Integration - A Methedology to Enhance Production and Maximize Economics in Horizontal Marcellus Shale Wells. SPE Annual Technical Conference and Exhibition. Florence, Italy.

29. Jaeger, J., \& Cook, N. (1979). Fundamentals of Rock Mechanics. New York: Chapman and Hall.

30. Keshavarzi, R., Mohammadi, S., \& Bayesteh, H. (2012). Hydraulic Fracture Propagation in Unconventional Reservoirs: The Role of Natural Fractures. 46th US Rock Mechanics / Geomechanics Symposium. Chicago, IL, USA.

31. King, G. (2012). Hydraulic Fracturing 101: What Every Representative, Environmentalist, Regulator, Reporter, Investigator, University Researcher, Neighbor and Engineer Should Know About Estimating Frac Risk and Improving Frac Performance in Unconventional Gas and Oil Well. SPE Hydraulic Fracturing Technology Conference. The Woodlands, TX. 
32. Marcellus Center for Outreach and Research. (2010). Depth to Marcellus Shale Base. University Park, PA, U.S.A.

33. Mayerhofer, M., Ehlig-Economides, C., \& Economides, M. (1995). Pressure-Transient Analysis of Fracture-Calibration Tests. Journal of Petroleum Technology, 229-234.

34. Mayerhofer, M., Stegent, N., Barth, J., \& Ryan, K. (2011). Integrating Fracture Diagnostics and Engineering Data in the Marcellus Shale. SPE Annual Technical Conference and Exhibition. Denver, CO.

35. McKay, M., Conover, W., \& Beckman, R. (1979). A Comparison of Three Methods for Selecting Values of Input Variables in the Analysis of Output from a Computer Code. Technometrics $221,239-245$.

36. Meyer, B. (1986). Design Formulae for 2-D and 3-D Vertical Hydraulic Fractrures: Model Comparison and Parametric Studies. Unconventional Gas Technology Symposium of the Society of Petroleum Engineers. Louisville, KY, USA.

37. Meyer, B., \& Bazan, L. (2011). A Discrete Fracture Network Model for Hydraulically Induced Fractures: Theory, Parametric and Case Studies. SPE Hydraulic Fracturing Technology Conference and Exhibition. The Woodlands, TX.

38. Meyer, B., \& Hagel, M. (1989). Simulated mini-frac analysis. Journal of Canadaian Petroleum Technology, 63-73.

39. MFrac - Meyer Fracturing Simulators (2012, April 26). MFrac Software and User's Manual. Ninth Edition, Baker Hughes Incorporated.

40. Muskhelishvili, N. (1953). Some Basic Problems of the Mathematical Theory of Elasticity. Nordhoof, Holland.

41. Neuhaus, C. W., Williams-Stroud, S., Remington, C., Barker, W. B., Blair, K., Neshyba, G., et al. (2012). Integrated Microseismic Monitoring for Field Optimization in the Marcellus Shale - A Case Study. SPE Canadian Unconventional Resources Conference. Calgary, Alberta, Canada. 
42. Newberry, B., Nelson, R., \& Ahmed, U. (1985). Prediction of Vertical Hydraulic Fracture Migration Using Compressional and Shear Wave Slowness. SPE/DOE 1985 Low Permeability Gas Reservoirs, (pp. 459-464). Denver.

43. Nolte, K. (1986). Determination of Proppant and Fluid Schedules From FracturingPressure Decline. SPE Production Engineering, 255-265.

44. Nolte, K. (1988). Fracture Design Considerations Based on Pressure Analysis. SPE Production Engineering (Feb.), 23-30.

45. Nordgren, R. (1972). Propagation of a Vertical Hydraulic Fracture. Society of Petroleum Engineers Journal , 306-314.

46. Obert, L., \& Duvall, W. (1967). Rock Mechanics and the Design of Structures in Rock. New York: John Wiley.

47. OSHA. (2013, October 1). Illustrated Glossary. Retrieved October 16, 2013, from Occupational Safety \& Health Administration Website: https://www.osha.gov/SLTC/etools/oilandgas/illustrated_glossary.html

48. Perkins, T., \& Kern, L. (1961). Widths of Hydraulic Fractures. Journal of Petroleum Technology, 937-949.

49. Smith, M. (1985). Stimulation Design for Short, Precise Hydraulic Fractures. SPE Journal (June) , 371-379.

50. Sneddon, I. (1973). Integral Transform Methods. In Mechanics of fracture I, Methods of analysis and solutions of crack problems. Leyden: G.C. Nordhoff International.

51. Steck, G., Iman, R., \& Dahlgren, D. (1976). Probabilistic Analysis of LoCA, Annual Report for FY1976. Abaquerque: Sandia National Laboratories SAND76-0535.

52. Valko, P., \& Economides, M. J. (1995). Hydraulic Fracture Mechanics. West Sussex: John Wiley \& Sons Ltd. 
53. Wade, A., \& Bilgesu, H. (2012). Impact of Hydraulic Fracture and Subsequent Increased Production Due to In-Situ Stress Changes in the Marcellus Shale. SPE Eastern Regional Meeting. Lexington, KY.

54. Wyss, G., \& Jorgensen, K. (1998, February). A User's Guide to LHS: Sandia's Latin Hypercube Sampling Software. Albaquerque, NM, USA.

55. Zhu, T. (2013). Some Useful Numbers on the Engineering Properties of Materials (Geologic and Otherwise). Retrieved July 5, 2013, from Tieyuan's Website: http://www.stanford.edu/ tyzhu/Documents/Some\%20Useful\%20Numbers.pdf 